Illinois State University

ISU ReD: Research and eData

Theses and Dissertations

$2-27-2020$

\title{
Visions For Mathematics Instruction, Instructional Practices, And Common Core: Individuality In Large-Scale Reform
}

Kelsey A. Clarkson

Illinois State University, kelsey.clarkson@mcusd709.org

Follow this and additional works at: https://ir.library.illinoisstate.edu/etd

Part of the Science and Mathematics Education Commons

\section{Recommended Citation}

Clarkson, Kelsey A., "Visions For Mathematics Instruction, Instructional Practices, And Common Core: Individuality In Large-Scale Reform" (2020). Theses and Dissertations. 1209.

https://ir.library.illinoisstate.edu/etd/1209

This Dissertation is brought to you for free and open access by ISU ReD: Research and eData. It has been accepted for inclusion in Theses and Dissertations by an authorized administrator of ISU ReD: Research and eData. For more information, please contact ISUReD@ilstu.edu. 


\section{VISIONS FOR MATHEMATICS INSTRUCTION, INSTRUCTIONAL PRACTICES, AND COMMON CORE: INDIVIDUALITY IN LARGE-SCALE REFORM}

\section{KELSEY A. CLARKSON}

\section{Pages}

The Common Core content standards and standards for mathematical practice (SMP) have introduced an unprecedented opportunity in U.S. history to consider the implications of a national scale standards reform effort that provides teachers the individualistic opportunity to select instructional practices aimed at achieving the standards. The content standards and SMP specifically lay out what students should be able to do by the end of each grade but do not describe how teachers should support students through instructional practices in order to achieve these goals (CCSSI, "Myths About Implementation," para. 1). Seemingly in contradiction to the Common Core State Standards Initiative's proclamation that instructional practices should be left to individuals and schools, Cobb and Jackson (2011) asserted that large-scale mathematics reform efforts are likely to be successful if "a detailed vision of high-quality mathematics instruction specifies concrete instructional practices that have the potential to lead to the attainment of learning goals" (p. 13). In the absence of a national-scale vision of high-quality mathematics instruction to accompany the Common Core Standards for Mathematics (CCSSM), the purpose of this study was to describe how teachers reasoned about specifying instructional practices aimed at addressing the goals of the CCSSM.

Four case study teachers were selected from an initial interview as to categorically represent the visions for mathematics instruction (V4MI) described by 10 secondary 
mathematics teachers from one mathematics department in one high school located in the Midwestern region of the United States within an urban city. The four case study teachers participated in a pre-lesson and post-lesson interview surrounding a lesson of their choice. In the initial, pre-lesson, and post-lesson interview, teachers reasoned about ideal, planned, and instructional practices. Using the method of constant comparative analysis, I found emerging themes in teachers' reasoning and described them as categories of reasoning about instructional practices. Themes emerged among the four case study teachers in the following forms of reasoning: prior knowledge, building conceptual knowledge, external sources of influence, establishing classroom culture, cultivating general learner qualities, and cultivating mathematics learner practices. During which interviews these categories of reasoning emerged (i.e., initial, pre-lesson, post-lesson interviews), the type of language case study teachers used when discussing each category of reasoning (i.e., teacher-centered or student-centered), the alignment or misalignment of the category of reasoning with teachers' V4MIs, and teachers explicit reasoning about V4MIs and CCSSM are explored. Findings suggest that teachers and those leading large-scale Common Core mathematics reform (e.g., administration, state-level lawmakers) should explore the external sources of influence that teachers adhere to when specifying instructional practices. Furthermore, teachers should be provided opportunities to build explicit connections between their V4MIs, instructional practices, and the goals of the CCSSM.

KEYWORDS: vision, instructional practices, common core state standards for mathematics, constant comparative analysis 
VISIONS FOR MATHEMATICS INSTRUCTION, INSTRUCTIONAL PRACTICES, AND

COMMON CORE: INDIVIDUALITY IN LARGE-SCALE REFORM

KELSEY A. CLARKSON

A Dissertation Submitted in Partial

Fulfillment of the Requirements

for the Degree of

DOCTOR OF PHILOSOPHY

Department of Mathematics

ILLINOIS STATE UNIVERSITY 
Copyright 2020 Kelsey A. Clarkson 
VISIONS FOR MATHEMATICS INSTRUCTION, INSTRUCTIONAL PRACTICES, AND COMMON CORE: INDIVIDUALITY IN LARGE-SCALE REFORM

KELSEY A. CLARKSON

COMMITTEE MEMBERS:

Craig J. Cullen, Chair

David Barker

Tami S. Martin

Lydia Kyei-Blankson 


\section{ACKNOWLEDGMENTS}

Thank you to all that have guided and supported me along this journey. I would like to thank my dissertation chair, Dr. Craig Cullen. His careful questioning, direct advice, transparency, and critical mind have exceeded my expectations. I would also like to thank my committee members: Drs. David Barker, Tami S. Martin, and Lydia Kyei-Blankson. I appreciate the time and consideration you put into your feedback for improving the quality of this work. Thank you to the participants in my study for allowing me in your classrooms and opening up to me with your most-personal thoughts about your profession.

I am grateful for my fellow doctoral students who have diversified, enriched, and supported my doctoral journey. Thank you to my friends, Carrie, Amy, and Sarah, for listening to me vent and helping me find space and time to work. Lastly, I would like to thank my family. Thank you to my mother, Cyndi, for always empowering me and making me feel like I can accomplish anything. Thank you to my father, Tom, for fostering my critical mind. To my children, Avery and Owen, thank you for giving me purpose. I hope to show you that you can be strong, you can work hard, and you can chase your dreams. And finally, to my husband and best friend, Jason, thank you for always being in my corner. You have given so much of yourself to make this journey possible, and I am forever grateful. 


\section{CONTENTS}

$\begin{array}{lll}\text { Page } & \text { Pag }\end{array}$

ACKNOWLEDGMENTS

CONTENTS

TABLES viii

FIGURES

CHAPTER I: INTRODUCTION OF THE PROBLEM AND ITS STUDY 1

Background of the Problem 3

National Standards as an Individualized Effort $\quad 4$

Statement of the Problem $\quad 4$

$\begin{array}{ll}\text { Theoretical Framework } & 5\end{array}$

$\begin{array}{ll}\text { Purpose of the Study } & 8\end{array}$

$\begin{array}{ll}\text { Research Questions } & 8\end{array}$

Chapter I Summary $\quad 9$

$\begin{array}{ll}\text { CHAPTER II: LITERATURE REVIEW } & 10\end{array}$

Learning from Standards-Based Reform in the 1980s, 1990s, and 2000s 10

$\begin{array}{ll}\text { CCSSM } & 12\end{array}$

$\begin{array}{ll}\text { Standards for Mathematical Practice } & 14\end{array}$

Identifying Instructional Practices Aligned with the Goals of CCSSM 14

Individual Teachers' Choices for Instructional Practices 16

$\begin{array}{ll}\text { Theories of Action } & 18\end{array}$

Examples of Theories of Action at Differing Levels of Reform 20

Exterior Reform Agency-level Action 20 
A Theory of Action for the CCSSM 25

Vision

Visions as Concrete Images

Individual Visions as Tools for Reform

Ways to Incorporate Individual Visions into Reform Efforts

Factors Influential When Translating Vision to Practice

Chapter II Summary

Participants

Selection of Case Study Teachers

Data Sources

Data Analysis

Describing Instructional Practices

Describing Visions for Mathematics Instruction

Evaluating Data Using Constant Comparative Analysis

Coder Agreement on Concepts That Were Thematic Among Teachers

Considering Conceptual Categories Within the Contexts of a Theory of Action, V4MIs, and the CCSSM

Ethics and Trustworthiness 
Synopsis of Simon's Lesson

Categories of Simon's Reasoning About Instructional Practices and Contexts Surrounding Those Categories

Personal Experiences

External Sources of Influence

Students' Individualized Needs

Establishing Classroom Culture

Goals for Learning of Mathematics

Assessment

Explicit Mention of V4MI and CCSSM

Paul

Synopsis of Paul's Lesson

Categories of Paul's Reasoning About Instructional Practices and Contexts

Surrounding Those Categories

Cultivating Learner Qualities

External Sources of Influence 
Categories of Marta's Reasoning About Instructional Practices and Contexts

Surrounding Those Categories

Prior Knowledge

Building Conceptual Knowledge

Mathematics Vocabulary

Other Mathematics Teachers' Classes

Explicit Mention of V4MI and CCSSM

Synopsis of Gwen's Lesson

Categories of Gwen's Reasoning About Instructional Practices and Contexts

Surrounding Those Categories

Cultivating Learner Qualities

Goals for Learning of Mathematics

Explicit Mention of V4MI and CCSSM

Themes in Teachers' Reasoning About Instructional Practices and Contexts

Surrounding Those Themes

Prior Knowledge

Building Conceptual Knowledge

External Sources of Influence

Establishing Classroom Culture

Cultivating General Learner Qualities

Cultivating Mathematics Learner Practices 
Explicit Mention of V4MI and CCSSM Considered for the Collective Group of Case

Study Teachers

$\begin{array}{ll}\text { Summary of Findings } & 139\end{array}$

Case Study Teachers' Reasoning Considered Collectively 139

$\begin{array}{ll}\text { Chapter IV Summary } & 140\end{array}$

$\begin{array}{ll}\text { CHAPTER V: CONCLUSIONS } & 142\end{array}$

Summary of Findings 143

$\begin{array}{ll}\text { Discussion of Findings } & 144\end{array}$

Reasoning About Instructional Practices Within the Framework of Cobb and Jackson's (2011) Theory of Action 144

Generalized Reasoning and Generalized V4MIs 148

Teachers' Reasoning Explicitly about V4MIs and CCSSM 149

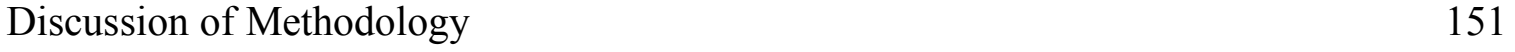

Limitations of the Study 153

Opportunities to Connect V4MI, Instructional Practices, and the CCSSM 154

Upper-level Support for Teachers 156

$\begin{array}{ll}\text { Suggestions for Future Research } & 157\end{array}$

Research Targeted at Deepening the Understanding of This Study 158

Research Targeted at Extending the Understanding of This Study 158

$\begin{array}{ll}\text { Closing Thoughts } & 159\end{array}$

$\begin{array}{ll}\text { REFERENCES } & 161\end{array}$

$\begin{array}{ll}\text { APPENDIX A: PARTICIPANT SELECTION CONSENT FORM } & 170\end{array}$

$\begin{array}{ll}\text { APPENDIX B: CASE STUDY CONSENT FORM } & 172\end{array}$ 
APPENDIX C: INITIAL INTERVIEW QUESTIONS

APPENDIX D: PRE-LESSON INTERVIEW QUESTIONS 


\section{TABLES}

Table

1. Examples of Teacher Statements Categorized for V4MI

2. Overview of Case Study Teachers' Representative of the Department

3. Summary of Data Sources

4. Generalized Names of Dancy and Henderson's (2007) Instructional Practices Categories

5. Iterations of $\mathrm{CCA}$

6. Simon's Reasoning for Specifying Instructional Practices

7. Understanding Simon's Categories of Reasoning about Instructional Practices

8. Paul's Reasoning for Specifying Instructional Practices

9. Understanding Paul's Categories of Reasoning about Instructional Practices

10. Marta's Reasoning for Specifying Instructional Practices

11. Understanding Marta's Categories of Reasoning about Instructional Practices

12. Gwen's Reasoning for Specifying Instructional Practices

13. Understanding Gwen's Categories of Reasoning about Instructional Practices

14. Themes in Teachers' Reasoning About Specifying Instructional 
15. Understanding Themes in Teachers' Reasoning About Instructional

Practices 


\section{FIGURES}

Figure

Page

1. Cobb and Jackson's (2011) vision component of the Theory of

Action

2. Considering the relationship between V4MI and instructional practices under CCSSM reform

3. Components of teachers' V4MIs as adapted from Hammerness's (2001) and Munter's (2014) frameworks

4. Individual task provided to students during Simon's chosen lesson

5. Cobb and Jackson's (2011) vision component of the Theory of Action

6. Individualized efforts in CCSSM reform: how teachers specified instructional practices

7. How Simon specified instructional practices

8. How Paul specified instructional practices

9. How Marta specified instructional practices

10. How Gwen specified instructional practices 


\section{CHAPTER I: INTRODUCTION OF THE PROBLEM AND ITS STUDY}

The first official version of the Common Core State Standards for Mathematics (CCSSM) was released to the public in June 2010 (Common Core State Standards Initiative [CCSSI], 2018) - at the end of my junior year as an undergraduate preservice secondary mathematics teacher. The following fall semester, I noticed the influence of the CCSSM trickling into my mathematics methods course and student teaching experience. Along with my fellow pre-service teachers, I practiced incorporating the Standards for Mathematical Practice (SMP) in lesson plans and spent a great deal of time digesting the content standards specific to each grade level and mathematics topic. I, along with my cooperating teacher, attended professional development and departmental meetings aimed at reforming practice in order to pursue the learning goals of Common Core. Through these experiences, I became excited about the opportunity to catalyze change in students' mathematical growth in a new era of mathematics standards reform.

Just a little more than a year later, as a new in-service teacher, I was ready to collaborate about ways to address the new standards and create opportunities for my students to have rich mathematical discussions, solve problems, and strategically use mathematical tools (i.e., experiences with the SMP). I still remember my sense of bewilderment when a new colleague handed me a binder and said, "Here are the four quarters of geometry homework assignments, quizzes, and tests with corresponding textbook pages noted. All of the geometry teachers quiz and test on the same days." The materials were dated 2005 and prescribed a topic for every day of the year. With this binder in hand, I wondered how I was going to plan instruction for the "Common Core environment" that I envisioned.

I knew what I wanted my classroom to look like-I could close my eyes and see students talking excitedly about their differing approaches to a mathematical task rooted in a career-based 
or nature-based context. I saw myself walking around and listening, probing students' thinking by asking an open-ended question or offering a word of encouragement. I was hoping that my more-experienced colleagues had a supportive plan in place for the practices that would help me address the stringent content goals of the geometry binder while also being true to the vision I held for my mathematics classroom. Upon attending the first departmental meeting, I realized my hopes might not be fulfilled. The principal addressed the mathematics department about the opportunity for change under the adoption of the CCSSM. As he spoke, a veteran teacher leaned into me and whispered, "Don't panic about a bunch of extra work. This fad, too, shall pass. Just stick to what you have been doing in your student teaching."

Over the next six years at two schools that differed vastly in student and teacher makeup, achievement, and location, I met mathematics teachers who approached the era of Common Core reform in the way described by that veteran teacher on my first day: plugging through each day re-enacting the comfortable instructional practices gained during their careers. However, I also worked with teachers who were eager to shape their teaching in a way that supported goals for students outlined in the CCSSM. I noticed that teachers' personal and differing visions for mathematics instruction seemed to influence how they utilized the CCSSM and what instructional practices they chose for their classroom. As the first decade of CCSSM adoption and implementation comes to a close, I am left to wonder about that veteran teacher and all other teachers I met during my time in the classroom. How have they chosen to address the CCSSM in light of their personal visions for mathematics instruction? And more broadly, how do these individual differences connect to a large-scale approach for implementing the CCSSM? 


\section{Background of the Problem}

Common Core is not our nation's first attempt at standards-based education reform, but it is the first of its kind as a plan for achieving national benchmarks through individualized efforts. Prior to Common Core, during the late 1980s and early 1990s, policymakers and educators began the work of creating content-specific standards and corresponding standardized assessments (Pense, Freeburg, \& Clemons, 2015). By signing the Goals 2000: Educate America Act (Goals 2000-Educate America Act Title III Public Law 103-227, 1994), President Bill Clinton formalized an ambition earlier pushed for by President George H. W. Bush: nationally-adopted academic standards and related standardized assessment (Thomas \& Brady, 2005). Associated efforts toward improving standardized academic achievement—and more interestingly in regards to this study, mathematics achievement — were unsuccessful, as evidenced by national achievement tests such as the National Assessment of Educational Progress (NAEP) and international comparisons such as the Trends in International Mathematics and Social Sciences assessment (Thomas \& Brady, 2005).

In response to disappointing academic performance as a nation, President George W. Bush signed the No Child Left Behind Act (NCLB; No Child Left Behind Act Public Law $107-$ 110, 2002). NCLB did not define grade-level proficiency and instead left it to each state to define their own standards for content and skills (Thomas \& Brady, 2005) and the levels of proficiency with which those standards were measured (Wallender, 2014). The state-led efforts to meet the requirements of NCLB resulted in growing disparities among public schools' performances across the nation (CCSSI, 2018; Thomas \& Brady, 2005; Wallender, 2014). The growing dissatisfaction with NCLB within political, educational, and communal realms as well as poor U.S. student performance on internationally-compared tests created momentum for a new 
national education initiative and the development of nationally-common educational standards (Pense et al., 2015; Schmidt \& Houang, 2012; Wallender, 2014).

\section{National Standards as an Individualized Effort}

The efforts to address the shortcomings of NCLB led to the creation of the Common Core State Standards for English Language Arts and Mathematics. Unlike the language of the NCLB, the Common Core provides mathematics standards that describe what students should understand and be able to do in relation to mathematics content at the end of each grade level from kindergarten to grade 12. Additionally, the standards include the eight SMP. The SMP describe "varieties of expertise that mathematics educators at all levels should seek to develop in their students" (CCSSI, 2019b, para. 1). The content standards and SMP specifically lay out what students should be able to do by the end of each grade, but the standards do not describe how teachers should support students through instructional practices in order to achieve these goals. Instead, the CCSSI (2019b) stated that, "Designers of curricula, assessments, and professional development should all attend to the need to connect the mathematical practices to the mathematical content in mathematics instruction" (para. 10). Further individualizing the plan for instructional practices, CCSSI (2019a) stated, "these standards establish what students need to learn but do not dictate how teachers should teach. Instead, schools and teachers will decide how best to help students reach the standards" ("Myths about Implementation," para. 1).

\section{Statement of the Problem}

The creators of the CCSSM assume teachers and education policymakers will make the translation from standards into improved instructional practices (Board on Testing and Assessment, 2009; Loeb, Knapp, \& Elfers, 2008). According to Loeb et al. (2008), current research on CCSSM reform assumes alignment between the goals of the standards reform 
initiative and teaching practices; however, teachers' views about what constitutes high-quality mathematics instruction are the intermediary between what is intended by the standards and what is decided upon as actions by the teachers. Munter (2009) suggested that "improvement in teachers' instructional practices ... will be greater in schools where teachers and instructional leaders have a shared vision for high-quality mathematics instruction" (p. 983).

However, Common Core is a reform effort that does not provide a collective vision that specifies the best instructional practices that have the potential to achieve the learning standards. Because the CCSSM is intentionally tacit about a corresponding vision for mathematics instruction and the instructional practices that emerge from such a vision, it is necessary to understand how teachers are reconciling their personal visions for mathematics instruction (V4MI) with the goals of CCSSM through their process for choosing instructional practices. The choice to consider individual's V4MIs as important within the large-scale Common Core reform is a valid one. Fullan (1993) emphasized the importance of the individual within the institutional change brought on during educational reform; he stated that individual teachers must examine and re-examine their vision of the future they prefer as "personal purpose is the route to organizational change" (p. 13). He argued that when close attention to the individual's vision is weakened, reform efforts are reduced to "a continual stream of fragmented, surface changes acquired uncritically and easily discarded" (Fullan, 1993, p. 13). Thus, considering individual's V4MI in the context of a large-scale reform effort is not unprecedented.

\section{Theoretical Framework}

Prior to and during our nation's attempt to reform mathematics instruction on a national scale with the CCSSM, smaller reform efforts at the state, district, and school levels have taken a different approach when specifying instructional practices. On these smaller scales, groups have 
created plans of action by spelling out teacher actions and teacher supports that result in the improved instructional practices aimed at achieving learning goals. One such plan, Cobb's and Jackson's (2011) “theory of action for improving the quality of mathematics teaching at scale" (p. 6), proved successful in improving the quality of mathematics teaching at the district level. Cobb and Jackson (2011) asserted that their theory of action was successful because the design of instructional system elements (e.g., instructional materials, goal-aligned assessments, professional learning communities, professional development) was driven by the district's goals for students' mathematical learning and vision of high-quality mathematics instruction.

In describing the foundation for their decisions regarding reform of an entire mathematics instructional system, Cobb and Jackson (2011) stated an important component was "a detailed vision of high-quality mathematics instruction [that] specifies concrete instructional practices that have the potential to lead to the attainment of learning goals" (p. 13). Herein lies the premise for success of many past large-scale reform efforts: the group inciting change — whether it be an entire state or a single mathematics department—must detail a vision that specifies instructional practices tailored to reach the standards chosen by the group. Figure 1 provides a visual representation of Cobb and Jackson's (2011) description of the relationship between vision, practice, and learning goals.

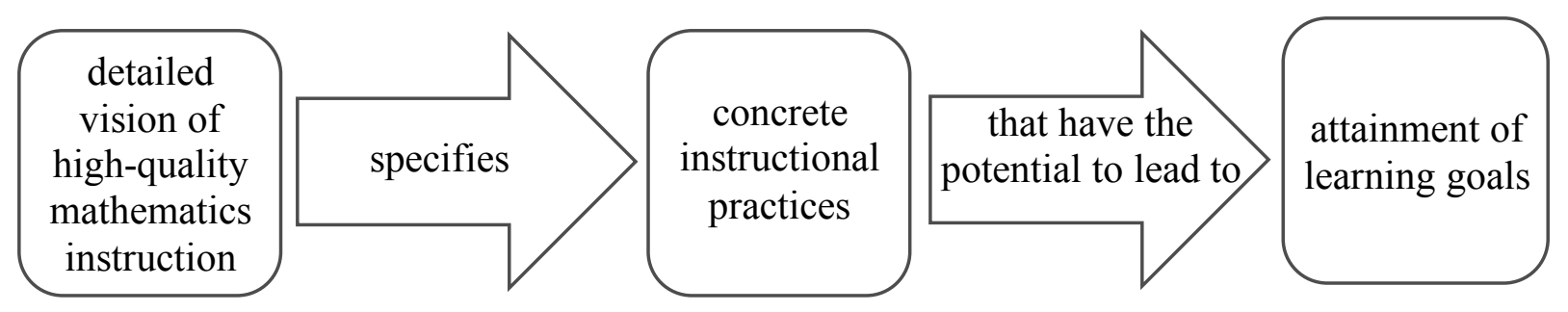

Figure 1. Cobb and Jackson's (2011) vision component of the Theory of Action. 
By choosing Cobb and Jackson's (2011) theory of action as a theoretical framework, I am able to regard the relationship of individual V4MIs, chosen instructional practices, and intended outcomes in the form of the CCSSM in a linear fashion. That is to say, I am able to conceptualize how V4MIs might precede teachers' choices for instructional practices aimed at achieving the goals of the CCSSM. The theory of action acts as a structure that brings form to researchable questions. Though Cobb and Jackson (2011) formulated a theory of action that was successful in improving mathematics teaching and learning in a district setting, I am left to wonder what their premise about vision might look like in the context of the CCSSM. Figure 2 reimagines the vision component of Cobb and Jackson's (2011) theory of action under the umbrella of CCSSM reform. Where the vision Cobb and Jackson (2011) described was explicit in its specification of concrete instructional practices, such specification cannot be assumed about teachers' V4MIs. And if teachers are made aware of their—perhaps otherwise tacit—V4MI, how will they make use of it to specify practices? The theory of action acts as a tool to transform this deliberation into researchable questions.

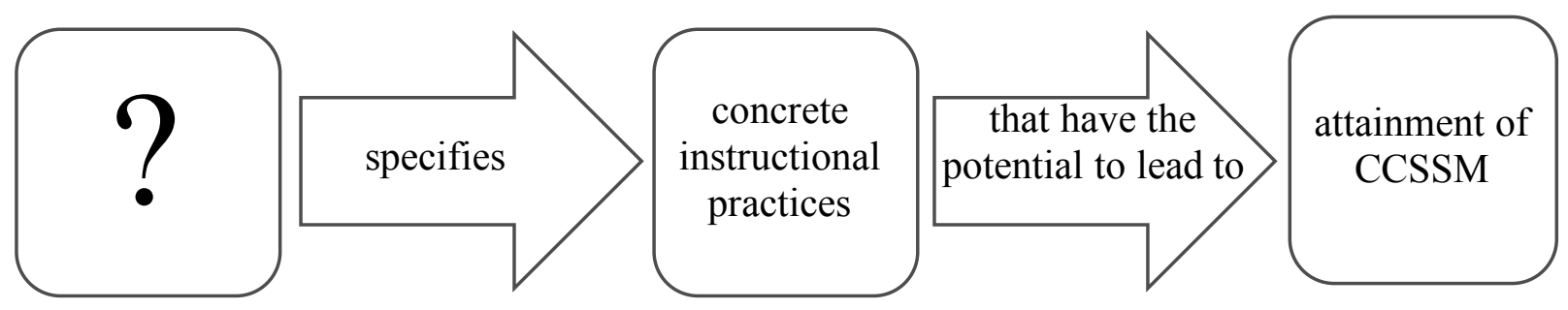

Figure 2. Considering the relationship between V4MI and instructional practices under CCSSM reform.

The current research aims to describe the process by which teachers move from V4MI to concrete instructional practices. Whether such instructional practices have the potential to lead to attainment of the CCSSM will not be addressed in this study. However, teachers were asked to 
reflect on ideal, planned, and enacted instructional practices aimed at achieving goals of the CCSSM.

\section{Purpose of the Study}

The purpose of this study is to describe how teachers reason about specifying instructional practices aimed at addressing the goals of the CCSSM. Because teachers' V4MIs can guide their instructional choices, and because much of teachers' thoughts about their V4MI might not be made explicit (Hammerness, 1999), I wanted to consider how teachers were informing their decisions about instructional practices. In order to understand the role of teachers' V4MIs in their reasoning, I first prompted teachers to explore their personal descriptions of ideal mathematics instruction. Because the connections between an individual V4MI and instructional practices within the context of the CCSSM has not been examined prior to this study, the purpose of this study was also to create and assess a methodology for such an investigation.

\section{Research Questions}

This study focused on the following research questions:

1. After being asked to describe their V4MI, how do teachers reason about specifying instructional practices aimed at achieving the goals of the CCSSM?

2. How can different forms of reasoning that teachers employ be understood within the context of a theory of action, V4MIs, and the CCSSM?

a. When, how, and with what consequences do teachers employ different forms of reasoning about specifying instructional practices?

b. What role did V4MIs and the CCSSM play in teachers' reasoning about specifying instructional practices? 
Research Question 2 was created to explore when throughout the study the teachers provided insight into different forms of reasoning about instructional practices. Research Question 2 also allowed me to consider teachers' explicit attention to their V4MI and the CCSSM as they discussed instructional practices that they deemed ideal or utilized in their own classrooms.

\section{Chapter I Summary}

The Common Core mathematics content standards and SMP introduce an unprecedented opportunity in U.S. history to consider the implications of a national-scale standards reform effort that provides teachers the individualistic opportunity to select instructional practices aimed at achieving those standards. To consider such implications, the premise of a theory of action (Cobb \& Jackson, 2011) situates visions, practices, and learning standards in a researchable context. This study explores teachers' reasoning about specifying instructional practices within the context of teachers' V4MIs and situates findings within the context of the CCSSM.

In the following chapters I describe this dissertation study and subsequent results. In Chapter II, I summarize related literature regarding standards-based reform, the CCSSM, theories of action, visions, and factors influencing instructional practice choices. In Chapter III, I delineate the qualitative methods chosen for this study, participants, sources of data, and process for analysis. In Chapter IV, I provide results from the analysis performed in this study. Particularly, stories of four case study teachers reveal how teachers might specify instructional practices after being asked to describe their V4MI. Additionally, I consider case study findings collectively to describe emerging themes among the reasoning of case study teachers. In Chapter V, I provide conclusions, implications, limitations, and recommendations. 


\section{CHAPTER II: LITERATURE REVIEW}

A review of the related literature will begin with a characterization of efforts to enact standards-based education reform — with a focus on mathematics education reform - in the United States during the 1980s, 1990s, and 2000s. By painting a picture of what we as a mathematics education community gained from those decades of standards-based reform, I am able to situate the subsequent section regarding implementation of the CCSSM within the context of our mathematics education goals as a nation at the time of Common Core's initial adoption. I will then describe relevant context and background of the CCSSM related to the issue of the logistics of implementation. In the third section, I will describe the role theories of action might play in implementation of the CCSSM with special attention to lessons learned from successful applications of theories of action in different educational contexts. In the fourth section I focus on the role vision has played as a pillar of most theories of action. After elaborating upon the relationship between institutional visions and personal visions and the roles they have played in teachers' instructional practices, I will close with a consideration of factors that may influence the translation of one's vision into instructional practices.

\section{Learning from Standards-Based Reform in the 1980s, 1990s, and 2000s}

In 1983, the National Commission on Excellence in Education called attention to the lack of rigorous academic standards in educational content areas (e.g., mathematics, science) in $A$ Nation at Risk. In the 1980s, state-led reform initiatives became increasingly prominent (Little, 1993). The decentralized nature of the U.S. educational system was evident in the abundance of state-led reform efforts coupled with local forms of education control (Cobb \& Jackson, 2011). Efforts to enact standards-based reform blossomed within schools, districts, private groups and industries, and university schools of education (Rorrer, Skrla, \& Scheurich, 2008). 
Perhaps most promising for mathematics education during this era of standards-based reform, the National Council of Teachers of Mathematics (NCTM) published in 1989 the Curriculum and Evaluation Standards, becoming the first professional organization to develop and broadcast academic standards (NCTM, 2000). These standards, specific to mathematics, called for an emphasis on conceptual understanding of mathematics over procedural understanding (Germain-McCarthy, 2014). Since 1990, these standards and subsequent implementation of related, research-informed practices have contributed to positive long-term trends for fourth- and eighth-grade students on the NAEP; unfortunately, a similar positive longterm trend has not been achieved to the same degree by tested high school students (NCTM, 2018).

Though efforts to successfully implement content-specific standards occurred nationally in pockets of schools and districts, dissatisfaction marked the period prior to NCLB in 2002. A disconnect between the goals in writing and the goals in action was manifested by such things as instructional practices and professional development for teachers (Little, 1993; Rosenholtz, 1985). As an example of this, Rosenholtz (1985) asserted that school administrators were creating conditions for instruction that were misaligned with the process of instruction. Similarly, Little (1993) placed on the state the unfulfilled responsibility of developing a coherent vision to connect teacher policy and reform ventures. Additionally, the gap between standards in writing and standards in practice could be viewed as a chasm when the influence of past reform efforts was considered. Little (1993) said that new systemic reform efforts often failed to fully account for the policy collision between current reform efforts and past reform efforts that was present in documentation and habit. 
Ambitious efforts to improve education for $\mathrm{K}-12$ students throughout the nation with a new approach to standards-based reform manifested in the passing of NCLB. Though the role of the federal government in education has been quite limited historically when compared to the majority of other industrialized nations (Cobb \& Jackson, 2011), NCLB was an effort to tie federal funding to the results of standardized tests used to measure students' grade-level proficiency and schools' overall academic growth from year to year (Pense et al., 2015). With best intentions, NCLB emphasized the necessity of high-quality teaching with the use of research-based practices and advocated for students' school choice based on school performance (Thomas \& Brady, 2005).

Smith and O’Day (1990) described this era of standards reform as a combination of topdown and bottom-up efforts. That is to say, control of inputs such as the length of the school day or the requirements for graduation were being specified by each individual state. At the same time, bottom-up efforts such as changes in key content concepts and active involvement of teachers were happening. The combination of these efforts, as encouraged by the federal government, emphasized standards, testing, and improvement in the majority of students. Unfortunately, as argued by Gitlin and Margonis (1995), politically motivated reform efforts often have neglected full consideration of implementation and accompanying problems. In the case of NCLB, resulting disparities between states and between subgroups of students (CCSSI, 2018; Thomas \& Brady, 2005; Wallender, 2014) was a death sentence for the NCLB era and cry for improved reform efforts.

\section{CCSSM}

President Obama announced the Race to the Top initiative in January of 2004, consequently allocating $\$ 4$ billion for states that showed they were working to make their lowest- 
performing schools successful, providing high-quality leadership in their schools, adopting challenging content standards and assessments, and tracking student progress (Lee, 2010). Though this initiative was not a direct funding of the creation of the CCSSM, Lee (2010) pointed to Obama's allusion to the standards in an excerpt from Obama's announcement for Race to the Top:

And even before states have received a single dime of taxpayer money, many of them have committed to instituting important reforms to better position themselves for a Race to the Top grant. Forty-eight states have now joined a nationwide partnership to develop a common set of rigorous, career-ready standards in reading and math. (para. 7)

The resulting partnership was the creator of the Common Core State Standards for English Language Arts and Mathematics.

Members of the National Governors Association (NGA) and the Council of Chief State School Officers (CCSSO) first met in 2009 to define what students should know by secondary school's end in order to be college- and career-ready (CCSSI, 2018). Revisions to the mathematics college- and career-readiness standards were made after considering feedback from Board-certified mathematics teachers, teachers from the American Federation of Teachers, and NCTM (NEA, n.d.). The partnership of CCSSO and states' NGA then delegated the task of creating Kindergarten through Grade 12 mathematics content standards to three individuals (Phil Daro, William McCallum, and Jason Zimba) whose combined expertise included K-12 education, higher education, and standards creation (Garland, 2014). The CCSSM writers sought to create standards that drew from the best of states' existing mathematics standards as well as the best of international mathematics standards (Garland, 2014). The first official version of the CCSSM was released in June of 2010 (CCSSI, 2018). Schmidt and Houang (2012) affirmed the 
quality of the standards by comparing the final CCSSM with individual states' mathematics standards. They determined that CCSSM most-closely aligned with the previous state standards of states that performed best on NAEP (Schmidt \& Houang, 2012).

\section{Standards for Mathematical Practice}

Informed by the NCTM process standards and mathematical proficiency strands described by the National Research Council (CCSSI, 2019b), the SMP consist of the following processes and proficiencies:

(a) make sense of problems and persevere in solving them;

(b) reason abstractly and quantitatively;

(c) construct viable arguments and critique the reasoning of others;

(d) model with mathematics;

(e) use appropriate tools strategically;

(f) attend to precision;

(g) look for and make use of structure; and

(h) look for and express regularity in repeated reasoning. (CCSSI, 2019b)

The SMP are a set of standards that describe what students should be able to do but do not describe how teachers should support these actions. CCSSI's (2019b) description of the SMP called for structural and material aides so that teachers are able to make choices for classroom instruction that support both the content standards and SMP outlined in the CCSSM. However, specific instructional practices are deliberately omitted from the structure of the CCSSM.

\section{Identifying Instructional Practices Aligned with the Goals of CCSSM}

Successful implementation of the CCSSM would mean a significant shift in what students and teachers need to know and be able to do (Dunlap, Webster, Jackson, \& Cobb, 
2015); hence, the shift has signaled a drastic departure from mathematics teaching practices that teachers would have consider typical in the decades leading up to Common Core (Jackson, Gibbons, \& Sharpe, 2017). As previously stated, an explicit description of best teaching practices did not accompany the CCSSM; therefore, teachers may have been left to wonder about changes that should be made to instruction. Coburn (2003) warned that reform efforts carrying implicit ideals concerning appropriate instructional practices "can be implemented at varying degrees of depth” (p. 5). Tacit implications for practice can lead to a limited understanding of what it means for a reform effort to be successful and divert attentiveness to the central purpose of improving teaching and learning (Coburn, 2003).

In an effort to provide guidance to teachers and other personnel invested in the outcomes of CCSSM reform, NCTM (2014) specified particular instructional practices that they believed best to provide learning opportunities for students that might lead to attainment of the goals of CCSSM. NCTM (2014) suggested the following instructional practices:

(a) Use cognitively demanding tasks for which no solution has been modeled and invite students to invent solution strategies;

(b) Facilitate discussions within the community of the classroom in order to build shared understandings of mathematical ideas and compare and contrast ideas;

(c) Allow students to share in the authority of driving discussion and posing and solving problems;

(d) Consider student interests, identities, and current understandings in order to create equitable and responsive opportunities.

In addition to laying out instructional practices that support with the goals of the 
CCSSM, NCTM (2013) stressed the importance of teacher professional development for ensuring that teachers are prepared to meet the call for reformed instruction and full implementation of Common Core. The advice presented by NCTM $(2013 ; 2014)$ had—and still has - the potential to greatly support teachers, schools, districts, and even states as the work to attain success with the CCSSM. Unfortunately, when states chose to adopt the national-scale standards, they did not necessarily adopt the instructional practices that NCTM (2014) asserted would support the standards. Ultimately, the CCSSM points to schools - and more-specifically individual teachers - to "decide how best to help students reach the standards" (CCSSI, 2019a, para. 1).

\section{Individual Teachers' Choices for Instructional Practices}

The decision to charge teachers with deciding on instructional practices to aid their students in achieving the goals of CCSSM might raise a few eyebrows, but it is a decision that should be weighed carefully for its shortfalls and benefits when considering past reform efforts. Cobb and Jackson (2011) concluded that in past efforts at large-scale improvement in mathematics, studies in educational policy (Elmore, 2004; Gamoran et al., 2003; McLaughlin, 2006 as cited in Cobb \& Jackson, 2011) have collectively evidenced failure to produce lasting changes in instructional practice. Coburn (2003) lamented when stating, "After many years of intense educational reform, educators, policymakers, and researchers still grapple with the question of how pockets of successful reform efforts might be 'scaled up"' (p. 3). Coburn (2003)

also warned that the adoption of a reform does not equate to its implementation with fidelity or implementation at all. Coburn (2003) detailed that externally-developed reforms may fall especially susceptible to such a fate of implementation — a warning that could apply to states' adoption of the externally-developed CCSSM. 
In the era of Common Core, Heyd-Metzuyanim, Munter, and Greeno (2018) experienced what could be described as a difference in understanding of the standards and the best instructional practices aimed at achieving those standards. One of the authors, Munter, collaborated with a high school algebra teacher, Ms. Q, as an extension of a professional development experience. Munter and Ms. Q worked to plan a lesson in which students would work to identify zeros of a cubic function without prior demonstration of a solution approach. As a goal of the professional development, Munter worked with Ms. Q to move toward implementing more cognitively demanding tasks and move away from demonstrations in the style of direct instruction. Both Ms. Q and Munter assumed they had the same objectives for enacting the lesson after the planning session; however, the way that Ms. Q enacted instructional practices was a surprise to Munter as he observed the lesson. Both envisioned students working in groups while the teacher pushed their thinking and a lesson closure that included interesting and rich mathematical conversation. However, the manifestation of that vision conflicted with the practices imagined by Munter. Differences included a focus on utility of the remainder theorem versus an exploration of the behavior of polynomials.

The case of Ms. Q and Munter as collaborators in planning revealed a danger in relying on individual visions of the best instructional practices to achieve a goal developed in light of CCSSM. Even so, consideration of individual teachers' roadmaps for achieving the goals of CCSSM might prove fruitful. Little (1993) was optimistic in stating that to be successful, standards-based reform required latitude for teachers to create local solutions to local problems and to identify practices that embody values important to them. Little (1996) furthered the importance of individuality in large scale reform by casting doubt on large-scale reform efforts that do not specifically account for teachers' individual perspectives, pasts, and contexts. 
The mixed reception of individual teachers' leeway to define best practice in the era of Common Core begs the following question: How should we, as a community of mathematics educators, researchers, and stakeholders, move toward successful individuality in teaching toward the goals of CCSSM? Little (1993) recognized the tension that can manifest in light of institutional priorities and individual choices; large-scale reform often requires a collective effort, but professional development supporting the teachers in reform often remains individualistic. This contrast in conditions must be considered in the context of Common Core. There is a need for research concerning progress made, challenges remaining, and actions needed to truly ensure that we reach the potential set forth by the CCSSM (NCTM, 2014). The writers of the CCSSM conveyed the message that "effective teaching is the nonnegotiable core that ensures all students learn mathematics at high levels and that such teaching requires a range of actions at the state or provincial, district, school, and classroom levels" (NCTM, 2014, p. 14). In order to heed this message, teachers, researchers, and other educational stakeholders should consider that the nature of reform must move past surface structures of standards to alter principles of pedagogy (Coburn, 2003). That is to say, it cannot be taken for granted that the standards will reach the students in the classroom; instead, it is necessary to judiciously define the development of instructional practices that support the standards (Coburn, 2003).

\section{Theories of Action}

In the past, large-scale education reform efforts at the district level (e.g., Cobb \& Jackson, 2011) and at the state level (e.g., Michigan; Spillane, 2000.) have created plans to connect standards reform to specific instructional practices best-suited to support students in achieving the goals of the standards. These plans, often referred to as theories of action, include supports for teachers (e.g., professional development and professional learning communities) 
that are aimed at guiding instructional practices and student achievement (Cobb \& Jackson, 2011; School Reform Initiative [SRI], 2016). Elmore (2004) described a theory of action as providing a connection between big ideas and fine-grained doings. When deciding on the proper doings for the context, the design of a suitable theory of action and underlying instructional system should be driven by the goals for mathematical learning in union with a vision for highquality instruction (Cobb \& Jackson, 2011).

Perhaps before theories of action served a long-standing purpose in the realm of standards-based reform, Rosenholtz (1985) described the synthesized findings from research about inner-city schools that had seen great success. "To combat low basic-skill acquisition, effective principals arm their schools with common objectives toward which to collectively aim, with full command of teaching strategies developed through collaborative efforts, with maximum time, materials, and technical assistance to implement them" (p. 381). In order for principalsand other instructional leaders charged with implementing reform — to take the actions that Rosenholtz (1985) described, it is essential that they make sense of the reform policies and come to understand the specifics of what needs to change about current instructional practices (Coburn, 2003; Spillane, 2000). It is also essential that enactors of reform explore ways to shift the authority of the reform effort away from the institution — in the case of Common Core, state and federal authority — and toward teachers, schools, and districts (Coburn, 2003). In doing so, there is a shift from understanding the reform to supporting practice of the reform (Coburn, 2003).

When making choices about how to best support reform-in-action, Finn (2002) delineated four over-arching directions in which creators of theories of action could steer their efforts. These directions are as follows: spell out ways that additional resources will support a betterfunctioning school system; make a plan for experts (e.g., mathematics education researchers, 
mathematics coaches) to retrain teachers in specific ways; embrace government standards and assessment and allow consequences for failing those standards to motivate changes in teaching and learning; create a market of choice for students (e.g., charter schools, voucher schools) to motivate school personnel to create the best-choice school (Finn, 2002). Though each of these courses of action might sound familiar when standing alone, Finn (2002) recognized that many theories of action employ several of these strategies.

Regardless of the course chosen for reform efforts, most theories of action often contain an institutional vision that describes the goals of the reform effort and guides leaders toward objectives and ideals that play out in instruction (Hammerness, 1999). Theories of action provide direction and a specific plan for those involved to follow; however, theories of action are not cut and dry with a bulleted list of actions that at the end guarantees success. "The most effective theories of action, more so than mission statements, visions, guiding principles, or values statements, are always drafts. Theories of action are meant to be tested, examined, added to and subtracted from" (SRI, 2016, p. 19). To get a sense of the content of a theory of action, the following section provides examples within different educational settings and under different standards-based reform efforts.

\section{Examples of Theories of Action at Differing Levels of Reform}

Examples of theories of action are plentiful among the related literature. I have chosen examples of theories of action that illustrate the variety in organizational level, purpose, and outcome of theories of action.

Exterior Reform Agency-level Action. SRI has provided an example of an exterior reform agency's theory of action for supporting educational reform in various schools and districts with differing visions (SRI, 2016). SRI's theory of action has illustrated the usefulness 
of a vision and supporting action plan that supports an organization created to support others. SRI has provided leadership coaching and institutes, seminars, literacy-focused teacher professional learning community supports, new teacher mentoring and induction programs, teacher content and grade-level team initiatives, and action research opportunities; the organization guides its efforts based on its mission statement. Their mission statement reads as follows, "SRI creates transformational learning communities fiercely committed to educational equity and excellence" (SRI, 2016, p. 1). In order to remain true to this mission, SRI created a theory of action to describe what they mean by transformational learning communities. This theory of action also detailed how they support those communities to become committed to equity and excellence. SRI (2016) asserted that learning communities must be accountable to student success, engaged in public assessment of adult and student efforts, and working to challenge assumptions about teaching and learning. The organization has found success in supporting learning communities by building relationships, working to understand specific contexts of transformational learning, using conversation protocols, modeling coaching and facilitation, supporting professional development, focusing on improvement and reinvention at the school level, and engaging in formal and informal leadership roles. SRI (2016) has attributed success to careful translation of their mission into actionable components.

State-level Action. In contrast to the form, function, and outcome of SRI's theory of action, Michigan schools participated in a research study examining the relationship between state and local governments as they shared roles in creating policies and theories of action for mathematics education reform (Spillane, 2000). Between 1992 and 1996, the state left it to local districts to translate mandates (e.g., mathematics content standards) into theories of action. Spillane (2000) conducted interviews with district leaders and educators in order to understand 
their translation of policy into actionable descriptors. The majority of interviewees echoed the same handful of descriptors (e.g., real world connections, hands-on experiences, active learning), but Spillane (2000) conveyed concern about the responses. Though descriptors of practice were consistent among differing district leaders, responses reflected an attachment to familiar reform descriptors of the past as opposed to novel reform effort descriptors (e.g., student communication, student reasoning). Spillane (2000) lamented that administration seemed more concerned with the form practice took than with the function practice served. He warned that individuals charged with translating mathematics education vision into practice should either specialize in the content area or should be supported by others to understand the mathematical meaning behind policy mandates.

School-level Action. Ferrucci (1996) provided an account of action toward mathematics educational reform at Deep Brook Elementary School. The elementary school was housed within a district that had defined a vision for mathematics instruction that emphasized a problemsolving atmosphere. Their explicit vision called for student-centered practices that elicited exploration, data analysis and verification, conjecture formation, and mathematical discourse (Ferrucci, 1996). The district's shared vision called for taking risks with new materials and techniques and asking students to articulate their mathematical thinking in both oral and written forms. Ferruci (1996) described the process teachers at Deep Brook enacted in order to personalize the shared vision and NCTM Standards (i.e., the Curriculum and Evaluation Standards for School Mathematics and the Professional Standards for Teaching Mathematics). Deep Brook supported all of its elementary teachers as they designed lessons that embodied the practices within their collective vision. The chosen standards served as a tool for reflection when 
deciding if vision-aligned instructional choices were successful in leading to student growth, and teachers responded to the findings of their reflection with refined courses of action.

As an example of school-level action in a high school setting, Anderson, Steffen, Wiese, and King (2014) described reform efforts at LaFollette High School in Madison, Wisconsin. The researchers regarded the reform efforts as a model for others to follow or research. Part of the success they saw as a school was attributed to the collaborative nature of principals, instructional coaches, and teachers as they constructed and annually revised their plan (Anderson et al., 2014). LaFollette serves as an example of a concise, explicit theory of action:

If all staff collaborate purposefully to: design standards-based tasks and supports; shift the cognitive load so that students think, read, and write critically; and measure and reflect on the impact of their actions on students learning; then all students will become more engaged, collaborative, and independent critical thinkers, readers, and writers whose formative and summative assessment results reflect growth for career, college, and community. (Anderson et al., 2014, p. 59)

By carefully choosing to carry out these action steps collaboratively and with fidelity, LaFollette has seen significant improvements in discipline, failure rates, attendance, and student assessment results.

District-level Action. Milwaukee public schools (MPS) have served as an example of intentional reform efforts that have spanned several decades (Montgomery, Darling-Hammond, \& Campbell, 2011). After seeing little success in the 1990s and 2000s under an aggressive school choice theory of action modeled after market forces, MPS turned their attention to building the professional capacity to carry out common instructional practices in conjunction with common standards for learning (Montgomery et al., 2011). MPS took the intentional action 
steps of coaching teachers to develop content knowledge, developing useful and streamlined curriculum, and aligning the oversight of administration with the leadership of teacher leaders. Unfortunately, MPS had seen struggle in their efforts, as their continued use of school choice was at odds with streamlining practices among all schools. In response to this struggle, Montgomery et al. (2011) suggested that MPS needed to "continue to communicate, develop, and support a strong shared vision for instructional improvement" (p. iv).

In Contrast to MPS, Miller River Unified Union School District in rural Vermont began reform efforts in 2013, and they attributed reform success to their instructional vision. In discussing Miller River, Jones (2018) described the necessity of a clear instructional vision as the component that "drives the instructional choices that teachers make in their classrooms and gives them a roadmap of sorts" (para. 3). Miller River's instructional vision team-composed of teachers representative of grade levels and content areas - has worked to ensure district efforts remain true to their vision through leading in-service workshops, providing input in district-level decisions, scrutinizing documents and plans, and providing feedback about what works in classrooms. Crafted to support their vision, Miller River's theory of action has described three necessary proficiencies supported by specific performance indicators. As an example, one proficiency holds that expectations for students and outcomes must be clearly and consistently communicated. Indicators that this is happening include utilizing learning targets, providing student work examples in class to scaffold student learning, and communicating student progress to students and families on a frequent and consistent basis.

Specific to the realm of mathematics education — and perhaps most essential to the understanding of the current study — is a theory of action developed by the Middle School Mathematics and the Institutional Setting of Teaching (MIST). Beginning in 2007, members of 
MIST collaborated with four urban school districts in order to make ambitious efforts toward reforming middle school mathematics instruction (Munter \& Correnti, 2017). At the end of the first four-year phase of MIST, Cobb and Jackson (2011) formalized their "theory of action for improving the quality of mathematics teaching at scale" (p. 6). Using a grounded theory approach informed by interviews, surveys, observations, and material collection from administrators, teachers, and others involved, Cobb and Jackson (2011) spelled out the key elements needed in an instructional system in order to experience successful mathematics education reform. They asserted that the design of instructional system elements (e.g., instructional materials, goal-aligned assessments, professional learning communities, professional development) should be driven by the district's goals for students' mathematical learning and vision of high-quality mathematics instruction (Cobb \& Jackson, 2011). Acting as an involved researcher in the MIST project, Munter (2009) observed that a shared vision for high quality mathematics instruction enhanced the impact of MIST professional development and student achievement. MIST professional development specifically targeted instructional practices consistent with the MIST districts' visions (Munter \& Correnti, 2017).

\section{A Theory of Action for the CCSSM}

Examples within the literature demonstrate that theories of action have played vital roles in reform efforts at many levels. To be sure, in light of the "flailing about" (Finn, 2002, p. 291), false starts, and lack of improved achievement since A Nation at Risk in 1983, we must proceed with "some kind of theory of action. That is, some plausible notion of what we think is most apt to drive the improved instruction results that we seek" (p. 291). It should be noted that theories of action can and have been crafted at state, district, school, and organizational levels to carry out CCSSM-based reform efforts. Even so, it may serve the mathematics education community well 
to consider a theory of action created at the scale of the standards; that is, such a theory of action would spell out specific steps that anyone adopting the CCSSM could take to enact the instructional practices intended by the writers of the standards, and such practices could lend themselves to the individual tailoring desired in the Common Core era.

NCTM (2018) has provided a scaffolding on which to build such a CCSSM theory of action. Their recommendations during the era of Common Core have included the following: all students should learn a set of essential concepts (e.g., within the topic of functions, there are families of functions with distinguishing structures or attributes); tracking of teachers and tracking of students into course pathways that are qualitatively different must end; all students need to participate in four continuous years of coherent mathematics instruction including two to three years in a common pathway focusing on essential concepts; and instructional practices should be informed by mathematics education research. Specifically, NCTM (2018) laid out a set of recommended, research-based instructional practices such as eliciting and using evidence of student thinking, connecting mathematical representations, and promoting discourse among student peers that leads to understanding of others' mathematical ideas.

However useful NCTM's (2018) recommendations might be, they are not a packaged deal with the CCSSM. Additionally, the specifics (e.g., mathematical content, classroom tasks, dialogue) remain individualistic. Little (1996) warned of danger in providing idealistic visions for instructional practice and school reform in an atmosphere without support for the individual. Pursuit of this somewhat general ideal can lead to extremely negative emotional experiences and even shifts or cessations of careers in education (Little, 1996). As such, imagining the benefits of a CCSSM theory of action should occur with attention to individual teachers' hopes and needs. 
In the following section, I will explore the concept of individual visions and the role they might play in the conceptualization of a CCSSM theory of action.

\section{Vision}

A vision for classroom instruction "consists of images of what teachers hope could be or might be in their classrooms, their schools, their community and, in some cases, even society" (Hammerness, 2001, p. 145). When prompted to explore their visions, Hammerness (1999) found that teachers visions are specific, detailed, powerful, and constant over time. Though Johnston (1992) used the term images instead of visions, he described a construct that allows teachers to consider themselves within their teaching contexts and make decisions about practice based on those considerations. Johnston (1992) found that these images provided an opportunity to relate discussions about teaching to classroom reality.

\section{Visions as Concrete Images}

Considering vision as a set of images allows us to explore the relationship between visual pictures and individual vision. Snyder (1980) discussed the concept of vision as it related to a physical photograph. A photograph is caused by the objects it represents, but in taking the photograph, the photographer has provided a form of expression. They have chosen to attend to certain objects from a certain point of view. Furthermore, one would never be able to attain the vision depicted in a photograph — the human eye focuses centrally, does not see in sharp focus across the plane, and does not border a rectangular scope of vision as most photographs do.

"What is certain is that the depiction of what we see will always require a defined notion of the object of vision" (Snyder, 1980, p. 526). Likewise, Goodwin (1994) recognized the perspectival nature of vision as it was situated within communities of practice (i.e., within a group of experts in a field). 
Maxson and Sindelar (1998) operationalized vision as both pictorial and situated within the education community of practice by creating a vision assignment for elementary preservice teachers. These researchers asked preservice teachers to draw a picture of themselves and their students accompanied by a narrative describing what was happening in the picture. Though each picture represented a differing vision, Snyder (1980) urged us as a mathematics education community to accept each such vision as credible and warranted. Snyder (1980) recognized that we may have never saw things quite the way they are depicted in someone else's vision (i.e., as a picture, in writing, spoken, or acted out). Even so, individual visions are credible representations of the notions we carry with us about how things should appear and operate (Maxson \& Sindelar, 1998).

\section{Individual Visions as Tools for Reform}

Considering vision as representations of teachers' notions about how things should appear and operate might give rise to confusion between the terms vision and beliefs. The semantic distinction here is between future and present. The term vision allows for voicing the possibility for change and improved instruction; therefore, visions differ from beliefs, which are viewed as being static ideals (Munter, 2014). Vision should be seen as a tool for understanding the world while also foreseeing the future (Hammerness, 1999).

Such a function for individual vision has the potential to play a significant role in CCSSM reform efforts. As Fullan (1993) suggested, the key to educational reform is not considering the individual teacher; instead, the key is considering the personal vision of that teacher. If the goal is to improve the practice of teaching, then we must recognize that "teachers' intuitions, skills, values, and feelings about what they do are part of their practice" (Simon \& Tzur, 1999, p. 254). Because vision reflects teachers' desired skills and values, we must connect 
visions to reform of teaching practice. NCTM (2014) suggested intentional, structured reflection opportunities as a way for teachers to improve their practice; one way to provide structure is to use teachers' visions as a guide to prompt reflection on their practice (Hammerness, 1999). Reflecting on practice while using vision as a guidepost has been shown to benefit teachers in learning, increasing motivation, and building agency as they worked toward their visions of ideal classroom practice (Hammerness, 1999). Some researchers have found that as teachers have utilized vision to reflect on their practice, they have often felt motivated to learn and use new instructional practices (Fullan, 1995; Brown \& Moffett, 1999).

As we consider visions as tools for reflection, we must distinguish between visions of instruction and visions in instruction — a distinction pointed out by Munter (2014). The former allows reflection on an ideal image of instruction held within the teacher's imagination or depicted through some medium, whereas the latter allows the teacher to view themselves in instruction (e.g., by watching a videotaped lesson) as a way to prioritize focus and reflection on elements of instruction they deem important. As a note, the current study aims to provide teachers' an opportunity to explicate their visions both of and in instruction with references to this holistic vision as their visions for instruction (V4MIs).

Absent attention to personal vision, Gitlin and Margonis (1995) found that teachers were resistant to reform efforts and longed for agency to teach in ways they found personally agreeable. Fullan (1992) and Goodwin (1994) warned that when externally-sourced ideals (e.g., visions created by administration or those outside of the community of practice) have been imposed upon others, disconnectedness when moving forward has been imminent. Hammerness (1999) stated, "A balance must be achieved between attention to the visions of both individuals and institutions" (p. 143). Leaders might achieve this balance by valuing individuality when 
moving toward a collaborative vision (Fullan, 1992). The following section provides specific actions that allow incorporation of individual visions into collective reform efforts that include collective visions and action plans aimed at improving instruction.

\section{Ways to Incorporate Individual Visions into Reform Efforts}

Munter $(2009,2014)$ described a specific framework for considering individual visions within the structure of large-scale reform. Through a series of interviews with hundreds of middle school mathematics teachers, he created a series of rubrics that could be used to assess the current state of a teacher's vision of high-quality mathematics instruction (VHQMI). The VHQMI rubrics — created and utilized within the context of the MIST project — allow for measure along a trajectory from less to more sophisticated visions focused on the role of the teacher, classroom discourse, and mathematical tasks (Munter, 2014). The VHQMI framework of rubrics allowed for an understanding of individual teachers' VHQMI in transition toward a particular vision that aligned with the instructional vision promoted by leaders in MIST districts

(Munter \& Correnti, 2017). In understanding where a teacher was along the VHQMI trajectories, school and district leaders were able to anticipate teachers' individualized needs and appropriate supports (Munter, 2014).

Imagining a different role for individual visions than Munter, Hammerness (1999) alluded to specific professional development activities that might incorporate visions into reform efforts. She suggested that teachers be provided opportunities to consider, articulate, and collaborate about their personal visions while paying special attention to where teachers' individual visions mesh, oppose, and build on one another. The potential of personal ideals within the setting of professional development can build community and commitment — qualities that organizational visions are meant to promote (Hammerness, 2001). As teachers collaborate 
about their visions, Hammerness (1999) asserted they are able to consider contexts that allow for an appropriate reach toward their visions. That is to say, understanding factors that either support or hinder progress toward their visions might help teachers to navigate the gaps between vision and daily work (Hammerness, 2004).

\section{Factors Influential When Translating Vision to Practice}

While the previous two sections of this literature review have detailed how individual visions might be put to use in effecting change in instructional practices, such a relationship should be considered as non-direct. That is to say, teachers are not able to enter their classrooms every day and enact ideal mathematics instruction; as has been established, vision is a goalpost or a future reach. To understand the inability to fully realize every aspect of one's V4MI, it is useful to consider the factors that act to filter, shape, edit, or shift vision as it is translated into practice.

One such factor is people. Teacher's consciously and unconsciously make decisions about instructional practices based on the level of social support for their vision (Little, 1996). Colleagues, fellow teachers, and those in positions of authority provide a degree of support or resistance for certain instructional practice choices (Clarke, 1997; Hammerness, 1999). Parents and others who loudly voice dominant cultural beliefs in support of traditional instructional practices can be an obstacle for teachers working to enact non-traditional instructional practices (NCTM, 2014). Additionally, student difficulties perceived as out of the teacher's locus of control lead teachers to compensate through their choices for instruction (Jackson et al., 2017).

By zooming out to the level of the institution, other factors can be described as impacting the translation of vision into concrete instruction. Institutional policy provides structure and guidance that affects daily practice (Little, 1996; Hammerness, 2004). More concretely, the day- 
to-day conditions for teaching impact decisions about instruction and commitment to enacting change (Clarke, 1997). Specific examples of such conditions include availability of technology and access to instructional materials and tools (NCTM, 2014).

On an even larger scale than the institution, national and state contexts affect teachers' abilities to translate vision into practice (Hammerness, 1999, 2004). In the context of CCSSM reform, the reform movement as adopted at the state level has affected teachers' decisions about instruction (Clarke, 1997). National and state standardized assessments also act to filter teachers' choices for content (Hammerness, 2004) and decisions about what students should be able to do (Dunlap et al., 2015; NCTM, 2014).

Finally, it is important to consider teachers' opportunities to learn and grow in ways that support their ability to act out high-quality mathematics instruction that is aligned with their vision (Hammerness, 1999). If the aim is to reform mathematics instruction to be high-quality and aligned with the goals of CCSSM, professional development is a necessary tool to equip teachers with sound abilities to choose and enact high-quality instructional practices (Clarke, 1997; Little, 1993; NCTM, 2014).

\section{Chapter II Summary}

The goal of this study is to provide understanding about how teachers reason about their choices for instructional practices after being asked to describe their V4MI and to place this understanding within the context of Common Core reform and the utility of a theory of action. In

this chapter, I synthesized literature related to concepts needed to understand the current study. A characterization of standards-based reform prior to the CCSSM provides context for lessons we have learned as a mathematics education community aimed at reform. A description of the CCSSM and nuances of its adoption and implementation provide an invitation to introduce 
theories of action as a possible implementation support. In exploring theories of action, I have detailed the multiple levels and forms these theories can take and explored a possible conceptualization of what theory of action might mean in relation to the CCSSM. Finally, I confront the issue of incorporating individual visions into theories of action for large-scale reform and explore factors that have the potential to alter or infiltrate individuals' visions as they attempt to translate those visions into instructional practices aimed at achieving the goals of reform. 


\section{CHAPTER III: METHODOLOGY}

In order to explore how teachers' reason about instructional practices and how that reasoning can be situated within the contexts of V4MIs and the CCSSM, I asked the following research questions:

1. After being asked to describe their V4MI, how do teachers reason about specifying instructional practices aimed at achieving the goals of the CCSSM?

2. How can different forms of reasoning that teachers employ be understood within the context of a theory of action, V4MIs, and the CCSSM?

a. When, how, and with what consequences do teachers employ different forms of reasoning about specifying instructional practices?

b. What role did V4MIs and the CCSSM play in teachers' reasoning about specifying instructional practices?

Because I am studying how individuals specify instructional practices after describing their V4MI, I constructed a methodology that would allow me to understand their unique perspectives and choices. Thus, I chose to employ a qualitative research methodology. Such a methodology can help the researcher to understand a process from the perspective of the individuals and "make sense of their work and experience" (Merriam, 1998, p. 11).

My goal was to describe the multitude of ways that teachers reasoned about ideal, planned, and enacted instructional practices aimed at achieving the goals of the CCSSM. The use of an instrumental multi-case study approach allowed me to analyze several sources of qualitative data within each teacher case and across cases (Yin, 2003). Yin (2003) suggested that a single case study of a group of people occurs when the researcher is investigating a single phenomenon as it manifests within the group. Because I was considering each teacher case as 
representative of a different V4MI, all four teachers were considered individual cases and thus this study is a multi-case study rather than a single case study of a group. Because the standards for comparison within the context of the first two research questions are not clearly defined by prior researchers' frameworks or methodologies, this study was best executed as an instrumental case study (Yin, 2003). Instrumental case studies allowed me to describe understanding past the particular cases examined (Yin, 2003). Specifically, an instrumental multi-case study allowed me to consider how teachers' individual case studies might reveal an understanding of how teachers' reasoning might relate to the premise of a theory of action (i.e., how individual visions could specify instructional practices aimed at achieving the goals of the CCSSM).

Such a methodology helped me to work within the structure of Cobb and Jackson's (2011) theory of action that "a detailed vision of high-quality mathematics instruction specifies concrete instructional practices that have the potential to lead to the attainment of learning goals" (p. 13). I knew that I was investigating the "vision" piece of that statement. Specifically, how were teachers using their V4MI to guide instruction? Were teachers making instructional choices based on reasoning disconnected from their V4MI? Thus, I gathered data regarding visions, instructional practices, and learning goals through the use of qualitative interviews and lesson artifacts surrounding lessons purposefully chosen by the participants as examples of how their V4MI might play out in instruction.

I initially interviewed the 10 participating teachers, which allowed me to describe teachers' V4MIs and select four teachers as cases that were representative of similarly-grouped V4MIs that emerged among all participating teachers. I followed the four case study teachers through the process of planning, enacting, and reflecting about a lesson chosen by them as exemplifying their V4MIs. Interviews during the planning stage allowed me to discuss with 
teachers the instructional practices they hoped to enact and how those practices aligned or misaligned with their V4MIs. A final interview gave me insight into teachers' reflections - aided by videos of the lessons - about their enacted instructional practices' alignment with their V4MIs. This data, enriched by evidence from written statements, lesson artifacts, and lesson observation, allowed me to consider teachers' V4MIs and reasoning about instructional practices within several contexts.

\section{Participants}

Participants in this study's initial interview stage included 10 secondary mathematics teachers from one mathematics department in one high school located in the Midwestern region of the United States within an urban city. The mathematics department contained 11 teachers in all, and one teacher chose not to participate in the study. Of the 10 teachers who participated, years of teaching experience ranged from 3 to 40 . The high school student population was diverse in socioeconomic status, race and ethnicity. At the time of the study, approximately $40 \%$ of students attending the school received public aid, lived in substitute care, or were eligible for free school lunch. The student body makeup was reported as $44.3 \%$ white, $30.7 \%$ black, $11.7 \%$ two or more races, $8.3 \%$ Hispanic, $4.9 \%$ Asian, and $0.2 \%$ Pacific Islander.

I used purposeful sampling in order to select a group of participants that teach in similar conditions. Merriam (1998) stated that purposeful sampling is appropriate when the investigator aims to "discover, understand, and gain insight" (p. 6) and must select a particular sample from which the most information can be learned about the question at hand. I selected a single department of teachers because I wanted to explore the diversity of ways in which teachers specify instructional practice within a relatively homogenous environment. My goal was to select teachers in a secondary setting because they are immersed in teaching mathematics for the 
majority of their teaching day. I wanted to describe their visions and connections between vision and instructional practices in a mathematics-specific context, and elementary and middle school teachers often spend considerable time teaching non-mathematics content.

\section{Selection of Case Study Teachers}

I conducted initial interviews with each of the 10 participating teachers. During initial interviews, I asked questions that were modeled after Munter's (2009) open-ended interview about teachers' visions of high-quality mathematics instruction. Initial interview questions can be located in Appendix C. According to Munter (2009), the nature of these questions allowed participants to step outside of themselves. That is to say, the questions did not require participants to say what they do or would do in their own classroom, which may have caused them to bolster their response with things that they thought were desirable for others to hear. Instead, the questions took them out of the role of instructor and placed them in the role of observer; participants are were able to provide an in-depth description of what they would want to see in a mathematics classroom (Munter, 2009). Due to the nature of the interview questions, I, the interviewer, was able to understand what the participants would focus on as important in their own V4MI without being suggestive as to what they should include as important to their V4MI.

In the event that a case teacher provided only a minimal description of their V4MI, I was prepared with follow-up questions - also located in Appendix C_-based on Munter's (2009) categories for describing teachers' statements about vision. For example, I was prepared to ask teachers what they saw as the role of the instructor in a classroom exhibiting ideal mathematics instruction. The purpose of these follow-up questions was to give a greater chance of collecting rich data for focus teacher selection. In interviewing three of the 10 teachers in the sample, I 
asked one or two of these questions. I did not analyze any of the data gained from these responses, as I was able to describe each teacher's vision in enough detail to gain a sense of representative clusters of V4MIs without forcing teachers to detail pieces of a V4MI that they had not chosen to focus on initially.

I reviewed transcripts of all 10 teachers' initial interviews to locate statements related to Munter's (2014) categories for analyzing teacher's visions of high-quality mathematics instruction. After holding all initial interviews, I transcribed the interviews within four days. I chose to wait and transcribe initial interviews until after I had met with each teacher. I felt that this would allow me to immerse myself in the interview data when all interview transcripts were fresh in my mind. The analysis of these transcripts and identification of these four teachers is described in further detail in Chapter IV. By choosing to view teachers' V4MI through the lens of Munter's (2014) work, I was able to align my understanding of V4MIs with my theoretical framework. This is true because Munter's (2014) work and Cobb and Jackson's (2011) theory of action were both derived from the MIST reform effort.

The categories for understanding V4MIs were: (a) role of the teacher, (b) classroom discourse, and (c) mathematical tasks (Munter, 2014). For each teacher, I recorded all statements related to these three categories. All 10 teachers fell into three groupings: (a) those who discussed the role of the teacher and classroom discourse; (b) those who discussed classroom discourse and mathematical tasks; and (c) those who discussed the role of the teacher, classroom discourse, and mathematical tasks. I also noticed that all 10 teachers drew attention to their range when describing their V4MI. Hammerness (2001) defined range as the extent to which a teacher's vision extends past his or her own practice. Teachers either described their vision in terms of themselves, their students, and their class, or they extended their vision to include what 
they would hope to see in a department, school, or district (i.e., close or distant descriptions of range). Examples of categorized statements from two teachers can be found in Table 1.

Table 1

Examples of Teacher Statements Categorized for V4MI

\begin{tabular}{|c|c|c|}
\hline Category & Teacher A & Teacher B \\
\hline Role of the Teacher & $\begin{array}{l}\text { "The teacher's got to be } \\
\text { there for support in that } \\
\text { particular instance [of } \\
\text { student discourse], but they } \\
\text { got to be the teacher in the } \\
\text { sense that they got to } \\
\text { actually teach all the skills to } \\
\text { act that way, ask those } \\
\text { questions." }\end{array}$ & $\begin{array}{l}\text { "They do not } \\
\text { necessarily need to be } \\
\text { mathematicians, but } \\
\text { they need to be math } \\
\text { teachers. Ideally, there } \\
\text { are two teachers ... you } \\
\text { have freed up for kids to } \\
\text { get remediation and } \\
\text { enrichment." }\end{array}$ \\
\hline Classroom Discourse & $\begin{array}{l}\text { "Ideally it would be students } \\
\text { using their own questioning } \\
\text { and trying to come to } \\
\text { conclusions." }\end{array}$ & $\begin{array}{l}\text { "Everybody can talk. I } \\
\text { want them to talk to } \\
\text { each other. I want them } \\
\text { to ask somebody else." }\end{array}$ \\
\hline Mathematical Tasks & $\begin{array}{l}\text { Teacher A did not discuss } \\
\text { tasks, problems, or activities } \\
\text { in their vision. }\end{array}$ & $\begin{array}{l}\text { "They're engaged in } \\
\text { real world math. They } \\
\text { come up with real data } \\
\text { and being able to } \\
\text { crisscross. We used to } \\
\text { do activities with the } \\
\text { chemistry teacher." }\end{array}$ \\
\hline Range & $\begin{array}{l}\text { "I would probably look at } \\
\text { interactions, because in my } \\
\text { classroom I try to elicit } \\
\text { student discussions where } \\
\text { it's not only teacher based. }\end{array}$ & $\begin{array}{l}\text { "They need young } \\
\text { women. They need } \\
\text { people of color. Look at } \\
\text { the math department. } \\
\text { The more kids see } \\
\text { themselves in teachers } \\
\text { or in engineers, etcetera, } \\
\text { the more they think they } \\
\text { can do." }\end{array}$ \\
\hline
\end{tabular}

Note. Teachers A and B were not selected for case studies. 
I chose four teachers who were representative of varied groupings of V4MIs within the department. Varying cases are desired in order to detail the fluctuating circumstances surrounding the phenomenon of interest (Flyvbjerg, 2006). Specifically, varying cases of V4MIs were identified during the initial interview stage, and the chosen focus teachers were selected from the department teachers that were grouped by similar V4MIs. I hoped that by exploring cases of teachers with varying V4MIs, I might come to understand differences in ways that teachers utilized their V4MI as a tool for reasoning about specifying instructional practices. I represented teachers in the groupings that came to light upon identifying statements categorized by Munter's (2014) framework (i.e., role of the teacher, classroom discourse, and mathematical tasks) and Hamerness's (2001) definitions of close and distant range in vision. Table 2 below provides an overview of the teachers selected as case studies and the groups they represented from the 10 teachers participating in the initial interview. All four teachers had taught at the current school for at least 2 years, and their prior teaching locations were within the district that included the study site school. The selection process resulted in four focus teachers who had a wide range of years teaching. Simon had been teaching for 40 years, Marta for 8 years, Gwen for 12 years, and Paul for 3 years. As a note, I am using pseudonyms for all teachers.

Table 2

Overview of Case Study Teachers' Representative of the Department

\begin{tabular}{lll}
$\begin{array}{l}\text { Teacher } \\
\text { Pseudonym }\end{array}$ & Focus of Teacher's Vision in Initial Interview & Range in Vision \\
\hline Simon & role of the teacher; classroom discourse & distant \\
Marta & classroom discourse; mathematical tasks & close \\
Paul & role of the teacher; classroom discourse; mathematical tasks & distant \\
Gwen & role of the teacher; classroom discourse; mathematical tasks & close \\
\hline
\end{tabular}


Case study teachers participated in the remainder of the study (i.e., pre-lesson interview, lesson observation, post-lesson interview). Initial interviews were used as a tool to select these case study teachers as representative of V4MIs within the mathematics department. Additionally, the data collected during the initial interviews were used as a source for analysis in the cases of the four selected teachers.

\section{Data Sources}

I collected data to understand how teachers described their V4MI and how they reasoned about specifying ideal, planned, and enacted instructional practices aimed at achieving goals of the CCSSM. Methods for collecting data allowed teachers to consider their V4MI when describing ideal mathematics instruction, and planning and reflecting on classroom instruction. In this way, the data revealed a cohesive picture of teachers' thought processes about instructional practices while discussing their vision of instruction and in instruction. A summary of the collected data and its' purpose within the context of the study is provided in Table 3. Table 3

Summary of Data Sources

\begin{tabular}{|c|c|c|}
\hline Data's Descriptive Purpose & Interview Data & Other Sources of Data \\
\hline envisioning ideal instruction & initial interview & \\
\hline planning ideal instruction & pre-lesson interview & $\begin{array}{l}\text { - written lesson plan } \\
\text { written statement } \\
\text { connecting lesson to } \\
\text { V4MI }\end{array}$ \\
\hline reflecting on ideal instruction & post-lesson interview & $\begin{array}{l}\text { - lesson materials provided } \\
\text { to students } \\
\text { - } \text { copies of projected lesson } \\
\text { presentations } \\
\text { - field notes }\end{array}$ \\
\hline
\end{tabular}


The first source of data collected was the initial interviews during the case study teacher selection process. Initial interviews allowed me to investigate participants' visions of instruction outside of their own teaching and the instructional practices they would ideally choose in light of these visions. Though this data source was used as a tool to select focus teachers to act as case studies, I also utilized the initial interview data to understand the four focus teachers' visions for ideal mathematics instruction. I then followed the four focus teachers through the process of planning, implementing, and reflecting on a lesson aimed at achieving goals specified by the CCSSM. Teachers were specifically instructed to choose a lesson that they felt aligned with or exemplified their V4MI to ensure that teachers considered their V4MI throughout the data collection process. Directing teachers to focus on their V4MI was necessary, as the focus of this study is to examine connections between V4MIs and instructional practice.

Prior to their chosen lesson, I conducted a pre-lesson interview allowing teachers to explain their plans for the lesson and what they hoped students would be able to do as a result of the lesson. After the lesson was completed, I used a video-stimulated recall post-lesson interview to provide the teacher with an opportunity to reflect on the lesson with special attention to moments that best showcased their V4MI and moments that they wish to improve in the future to better align with their V4MI.

By asking open ended questions I hoped to allowed teachers to comment on their V4MI and chosen instructional practices in a free and spontaneous way (Fram, 2013). I did not use the video in an evaluative manner to see if teachers taught as they planned, rather I used it to prompt the teachers' descriptions of their V4MI and choice of instructional practices. Questioning planned for the pre-lesson and post-lesson interviews can be found in Appendices D and E; however, I used teachers' responses to uniquely guide follow-up interview questions. 
I made the choice to use video-stimulated recall interviews to allow teachers to mediate between my own understanding of their enacted practices and their descriptions of V4MI (Radišic \& Baucal, 2016). According to Radišic and Baucal (2016), video-stimulated recall proved an excellent tool to understand instructional practices, and teachers reflected that the video was representative of genuine practice as both they and their students were able to quickly turn their attention away from the video camera and act as usual during the lesson. As found by Anderson (2019), video stimulated data can be reliably triangulated by other data sources such as additional interviews on the topic and observation of the videoed lesson. Additional data sources such as those suggested by Anderson (2019) were used and are described following.

In addition to initial, pre-lesson, and post-lesson interviews, I collected other data. During the pre-lesson interview, teachers were asked to write a few sentences about how they hoped to see their vision come out during their planned lesson. The written statements were another opportunity for teachers to consider how their V4MI might inform and align with their planned practice. Comparing teachers initial, pre-lesson, and post-lesson interviews allowed me to triangulate data and strengthen my descriptions of teachers' V4MIs and relationships between teachers' V4MIs and instructional practices. Additionally, written lesson plans, written materials given to students during lessons, and copies of projected presentations from lessons were collected. I acted as an observer for the duration of the four case study teachers' chosen lessons and recorded field notes about the classroom, activities, and teacher and student actions.

\section{Data Analysis}

The methodology described here was designed to investigate how teachers reasoned about specifying instructional practices after verbalizing their V4MI. Investigating this phenomenon situated me in a qualitative and data-rich context but without a conceptual 
framework. This led me to explore the use of constant comparative analysis (CCA), because such a method allowed me to analyze the data for emerging themes as opposed to fitting the data to an existing framework. Fram (2013) explained that the experienced researcher using a grounded theory approach has the luxury of a mental library of research when employing CCA to develop a theory based on the data. Such an awareness of existing and related literature allows the researcher to recognize patterns in the data without adhering to an existing framework; thus, the experienced researcher is able to develop a theory through the iterative process of analyzing an artifact of data, using that evidence to direct collection of the next piece of data, and repeating said process until all data has been analyzed, compared, and findings exhausted.

As a novice researcher, I recognized that I needed the guidance of relevant research to direct my collection of data and to frame my investigation. However, I wished for the data to "speak" for itself as all available frameworks were not specific to the processes involved in specifying instructional practices - in light of personal V4MIs — aimed at the collective learning goals spelled out in CCSSM. According to Fram (2013), CCA can be a helpful process for novice researchers when developing new categories and recognizing relationships amongst categories in data. Specifically, Glaser (1965) pointed to CCA as a facilitator of "generation of theories of process, sequence, and change that pertain to organizations, positions, and social interactions" (p. 444). In the context of this study, I aimed to generate theories about teachers' processes of reasoning about instructional practices after verbalizing and considering their V4MIs. This phenomenon pertained to the organizational changes brought on by the CCSSM.

Outside of a grounded theory methodology, Fram (2013) argued that CCA can be used to maintain the research participants' views as insiders (i.e., emic perspectives) while maintaining the outsider concepts in theoretical frameworks during analysis (i.e., etic perspectives). I took 
this to mean that as a novice researcher, I could look to the related literature for guidance in understanding the three concepts in Cobb and Jackson's (2011) theory of action (i.e., vision, practices, goals) in order to frame my thinking about the concept under investigation (i.e., reasoning about specifying instructional practices). Then, I could look for patterns or relationships among the data surrounding the concept under investigation.

Thus, I interacted with the data twice prior to beginning CCA in order to describe V4MIs and instructional practices — using established frameworks to help me describe each. Prior to framing my understanding of the data by describing instructional practices and V4MI and because I am explicitly investigating connections between V4MI and the CCSSM, I asked the case study teachers to confirm the specific CCSSM goals they addressed in their chosen lessons. I worked in this order (i.e., describing first goals, then instructional practices, then V4MIs) so that teachers' V4MI would be the most-recent concept I had described. Because the research questions assumed that a teacher first possesses a V4MI and then moves to specify instructional practices to meet goals, I wanted the teacher's V4MI to be on the forefront of my conscious memory as I began the process of CCA.

Utilizing existing frameworks to describe V4MIs and instructional practices was an intentional step toward maintaining an etic perspective throughout the CCA process. Existing frameworks prevented me from noting only some instructional practices with which I was familiar or developing my own biased definition of V4MI or instructional practices. I knew that such an etic perspective would need to be intentional, as I have previously acted as a high school teacher with my own interpretations of vision, practices, and goals. Established and researchbased frameworks allowed me to reduce the effects of bias in my cognition of teachers' V4MI, instructional practices, and CCSSM goals. 


\section{Describing Instructional Practices}

Once I had verified with each teacher the CCSSM learning goals associated with each chosen lesson, I reviewed the data once again in order to detail the instructional practices chosen and enacted by each teacher. I needed to detail instructional practices in order to know where to look within the data to find reasoning about instructional practices. Dancy's and Henderson's (2007) framework for articulating instructional practices informed my descriptions. This framework was developed "for articulating practices and conceptions of individual instructors" (Dancy \& Henderson, 2007, p. 1). Though created for use in the physics classroom, this framework was informed by ten frameworks for instructional practice in mathematics, science, and general content (Dancy \& Henderson, 2007). I selected this framework because of its thorough, inclusive, and specific nature.

Dancy \& Henderson (2007) looked to other frameworks, literature, and field discourse that described alternative practice found to best support educational reform and intentionally bolstered the inclusiveness of their own framework by pairing each alternative practice with its counterpart of typical traditional instruction. They were careful to be explicit about the nonhierarchical nature of their framework - recognizing that both alternative and traditional practices can be "best" practice in different situations and that teachers may enact both alternative and traditional practices within a practice category. Furthermore, the specificity of Dancy's and Henderson's (2007) framework allowed me to understand what actions and choices are considered instructional practices. For example, instead of naming the practice of student inquiry, they provided specific examples of evidence such as "students pose problems and questions to be answered" (p. 10). My intention in this study was not to evaluate teachers' instructional practices. Instead, I aimed to gain an understanding of the things case study teachers 
said or did that could be considered instructional practices. Prior to using the framework, I generalized the names of Dancy's and Henderson's (2007) instructional practice categories in order to indicate the general instructional practice without bias toward judging the teacher as alternative or traditional. A complete listing of the category names used by Dancy and Henderson (2007), along with the generalized category names that I utilized during data analysis, can be found in Table 4.

Table 4

Generalized Names of Dancy and Henderson's (2007) Instructional Practices Categories

\begin{tabular}{|c|c|c|c|}
\hline $\begin{array}{l}\text { Instructional } \\
\text { Practice } \\
\text { Category }\end{array}$ & Generalized Name & $\begin{array}{l}\text { Generally Traditional } \\
\text { Practice }\end{array}$ & $\begin{array}{l}\text { Generally Alternative } \\
\text { Practice }\end{array}$ \\
\hline $\mathrm{P} 1$ & interactivity & $\begin{array}{l}\text { minimal degree of } \\
\text { interactivity }\end{array}$ & $\begin{array}{l}\text { significant degree of } \\
\text { interactivity }\end{array}$ \\
\hline $\mathrm{P} 2$ & sources of control & teacher control & student autonomy \\
\hline P3 & sources of knowledge & knowledge transmission & $\begin{array}{l}\text { knowledge } \\
\text { development —inquiry }\end{array}$ \\
\hline $\mathrm{P} 4$ & $\begin{array}{l}\text { nature of expectations } \\
\text { of students }\end{array}$ & $\begin{array}{l}\text { fixed expectations of } \\
\text { students }\end{array}$ & $\begin{array}{l}\text { adjustable } \\
\text { expectations of } \\
\text { students }\end{array}$ \\
\hline P5 & modes of learning & $\begin{array}{l}\text { competitive/individualist } \\
\text { learning modes }\end{array}$ & $\begin{array}{l}\text { cooperative learning } \\
\text { mode }\end{array}$ \\
\hline P6 & sources of motivation & external motivators & internal motivators \\
\hline $\mathrm{P} 7$ & assessment & $\begin{array}{l}\text { knowledge-based } \\
\text { assessment }\end{array}$ & $\begin{array}{l}\text { process-based } \\
\text { assessment }\end{array}$ \\
\hline P8 & content & knowledge-based content & broad content \\
\hline P9 & instructional design & $\begin{array}{l}\text { knowledge-driven } \\
\text { instructional design }\end{array}$ & $\begin{array}{l}\text { student-driven } \\
\text { instructional design }\end{array}$ \\
\hline $\mathrm{P} 10$ & problem solving & traditional problem solving & $\begin{array}{l}\text { alternative } \\
\text { problem solving }\end{array}$ \\
\hline
\end{tabular}


Using the framework developed by Dancy and Henderson (2007), I worked through each of 10 practice categories (e.g., minimal degree of interactivity/significant degree of interactivity, fixed expectations of students/adjustable expectations of students), read each descriptor within the alternative and traditional sections of each practice category, and referenced available data sources for indication that the teacher had enacted that descriptor. Data sources included researcher field notes, lesson plans, lesson artifacts, written pre-lesson statement, pre-lesson interview, and post-lesson interview. Video of lessons were not used as a data source for instructional practices because I only considered the instructional practices that teachers vocally described when planning and reflecting on the lesson. This allowed me to attend to practices that the teacher felt were either aligned or not aligned with their V4MI. I filled in the instructional practices framework with all descriptors specific to the teacher, included a rich description of the teacher's instructional practice choices for each practice category, and wrote a summary of instructional practices based on the teacher's completed framework.

In Chapter IV, I do not devote any specific portion of the findings to only describing instructional practices. Instead, instructional practices are noted with only the intention of detailing the reasoning surrounding the practice. The process of analyzing the data to detail and summarize instructional practices was a necessary precursor to place me in the etic perspective when later analyzing the data using the process of CCA.

\section{Describing Visions for Mathematics Instruction}

In order to understand the V4MIs in a way that would allow me to maintain an etic perspective and structure my findings during CCA in the next phase of analysis, I chose to adapt and combine ideas from Munter's (2014) framework for evaluating teachers' visions of highquality mathematics instruction and Hammerness's (2001) framework for describing teachers' 
vision constellations. Hammerness's (2001) framework was not content-specific, and it allowed for a description of focus, range, and distance. Though range (i.e., how far the teacher extends their focus, whether it be their own classroom or beyond) and distance (i.e., how far the teacher perceives his or her own instruction from the ideals of his or her vision) were useful in understanding teachers' visions, the concept of focus (i.e., the areas of interest that teachers discuss when asked about their vision and the clarity of those areas of interest) seemed to describe the same understandings of V4MIs as Munter's (2014) framework; however, Munter's (2014) framework provided the benefit of pointing to areas of focus that are important to mathematics instruction. Thus, I chose to detail teachers' V4MIs by tying applicable interview statements to the categories of role of the teacher, classroom discourse, mathematical tasks (Munter, 2014), range, and distance (Hammerness, 2001). Figure 3 illustrates the relationship among Hammerness's (2001) components of teachers' vision constellations and Munter's (2014) framework components for visions of high-quality mathematics instruction as I utilized them to describe teachers' V4MIs.

V4MI

(visions of and in instruction)

Range

how far the teacher extends their focus, whether it be their own classroom or beyond (Hammerness, 2001)
Distance

how far the teacher perceives his or her own instruction from the ideals of his or her vision (Hammerness, 2001)

\section{Focus}

the areas of interest that teachers discuss when asked about their vision and the clarity of those areas of interest (Hammerness, 2001); specifically, Munter's (2014) components of:

- role of the teacher

- classroom discourse

- mathematical tasks

Figure 3. Components of teachers' V4MIs as adapted from Hammerness's (2001) and Munter's (2014) frameworks. 
I used these categories in the most general sense, meaning that I did not assess teachers' likeness to any specific vision type described by Munter or Hammerness, nor did I evaluate any characteristic of any teacher's V4MI as being superior to any other. The goal of describing teachers' V4MIs was not to rank or evaluate the effectiveness or superiority of visions but instead to place teachers' choices for instructional practices in the context of their V4MI.

I needed to understand teachers' visions of instruction and their visions in instruction in order to maintain an etic perspective when considering the relationship between their forms of reasoning about instructional practices and their V4MIs. This meant understanding how they envisioned an ideal mathematics classroom as well as how they detailed moments that exemplified their vision or lack thereof in the context of their own teaching. I was able to coordinate understandings of vision of and vision in instruction by questioning teachers about their V4MI during the initial interview and during pre-lesson and post-lesson interviews. I looked to teachers' initial interviews to understand how they described their visions of instruction outside of the context of a specific lesson or their own teaching in practice. I referred to their pre-lesson and post-lesson interviews and pre-lesson written statement to understand how they described their vision in the context of a specific lesson and its enactment. Throughout this process, I identified statements fitting into the categories I chose for my V4MI framework (i.e., range, distance, and focus, with focus being conceptualized as role of the teacher, classroom discourse, mathematical tasks). If teacher statements could fit into more than one category, I included those statements in all applicable categories. This helped me to build a rich and inclusive description of teachers' V4MIs in each category of the framework.

I used categorized statements to build a summative narrative of each teacher's V4MI organized into the V4MI framework categories. The completed V4MI frameworks for each 
teacher functioned as a tool used by me to maintain an etic perspective when performing CCA to address the research questions. I created these V4MI frameworks specific to each teacher for my personal use to familiarize myself with each teacher's V4MI. This was necessary in order to maintain an etic perspective while performing data analysis, as I hold my own V4MI in the role of a past mathematics teacher. Detailed V4MI frameworks will not be included in the findings, as descriptions of case study teacher's V4MIs were used by me as a tool for considering the relationship between V4MI and reasoning about specifying instructional practices and as a concrete framework allowing me to step outside my role as a former mathematics teacher and inside my role as a researcher striving to understand teachers' reasoning from their point of view.

\section{Evaluating Data Using Constant Comparative Analysis}

Boije (2002) described a concrete example of the iterative process of CCA in the context of interviews. I studied Boije's (2002) example in the context of patients and their spouses dealing with a chronic illness and drew parallels to the interviews that I collected during the current study. In describing my CCA process, I will refer to Boije's (2002) analysis process and the corresponding iteration of CCA that I performed on my interview data. During each iteration, I produced memos describing the reasoning concepts, definitions I created for these concepts, and categories for concepts that related to addressing the first research question (i.e., After verbalizing their V4MI, how do teachers reason about specifying instructional practices aimed at achieving the goals of the CCSSM?). Table 5 summarizes each iteration of CCA that I performed on the data and describes the iteration's parallel to Boije's (2002) example of the iterative process of CCA in the context of interviews.

I framed my analysis by asking myself the following questions: (a) What instructional practice was discussed? (b) What connection was drawn - if any - to V4MI? and (c) How did the 
teacher explain or rationalize the instructional practice? Frameworks expounding upon instructional practices and visions (Dancy \& Henderson, 2007; Hammerness, 2001; Munter, 2014) helped me to locate within transcripts answers to questions (a) and (b). Answers to questions (a) and (b) helped me tie teachers' reasonings to specific strategies within the context of specific pieces of their V4MI. Answers to question (c) were noted and collected, as they were the sources of data that were used to form my answers to the first research question. I also included in each iteration's memo my thoughts about the process. Specifically, I noted my discovery of clues to locating reasoning and similarities and differences in teachers' reasoning at each iteration of CCA.

Table 5

Iterations of CCA

The Current Study's CCA

Iteration Description

Boije's (2002) Iteration of Paralleling Boije's (2002)

CCA Iteration of CCA Iteration Number

comparison within a single comparison of reasoning first iteration of CCA interview within a single initial interview comparison of reasoning third iteration of CCA within a single pre-lesson interview comparison of reasoning within a single post-lesson interview

(Table Continues) 
Table 5 cont'd.

Iterations of CCA

\begin{tabular}{|c|c|c|}
\hline $\begin{array}{l}\text { Boije's (2002) Iteration of } \\
\text { CCA }\end{array}$ & $\begin{array}{l}\text { The Current Study's CCA } \\
\text { Iteration Description } \\
\text { Paralleling Boije's (2002) } \\
\text { Iteration of CCA }\end{array}$ & Iteration Number \\
\hline \multirow[t]{3}{*}{$\begin{array}{l}\text { comparison between } \\
\text { interviews within the same } \\
\text { group }\end{array}$} & $\begin{array}{l}\text { comparison between all } \\
\text { initial interviews' reasoning } \\
\text { categories from the first } \\
\text { iteration of CCA }\end{array}$ & second iteration of CCA \\
\hline & $\begin{array}{l}\text { comparison between all pre- } \\
\text { lesson interviews' reasoning } \\
\text { categories from the third } \\
\text { iteration of CCA }\end{array}$ & fourth iteration of CCA \\
\hline & $\begin{array}{l}\text { comparison between all post- } \\
\text { lesson interviews' reasoning } \\
\text { categories from the fifth } \\
\text { iteration of CCA }\end{array}$ & sixth iteration of CCA \\
\hline $\begin{array}{l}\text { comparison from different } \\
\text { groups }\end{array}$ & $\begin{array}{l}\text { comparison between } \\
\text { reasoning categories from } \\
\text { second, fourth, and sixth } \\
\text { iterations of CCA }\end{array}$ & seventh iteration of CCA \\
\hline $\begin{array}{l}\text { comparison at the level of the } \\
\text { couple }\end{array}$ & $\begin{array}{l}\text { comparison at the level of the } \\
\text { teacher between reasoning } \\
\text { categories from first, third, } \\
\text { and fifth iterations of CCA, } \\
\text { during a teacher's initial, pre- } \\
\text { lesson, and post-lesson } \\
\text { interview }\end{array}$ & eighth iteration of CCA \\
\hline comparing couples & $\begin{array}{l}\text { comparing teachers; } \\
\text { comparison between } \\
\text { reasoning categories from } \\
\text { seventh and eighth iterations } \\
\text { of CCA }\end{array}$ & ninth iteration of CCA \\
\hline
\end{tabular}

I began by reading through one case study teacher's initial interview. Using answers to question (c), I noted similarities and differences between reasonings the teacher employed when 
choosing instructional practices and used these notes to create groupings of similar reasonings. I described groupings using concept names and definitions that detailed the similarities among groups of the teacher's reasons. I repeated this process with each of the other three initial interviews from the other three case teachers. At this primary stage of CCA, I did not compare reasonings among different teachers' initial interviews; I only compared and grouped reasonings within each teacher's initial interview. That is to say, I did not compare Simon's reasoning in his initial interview to Gwen's reasoning in her initial interview. I only compared Simon's different instances of reasoning within his initial interview to other instances of Simon's reasoning in his initial interview, and so on for each case study teacher. This iteration of CCA paralleled Boije's (2002) "comparison within a single interview."

After analysis of each initial interview, I reviewed the four memos and conceptual groupings that I had created. I compared and contrasted the reasonings teachers provided for favoring certain instructional practices and created a new memo using all four initial interviews. I again created conceptual groupings to help address the first research question. Some conceptual groupings that I had created based on single initial interviews remained intact and were combined with other conceptual groupings from other initial interviews. Other conceptual groupings from single initial interviews were deconstructed to form new conceptual groupings that better-described themes among teachers' initial interviews considered collectively. For example, Marta discussed instructional practices that she employed in order to increase student use of mathematics vocabulary. Within her initial interview, I had grouped this reasoning under the concept of "mathematics vocabulary;" however, this reasoning was grouped under "practices of mathematics learners" during the second iteration of CCA in order to combine Marta's reasoning about use of mathematics vocabulary with other teachers' reasoning about other 
mathematical practices they hoped to foster in their students. This iteration of CCA paralleled Boije's (2002) “comparison between interviews within the same group."

Following the same CCA process, I compared data within each teacher's pre-lesson interview and then compared data between all pre-lesson interviews as a group collectively. Next, I compared data within each teacher's post-lesson interview and then compared data between all post-lesson interviews collectively. Again, these iterations of CCA paralleled Boije's (2002) "comparison within a single interview" followed by "comparison between interviews within the same group." In the context of the current study, interviews within the same group refer to interviews within the group of initial interviews, interviews within the group of prelesson interviews, and interviews within the group of post-lesson interviews. Worded another way, all four initial interviews conducted with all four case study teachers were considered a single group of initial interviews.

Once I had created memos and concepts for groups of interviews (i.e., initial, pre-lesson, and post-lesson), I reviewed these documents for similarities and differences. I looked for recurring themes in concepts from groups of interviews. I created a memo about the process of comparing data between the groups of initial, pre-lesson, and post-lesson interviews and refined concept categories of reasoning about instructional practices. This iteration of CCA represented a cohesive collection of concepts from all three groups of similar interviews. Again, some concepts were re-worked, re-named, or combined with similar concepts. This iteration of CCA paralleled Boije's (2002) “comparison from different groups." In the context of the current study, different groups refers to the different phases of interviews. As an example, I compared the emerging categories of reasoning from the group of initial interviews to the emerging categories of reasoning from the group of pre-lesson interviews. 
After comparing concepts from groups of interviews, I turned my attention to understanding themes emerging from a single teachers' interviews considered as a strand. By this, I mean I reviewed memos and concepts from a single teacher's initial, pre-lesson, and postlesson interviews. Categories created to describe the teachers' reasoning during this iteration of CCA included reasoning appearing in more than one of the teacher's interviews, as this signified that category of reasoning was thematic for the teacher. I created new memos detailing my thoughts and re-conceptualized categories of reasoning for each teacher's strand of interviews. This process paralleled Boije's (2002) “comparison at the level of the couple.” Because the current study does not involve couples, it should be noted that Boije (2002) looked for themes among several interviews with the same couple consisting of a person inflicted with a health condition and their significant other. Paralleling this, I looked for themes among several interviews with the same teacher.

In the ninth and final iteration of CCA, I compared memos and categories of reasoning generated in the seventh and eighth iteration for each group of interviews (i.e., the group of initial interviews, the group of pre-lesson interviews, and the group of post-lesson interviews) and for each teacher from their strand of interviews (i.e., initial, pre-lesson, and post-lesson interviews). This allowed me to look for similarities and differences among the four teachers' reasoning about specifying instructional practices. Categories of reasoning included in this iteration of CCA were present in more than one teacher's categories of reasoning created in the seventh and eighth iterations of CCA. Such a prevalence of the concept signified that it was a theme for individual teachers as well as a theme among teachers. This iteration of CCA paralleled Boije's (2002) final iteration of CCA deemed "comparing couples." 
Each iteration of CCA was essential to understanding the concepts teachers employ when reasoning about their choices for instructional practices, but only concepts synthesized during the eighth and ninth iterations of CCA will be reported in the findings in Chapter IV. The final two iterations of CCA allowed for a rich description of each teacher's themes in reasoning about instructional practices and a rich description of reasoning about instructional practices that appeared thematic among the case study teachers when they were considered collectively.

\section{Coder Agreement on Concepts That Were Thematic Among Teachers}

In the final iteration of CCA, my goal was to create a framework that described themes in the experiences of the four case study teachers with respect to their reasoning about specifying instructional practices. My goal was not to create an all-inclusive framework that might be used to explain any teachers' reasoning about specifying instructional practices. Instead, the nonevaluative framework created from the eighth and ninth iterations of CCA were used as a tool to address the second research question (i.e., How can different forms of reasoning that teachers employ be understood within the context of a theory of action, V4MIs, and the CCSSM?).

I believed it impractical to ask a second coder to re-enact the iterations of CCA that led me to a framework that described reasoning about instructional practices that appeared thematic among the case study teachers. Therefore, I created a method for checking agreement and inclusivity of concept names and definitions within the final framework of categories of reasoning. I asked a second researcher to review various episodes of transcript in order to identify units of analysis and code these units as fitting into one of the framework's concept categories.

I defined a unit of analysis as a teacher's reasoning for favoring, choosing, or enacting an ideal, planned, or enacted instructional practice. The instructional practice might be implied (e.g., 
teachers might discuss what happened "as a result of this portion of the lesson"), but the reasoning had to be explicit. More than one unit could contain the same instructional practice if the teacher provided more than one qualitatively different reason for that instructional practice.

Lombard, Snyder-Duch, and Bracken (2010) suggested that around 10\% of the total content analyzed should be sufficient to check for coder agreement. I chose to provide the second coder with three out of 24 pages of transcribed text, accounting for $12.5 \%$ of total content. I compiled transcribed excerpts from each interview of each teacher so that the sample would be representative of the entire data set. This resulted in a compilation of transcribed episodes of initial, pre-lesson, and post-lesson interviews from all four case study teachers. I ensured that episodes reflected complete thoughts; that is to say, I chose transcription that included a teacher beginning and ending discussion of a topic and did not provide incomplete thoughts or sentences. The second coder worked independently to identify units of analysis and categorize them according to the framework I provided. I independently did the same.

I adhered to Walther, Sochacka, and Kellam's (2003) specification of $80 \%$ agreement on $95 \%$ of codes a sufficient to "mitigate interpretive bias" (p. 650) and deem reliable coding. By calculating the percentage of agreement as number of units of agreement divided by number of total units, the second coder and I reached an initial percentage agreement of $84 \%$ on 19 units coded. The 19 identified units consisted of 16 identified by both coders, two additional units were identified by me, and one additional unit was identified by the second coder. On the 16 mutually identified units, we had $100 \%$ agreement. Thus, all disagreements were the result of extra or missing units to be coded. Upon discussing the disagreements, we decided that reasoning that is repetitive and in reference to the same instructional process should not be counted as multiple units of analysis. Upon redefining repetitive reasoning about the same instructional 
practice as a single unit of analysis, I read through all interview transcripts to eliminate any other units of analysis that were duplicated reasoning about a single instructional practice. This resulted in eliminating five units of analysis but did not alter the results of any iteration of CCA. By this I mean, the categories of reasoning that I had developed remained thematic by occurring more than once within the data being analyzed at each iteration of CCA.

Our conversation about agreement yielded a beneficial alteration to the name of a category of reasoning in the framework created at the ninth iteration of CCA. Specifically, one concept category that had been termed "external sources of authority" was renamed as "external sources of influence." This distinction was made to clarify teacher's choice to adhere to the source of influence instead of allowing the concept name to convey that the teacher had no choice.

\section{Considering Conceptual Categories Within the Contexts of a Theory of Action, V4MIs, and the CCSSM}

In order to assign meaning to the categories of teachers' reasoning about instructional practices, memos and conceptual categories of teachers' reasons for specifying instructional practices were reviewed at each iteration of CCA in order to reflect on questions suggested by Strauss \& Corbin (1998). The following questions helped me clarify the contexts surrounding the categories of reasoning about instructional practices:

- What is the category?

- When does the category occur?

- How does the category occur?

- With what consequences does the category occur? 
I considered these questions in order to understand what the conceptual categories meant within the context of the study. Specifically, to determine when the category occurred, I considered if the category emerged in the initial interview, pre-lesson interview, or post-lesson interview. To answer how the category occurred, I reflected on the language used in instances of the category and distinguished between teacher-centered and student-centered language (i.e., the teacher reasoned by discussing his or her actions and past experiences or by discussing students' actions and past experiences). To answer with what consequences the category occurred, I looked to statements the teacher made about whether instructional practices related to the category aligned or did not align with the teacher's V4MI. Indicators of alignment also occurred when a teacher described a practice as 'ideal' or 'part of their vision.'

In considering the four case study teachers collectively, I compared teachers' individualized answers to the questions suggested by Scott (2004) to consider when, how, and with what consequences the categories of reasoning occurred. Specifically, I looked for similarities in the stages of interviews that that the category occurred, the use of teacher-centered or studentcentered language, and the reflection on the alignment with V4MIs that resulted from instructional practices connected to the category if reasoning. If all teachers contributing to a category generated by the final iteration of CCA shared the same responses to the question, I included those results in the collective reporting of results in Chapter 4. For example, Gwen, Marta, and Simon evidenced reasoning about instructional practices that was categorized in the collective results framework as Building Conceptual Knowledge. All three of these teachers reasoned about building conceptual knowledge in their initial, pre-lesson, and post-lesson interviews. Therefore, when presenting results, I reported that Building Conceptual Knowledge occurred collectively in all three interview phases. In contrast, Gwen and Simon evidenced 
reasoning about instructional practices that was categorized in the collective results framework as Attention to Assessment. Gwen reasoned about her attention to assessment in the pre-lesson and post-lesson interviews, and Simon reasoned about his attention to assessment in the initial interview and post-lesson interview. Because the individual teachers' results for when the category occurred were not the same, I did not report thematic understandings about when the category of Attention to Assessment occurred in the collective results.

\section{Ethics and Trustworthiness}

In designing and carrying out this qualitative study, several of the methods that I chose ensured that data was collected, maintained, and analyzed in ways that were ethical and trustworthy. I enacted the following measures asserted by Bloomberg and Volpe (2019) and Merriam and Tisdell (2016) to maintain confidentiality: (a) I assigned each participant a pseudonym; (b) participants' identities were not revealed to anyone by me; (c) I obtained informed consent from participants prior to beginning the study; (d) data was maintained on a password-secured computer and paper documents in a secure file cabinet; and (e) data was never linked to information such as age or date of birth of the participants.

In order to ensure that the data was credible, I detailed biases that I brought into the study by being a teacher with my own V4MI and teaching experiences. Making note of and thoroughly considering these biases helped me to repetitively reflect on whether or not I was portraying the participants' points of view and not my own (Merriam \& Tisdell, 2016). I made an effort to triangulate the data concerning teachers' V4MIs by asking them to describe their V4MI in four contexts (i.e., in an initial interview, in a pre-lesson interview, in a post-lesson interview, and in a written reflection). 
In an effort to bolster the trustworthiness of my study, I also enacted several measures meant to ensure dependability and confirmability of my study. Research can be considered dependable if the process was clearly documented, logically set forth, and traceable (Merriam \& Tisdell, 2016). I have provided a detailed explanation of how data was analyzed and collected, and I took thorough and detailed field notes throughout the process to ensure that my explanation of the research process was true and complete (Bloomberg \& Volpe, 2019; Meriam \& Tisdell, 2016). These notes have been maintained and stored and are available for review by interested colleagues. Confirmability—demonstrating how conclusions were reached and ensuring conclusions were a result of data (Merriam \& Tisdell, 2016) — was sought by maintaining detailed memos of my thoughts, processes, and reasons for conclusions at every stage of data collection and analysis. I also sought a second coder to establish interrater reliability. The second coder helped me to consider if the categories of reasoning that I had created during iterative rounds of CCA were logical and thorough.

Finally, it was my goal to provide insight into the data in a way that might be transferable. According to Merriam and Tisdell (2016), transferability ensures that insights gained from data analysis can be generalized to other settings or people while maintaining the richness of the data specific to the study. I have outlined the process I carried out to purposefully sample teachers with varying V4MIs within the setting of a single high school mathematics department. It is my hope that readers can form opinions about my interpretation of the data and findings in this study and derive meaning and relevance from this study as it relates to other teachers in other settings. 


\section{Chapter III Summary}

For this chapter, I first described the methods I chose for conducting qualitative research. I also described the selection of four case study teachers from among 10 teachers in a secondary mathematics department at a school in the Midwestern region of the United States. Case study teachers participated in an initial interview as well as pre- and post-lesson interviews that encompassed the planning, enactment, and reflection surrounding a lesson chosen by the teachers. I then detailed the conceptual frameworks I used for analyzing data to gain an understanding of teachers' instructional practices and V4MIs. Following, I described the processes I employed to utilize the data and my descriptions of instructional practices and V4MIs to address the research questions. Specifically, I described the iterations of CCA that I performed as well as the questions I asked about the categories of reasoning that emerged from the process of CCA. In Chapter IV, I will detail the findings of my study. Finally, in Chapter V, I will then share conclusions, limitations of the study, and recommendations for future related research. 


\section{CHAPTER IV: FINDINGS}

I have chosen to first present findings for each case study teacher (i.e., Simon, Paul, Marta, and Gwen) separately. In doing so, I hope to paint a picture of each teacher's unique ways of reasoning about envisioning, planning, and enacting certain instructional practices aimed at achieving the goals of the CCSSM. I will begin each case teacher's results by providing a description of the teacher. This description should help the reader become familiar with each teacher by sharing background information (e.g., courses taught, years of teaching experience). I will also provide a concise description of the lesson each teacher chose to use for pre-lesson and post-lesson interviews. By providing a description of the chosen lesson, I hope to provide a more-concrete context with which the reader can associate the teacher's reasoning about instructional practices.

After providing context in the form of a teacher description and lesson description, I will move to addressing the first research question (i.e., After being asked to describe their V4MI, how do teachers reason about specifying instructional practices aimed at achieving the goals of the CCSSM?) I will provide a table that summarizes the conceptual categories for the focus teacher's reasoning about instructional practices. I will also provide tabular results addressing the second research question (i.e., How can different forms of reasoning that teachers employ be understood within the context of a theory of action, V4MIs, and the CCSSM?) To address this question, I will describe when, how, and with what consequences each category of reasoning occurred. Then, I will elaborate on the circumstances surrounding each category of reasoning and provide excerpts of interview transcript that evidence reasoning within each category. Additionally, I will describe the teacher's explicit mention of their V4MI or CCSSM for furthered understanding of the role of V4MIs and the CCSSM in teachers' reasoning about 
instructional practices. Specifically, I will describe instances that teachers' V4MIs were both aligned and misaligned with the instructional practices chosen or carried out and elaborate about details of the teachers' experiences that might provide insight into the relationships between V4MIs and instructional practices.

Following the results for each of the four case study teachers, I will present findings about the case study teachers as a group. Specifically, I will present categories of reasoning about instructional practices that appeared thematic for more than one teacher and discuss commonalities in when, how, and with what consequences each category of reasoning occurred and commonalities in categories of reasoning within the context of V4MIs and the CCSSM.

\section{Simon}

At the time of this study, Simon had been teaching for 40 years. He had moved within the district during that time to teach at multiple high schools and had expressed great satisfaction in being able to gain a teaching position at the high school that was the site for this study. In his initial interview, he commented on the culture of the school and the support he felt from the administration. Comments made during his initial interview reflected this sentiment:

I'll tell you what the thing is about [school name]. We got a principal that supports us, that respects us. And I think you have to have that or you're not going to walk into that classroom everyday doing your best, but it's expected. I mean he calls me Dr. Schultz. Well, I'm not a doctor ..., but that's the respect that I get from him that he values me very much, and you've got to know that your administration is behind you. . We have a top-notch crew here that is respected and appreciated, and that's the difference. And that's why, as you know, I've been banging to get in this door for a while before I got here. 
At the time of this study, Simon was teaching both Geometry and Math Investigations (a course that allows seniors to explore the mathematics content of their previous classes such as Algebra and Geometry). When asked to choose a lesson for me to observe and for the purpose of prelesson and post-lesson interviews, Simon chose a Geometry lesson in which he addressed arc length and area of circle sectors.

\section{Synopsis of Simon's Lesson}

Simon began his lesson by asking students to complete an individual task in which they considered the amount of liquid that would be held by a vase described as a rectangular prism when poured from a cylindrical jug. Both the cylindrical jug and rectangular prismatic vase were given as figures on a worksheet, and all dimensions needed to calculate volume for both figures were labeled. The situation considered in this individual task is depicted in Figure 4.
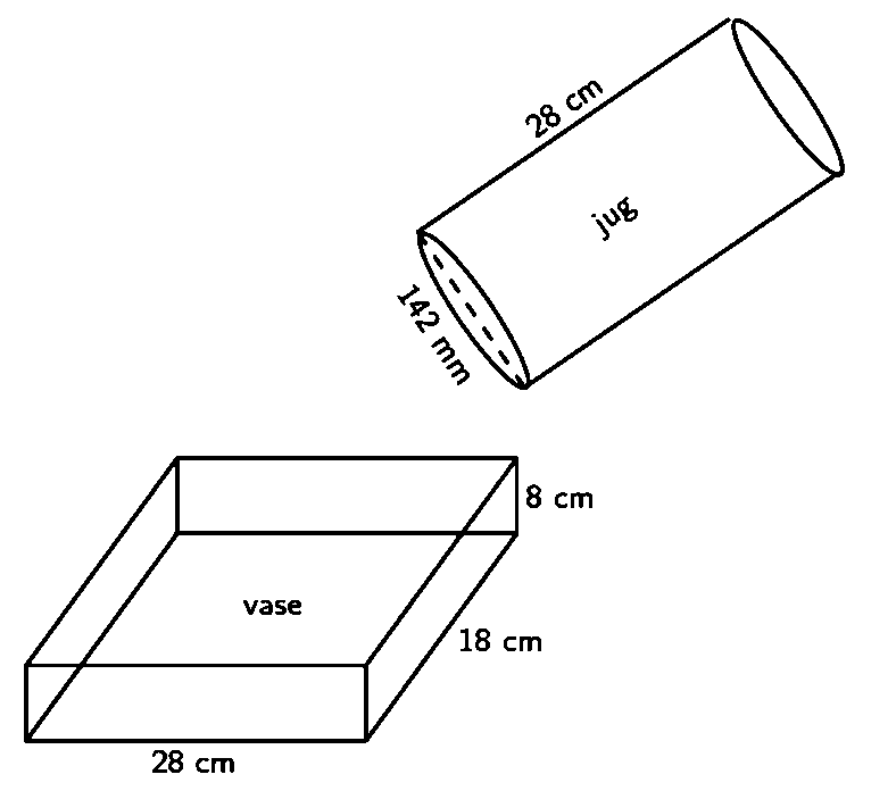

Figure 4. Individual task provided to students during Simon's chosen lesson.

After the volume task at the beginning of class, the remainder of the lesson was focused on finding arc length and areas of sectors of circles. In the lesson, Simon described the relationship between radius, arc, and central angle measures several times and presented an 
explanation for both arc length and sector area formulas. He stated in the pre-lesson interview that students had previously explored the relationship between arc length and central angle. Students worked independently to use the correct formulas in order to find arc length or sector area given figures of circles. Students utilized examples projected on the front board and wholegroup guidance from Simon throughout their independent work time. Figures were labeled with central angles measured in degrees and radii measured in various standard units (e.g., centimeters, inches, feet, meters). Directions on the student worksheet stated, "Round to the nearest tenth.”

In order to report the CCSSM that Simon intended to target with his lesson, I followed up with Simon after the post-lesson interview via email. Following are content standards and SMP identified by Simon as being addressed in whole or in part by his chosen lesson.

- CCSS.MATH.CONTENT.HSG.C.B.5. "Derive using similarity the fact that the length of the arc intercepted by an angle is proportional to the radius, and define the radian measure of the angle as the constant of proportionality; derive the formula for the area of a sector" (NGA \& CCSSO, 2010e).

- CCSS.MATH.PRACTICE.MP5. "Look for and express regularity in repeated reasoning" (NGA \& CCSSO, 2010f).

\section{Categories of Simon's Reasoning About Instructional Practices and Contexts Surrounding Those Categories}

As evidenced in Simon's interviews, he reasoned about ideal, planned, and enacted instructional practices in ways that I was able to conceptualize in six categories. In order to be included in Simon's conceptual framework for how he specified instructional practices, the concept appeared within more than one of Simon's interviews, and he connected the concept to 
specifying instructional practices more than once within each of those interviews. Table 6 provides each concept's name and a description of reasoning in that category. Following Tables 6 and 7, I have gone into detail about the ways that Simon reasoned about instructional practices and associated these practices with his V4MI. I have provided examples of each category of reasoning as evidenced by interview transcript. Because some concepts were coded as many as 10 times, examples within each category are not exhaustive. Instead, I chose examples that were poignant in their concise connection of instructional practice and reasoning. That is to say, Simon presented his discussion of an instructional practice and his reasoning for favoring, planning, or enacting that practice in a concise and easy-to-follow transcript excerpt.

Table 6

Simon's Reasoning for Specifying Instructional Practices

\begin{tabular}{|c|c|}
\hline Category of Reasoning & Examples of Reasoning \\
\hline Personal Experiences & $\begin{array}{l}\text { - witnessed other teachers passing their own beliefs } \\
\text { about mathematics to students } \\
\text { - lacked professional development for using } \\
\text { calculators } \\
\text { - wanted to know final answer to check work when he } \\
\text { was in higher-level mathematics courses } \\
\text { - has found sarcasm as an effective way to guide } \\
\text { student behavior }\end{array}$ \\
\hline External Sources of Influence & $\begin{array}{ll}\text { - } & \text { building administration } \\
\text { - } & \text { district-level administration } \\
\text { - } & \text { parents } \\
\text { - } & \text { access to calculators } \\
\text { - } & \text { scheduled length of classes }\end{array}$ \\
\hline Students' Individualized Needs & $\begin{array}{ll}\text { - } & \text { remaining on-task } \\
\text { - } & \text { persevering } \\
\text { - } & \text { early, embedded perceptions of mathematics } \\
\text { - frustrations with doing mathematics }\end{array}$ \\
\hline
\end{tabular}

(Table Continues) 
Table 6 cont.'d

Simon's Reasoning for Specifying Instructional Practices

\begin{tabular}{|c|c|}
\hline Category of Reasoning & Examples of Reasoning \\
\hline Establishing Classroom Culture & $\begin{array}{l}\text { - active mathematical dialogue between student and } \\
\text { teacher and between student and student } \\
\text { - environment in which students know teacher cares } \\
\text { - students and teacher are a team }\end{array}$ \\
\hline Goals for Learning of Mathematics & $\begin{array}{l}\text { - remediation of prior knowledge } \\
\text { - deeper conceptual understanding } \\
\text { - learning to find and correct mistakes within their } \\
\text { mathematical work } \\
\text { - deciphering classmates' written work }\end{array}$ \\
\hline Assessment & $\begin{array}{l}\text { - hoped to teach students to decode the wording of } \\
\text { standardized assessment questions } \\
\text { - } \text { students' poor skill execution on past classroom } \\
\text { tests } \\
\text { - aimed to improve test scores }\end{array}$ \\
\hline
\end{tabular}

To address the first research question, I will provide a description of the categories of Simon's reasoning about specifying instructional practices. To address the second research question - understanding different forms of reasoning within the context of a theory of action, a V4MI, and the CCSSM-I will explore when, how, and with what consequences each category of reasoning emerged. As a reminder, I chose the following questions suggested by Scott (2004) to understand the meaning of the categories conceptualized using CCA:

- What is the category?

- When does the category occur?

- How does the category occur?

- With what consequences does the category occur? 
I reported when and how each category occurred and also the consequences of that category occurring. That is, the results reflect the interviews in which the category emerged, the consistencies in the language used by the teacher when discussing that category, and the teacher's account of that category leading to instructional practices that aligned or did not align with ideal instructional practices described in the teacher's V4MI.

As an example of how I used Scott's (2004) questions, I will describe answers to the questions of when, how, and with what consequences Simon reasoned about Establishing Classroom Culture. Simon reasoned about instructional practices in ways that fell into the category of Establishing Classroom Culture during the initial interview and post-lesson interview. He did not discuss establishing classroom culture as a reason for instructional practices while discussing his lesson plans in the pre-lesson interview. Simon's statements about establishing classroom culture contained language referring to his own actions and thoughts such as "I always tell the kids ..." and "I tend to ..." In the instances that Simon reasoned about instructional practices by discussing Establishing Classroom Culture, he reflected that the instructional practices aligned with his V4MI.

Table 7 delineates answers to the questions chosen to place meaning on the categories conceptualized using CCA. 
Table 7

Understanding Simon's Categories of Reasoning about Instructional Practices

\begin{tabular}{|c|c|c|c|c|c|}
\hline \multirow[t]{2}{*}{$\begin{array}{l}\text { Category of } \\
\text { Reasoning }\end{array}$} & \multicolumn{3}{|c|}{$\begin{array}{l}\text { When Category Occurred } \\
\text { (Type of Interview and } \\
\text { Number of Times) }\end{array}$} & \multirow[t]{2}{*}{$\begin{array}{l}\text { How Category Occurred } \\
\text { (Focus of Language } \\
\text { Used) }\end{array}$} & \multirow{2}{*}{$\begin{array}{l}\text { Consequences of Category } \\
\text { Occurring (Did Resulting } \\
\text { Instructional Practices } \\
\text { Align with V4MI?) }\end{array}$} \\
\hline & initial & $\begin{array}{l}\text { pre- } \\
\text { lesson }\end{array}$ & $\begin{array}{l}\text { post- } \\
\text { lesson }\end{array}$ & & \\
\hline $\begin{array}{l}\text { Personal } \\
\text { Experiences }\end{array}$ & 6 & & 4 & $\begin{array}{l}\text { teacher actions and } \\
\text { teacher's past } \\
\text { experiences or behaviors }\end{array}$ & $\begin{array}{l}\text { sometimes aligned with } \\
\text { and sometimes did not } \\
\text { align with V4MI }\end{array}$ \\
\hline $\begin{array}{l}\text { External } \\
\text { Sources of } \\
\text { Influence }\end{array}$ & 5 & & 4 & $\begin{array}{l}\text { teacher actions and } \\
\text { teacher's past behaviors } \\
\text { and experiences }\end{array}$ & $\begin{array}{l}\text { sometimes aligned with } \\
\text { and sometimes did not } \\
\text { align with V4MI }\end{array}$ \\
\hline $\begin{array}{l}\text { Students' } \\
\text { Individualized } \\
\text { Needs }\end{array}$ & 2 & 2 & 4 & $\begin{array}{l}\text { student actions and } \\
\text { students' past behaviors } \\
\text { and experiences }\end{array}$ & $\begin{array}{l}\text { sometimes aligned with } \\
\text { and sometimes did not } \\
\text { align with V4MI }\end{array}$ \\
\hline $\begin{array}{l}\text { Establishing } \\
\text { Classroom } \\
\text { Culture }\end{array}$ & 2 & & 3 & $\begin{array}{l}\text { teacher actions and } \\
\text { teacher's past behaviors } \\
\text { and experiences }\end{array}$ & aligned with V4MI \\
\hline $\begin{array}{l}\text { Goals for } \\
\text { Learning of } \\
\text { Mathematics }\end{array}$ & 2 & 2 & 6 & $\begin{array}{l}\text { student actions and } \\
\text { students' past behaviors } \\
\text { and experiences }\end{array}$ & $\begin{array}{l}\text { sometimes aligned with } \\
\text { and sometimes did not } \\
\text { align with V4MI }\end{array}$ \\
\hline Assessment & 3 & & 2 & $\begin{array}{l}\text { student actions and } \\
\text { students' past behaviors } \\
\text { and experiences }\end{array}$ & aligned with V4MI \\
\hline
\end{tabular}

Personal Experiences. Simon utilized his personal experiences from the past as reasoning for certain instructional practices six times during his initial interview and four times during his post-lesson interview. Simon discussed personal experiences of witnessing other teachers passing their own beliefs about mathematics to students, recognizing his own lack of professional development for using calculators, wanting to know the final answer to check work 
when he was in higher-level mathematics courses, and finding sarcasm an effective tool for guiding student behavior. Instructional practices that Simon tied to past experiences included enlisting mathematics-specific teachers in grades prior to high school, learning how to use the calculators alongside students, providing answer keys for assigned student work, and using sarcasm to redirect students or guide student behavior. When discussing personal experiences, Simon's language focused on his own actions, past behaviors, and experiences. He reflected that some instructional practices tied to personal experiences aligned with his V4MI and some did not. Following are examples of such reasoning that provide an illustration of the how Simon reasoned about instructional practices by discussing personal experiences.

During his initial interview, Simon commented on this vision for content-specific mathematics teachers in grades prior to high school. He stated, "You've got to have a math teacher that goes around just like an art teacher and goes class to class. Spends an hour in sixth grade, an hour in seventh grade. Because too many of these, and I love them, but I see that too many of these elementary teachers hate math, and they teach kids that that's the ugly one." This example illustrates Simon's use of personal experiences with elementary teachers in specifying his vision for the ideal practice of content-specific mathematics teachers in lower grades. In this statement, Simon reflected on his personal observations of teachers. As he views it, the current practice of teachers instructing multiple content areas does not align with his V4MI, but his suggested instructional practice of mathematics-specific content teachers in lower grades would align with his V4MI.

Simon also reasoned about his own practice using personal experiences. During his postlesson interview, Simon reflected on his practice of projecting final solutions on the board while students worked to find solutions on their worksheets. He reasoned that, "If they have the 
answers they have to get to, they're not getting those [wrong] answers. They're asking why. . . Any of us that have taken higher-level math know that we wanted to know what the final answer was." In saying this, Simon supported his use of an answer key with his personal experience of wanting to know the final solutions as a student in higher-level mathematics courses.

Additionally, Simon reflected on his use of sarcasm as an instructional practice aimed to redirect off-task students. He discussed his success with using sarcasm in the past and reflected that students seemed to enjoy his less-straightforward approach. One of several comments on the use of sarcasm is as follows: "I tend to use sarcasm with them, and they like it. They understood what I said.” As with other examples of Simon's reasoning about personal experiences, he focused on his own behavior and method for addressing students. By stating that students like his use of sarcasm, I coded this reasoning and subsequent practice of using sarcasm as aligning with Simon's V4MI.

Discussion of personal experiences peppered Simon's initial and post-lesson interviews and was used to reason about ideal and enacted practices. When discussing personal experiences, Simon connected these experiences to instructional practices that he found favorable. That is to say, he did not reason about instructional practices connected to personal experiences as practices that he wished he had enacted differently.

External Sources of Influence. Simon commented on external sources of influence when discussing instructional practices that he felt he needed to enact. He reasoned about external sources of influence five times during his initial interview and four times during his post-lesson interview. External sources of influence voiced by Simon included administration at the building and district levels, parents, and availability of resources such as calculators and time. Instructional practices that Simon tied to external sources of influence included such things 
as putting in optimal effort as a teacher, adhering to a specific grading policy, following guidelines of Individual Education Plans, revisiting the lesson target with students during the lesson, including a fully-completed example problem on student worksheets, demonstrating calculator actions in a whole-class setting, and adjusting lessons to fit within allotted class times. When discussing external sources of influence, Simon's language focused on his own actions, past behaviors, and experiences. He reflected that some instructional practices tied to external sources of influence aligned with his V4MI and some did not. In illustrating Simon's reasoning surrounding these three instructional practices, I hope to highlight that instructional practices enacted because of external sources of influence were sometimes aligned and sometimes misaligned with Simon's V4MI.

During Simon's initial interview, he discussed the school district's grading policy. Per this policy, the districts grading scale narrowed the " $F$ " grade band to a percentage between 40 and 59. Students who did not complete assignments received a $40 \%$ grade mark for the missing assignment. An attempt to complete any assignment—regardless of accuracy—received at least a $50 \%$. Additionally, the district grading policy had mandated that summative assessment comprise $65 \%$ of the students' overall course grade. In regard to following this policy, Simon stated, "Is it the standard of excellence when we were giving them $40 \%$ for nothing and $50 \%$ for a name? ... It's the district level. But I think that some of our students aren't test takers. And so, $65 \%$ of their grade is on a test that they can't pass to save their soul. I mean, so we're setting them up and then we're giving them $50 \%$ for nothing, so I guess that comes back to every day those kids got to know you're working with them." I interpreted Simon's statement to mean that he did not agree with the district grading policy; however, he chose to follow the grading guidelines set forth by the district. The misalignment of the district grading policy with Simon's 
V4MI suggested an instructional practice that was out of Simon's personal control. In other words, Simon did not feel that he was able to alter his grading scale or policy to align with his V4MI because of the district policy, which he perceived as an external source of influence and thus outside of his locus of control.

Though Simon's description of the district grading policy reflected a misalignment between instructional practice and his V4MI, not all comments about external sources of influence reflected that resulting instructional practices were at odds with Simon's V4MI. For example, during Simon's post-lesson interview, he discussed his practice of revisiting the target of the lesson at different points throughout the lesson. By this, I mean Simon would remind students that the goal of the lesson was to understand how to find arc length and area of a sector of a circle and that, conceptually, both of these calculations were an act of finding a portion of the circumference or a portion of the circle's area. When viewing himself revisiting the target on his videoed lesson, Simon stated, “And that's an effort to do what [building administration] requested we do. To revisit the target." When questioned about the practice of revisiting the lesson target, Simon stated that revisiting the day's target was an effort to "make sure the kids understand the vocabulary we've used, and they're having deep math talk." I took this statement to mean that Simon saw value in the building administration's suggested practice of revisiting the lesson target.

In another instance during the post-lesson interview, Simon reflected on his practice of providing a fully-completed example of finding the area of the sector of a circle on the student worksheet. In providing his reasoning for doing so, Simon stated, "That's what I try to do is to give them [an example problem]. Because I had a parent that said, look there's no examples. So, I always try to make sure at least one is done there in its entirety on the worksheet." When I 
asked him how that practice aligned with his V4MI, Simon stated, "I'm doing that in response to the parent, but I still don't think it's bad practice. They have something there that they can look back at." In this instance, Simon seemed to recognize that an external source of influence may alter his teaching practices, but that alteration can still align with his personal views about good teaching practice. Simon did not make it clear why he was not providing an example problem prior to the parent suggestion. It is possible that Simon had not yet considered this instructional practice. It is also possible that he viewed such as instructional practice as consuming time that he might spend carrying out other duties of a teacher (e.g., grading, preparing lessons)

Students' Individualized Needs. Simon reasoned about several instructional practices by conveying that he was acting to meet the needs of individual students. He reasoned about individualized student needs twice in his initial interview, twice in his pre-lesson interview, and four times in his post-lesson interview. The needs of individual students that Simon discussed included remaining on task, persevering, overcoming early embedded perceptions of mathematics, and alleviating frustration with doing mathematics. To address these needs, Simon connected his reasoning to the following instructional practices: questioning with the purpose of engaging students, waiting until students were on task, arranging desks in rows, forming positive teacher/student relationships, providing individual student practice opportunities, providing time for students to complete homework in class, and teaching students to ask themselves what they did wrong when coming to an incorrect solution. When reasoning about students' individual needs, Simon used language that focused on student actions, past experiences, and behaviors. He reflected that some instructional practices tied to students' individualized needs aligned with his V4MI and some did not. 
One such individualized need helping students that got frustrated with doing mathematics. Simon said, "They were to finish this paper today in class. Because they take it home and do it wrong. . . and then they get all mixed up and get frustrated." He reasoned that it was "ideal" for students to be able to turn the paper in by the end of class.

At several points in Simon's initial and post-lesson interview, he discussed the need to keep some students on task through his own actions. He talked about students struggling with engagement due to cell phone use, talking, and other distractions. In the following excerpt from his post-lesson interview, Simon reflected on his decision to place desks in rows so that students could remain on-task. In the excerpt, I refer to myself as the interviewer.

Simon: I know why people arrange classrooms this way. Because it helps with keeping the volume down, discipline down.

Interviewer: Arrange classrooms in rows?

Simon: By putting them in cemetery rows. And basically, that's why I've tried lots of seating arrangements and toward this time of the year, they will sit and talk across the pod or whatever and not even pay attention. So, I'm back in cemetery rows. I don't like them. I'd much rather see students like they were just doing-where they were interacting with each other and looking at how, whether they agreed.

Interviewer: So, in your vision, would it be fair to say that you would like to see that same interaction, but you would like to facilitate it by having them in groups?

Simon: Exactly. And see more of the student-led discussion instead of predominantly teacher-led, but we all know that sometimes you got to do what you got to do. In this instance, Simon's practice of putting desks in rows does not align with his V4MI, but he has reasoned about this practice as necessary to eliminate the distractions of off-task talking or 
disciplinary issues. During Simon's post-lesson interview, he viewed two students on video that were talking during the lesson and apologized to me for their behavior. In my field notes, I had recorded that the students were asking each other about the sector area problem that was projected in the front of the room. This apology from Simon led me to consider Simon's level of comfort with student discussion. It is possible that Simon is wary to engage students in the type of mathematics discussion he described as part of his V4MI for fear of lacking the ability to guide students' conversations as he can in a whole group setting. It is also possible that Simon assumes that students are not capable of staying on task while discussing mathematics in small groups. In the exchange above, Simon's default interpretation was that when students were talking to one another they must be off task.

Simon spoke about his wish to embed the practice of perseverance in his students. In his post-lesson interview, Simon stopped the video of himself teaching when he had mentioned perseverance in class. He then told me, "I pushed that big last week-the perseverance. I talk to them quite a bit about what that math practice means." After describing some students' inabilities to identify where they went wrong when completing a mathematics problem, he described a hope that he could help students to "get in there and figuring out what you did wrong."

Establishing Classroom Culture. Twice during his initial interview and three times during his post-interview, Simon reasoned about instructional practices by discussing the type of classroom culture that he hoped to build. Simon expressed his desire for a classroom culture in which the students and teacher work as a team as opposed to the students viewing the teacher as a superior other who dictates what the students should do. Simon also described a culture such that all students contribute to the classroom conversation and feel comfortable to answer his 
questions directed at the whole class. Instructional practices that were tied to reasoning about classroom culture included questioning students during whole-group instruction, allowing students to sit by his desk, letting students know that he cared, and choosing specific seating arrangements. When reasoning about establishing classroom culture, Simon used language that focused on teacher actions, past experiences, and behaviors. He reflected that some instructional practices tied to establishing classroom culture aligned with his V4MI.

The following excerpt from Simon's initial interview illustrated such reasoning about what Simon would look for when viewing another classroom for ideal mathematics instruction:

Interviewer: Is there anything else you would look for?

Simon: "That the teacher is working with the students and not against them. I always tell the kids, "I'm here to work with you. I'm not the opposing team here." I think that's one of the biggest things that makes me successful. I think that a lot of times that's what we see in classrooms is that opposition. I know it. You don't. And so, I'm powerful and you're weak. And that doesn't work.

At the conclusion of Simon's post-lesson interview, I asked him if there was anything that he did not already reflect on that he would like to voice. He stated, "As we talked about in the ideal classroom, they have much stronger feedback from all students to questions that are posed. Because they tend to just wait for me to answer them. Ideally, I would be getting feedback when I'm asking those questions.” I took Simon's statement to mean that he enacts the instructional practice of asking questions to the whole class because he would like to establish a culture that fosters feedback from all students. As a note, the term feedback often reminds mathematics educators of assessment; I did not include this line of reasoning in the assessment category, as Simon used the term feedback to mean student response to his questions and did not 
relate his hope for student feedback to the idea of assessing student understanding. He only expressed a wish for students to respond to his questions.

Goals for Learning of Mathematics. When reasoning about specifying instructional practices, Simon discussed his goals for students' learning of mathematics two times in his initial interview, two times in his pre-lesson interview, and six times in his post-lesson interview. $\mathrm{He}$ stated that some of his goals were helping students remediate mathematical knowledge they had not yet mastered and improving students' conceptual understanding of mathematics topics. In addition, he voiced that he wanted to help students learn how to find and correct mistakes within their own mathematical work and decipher others' mathematical work. Instructional practices that Simon connected with reasoning about goals for learning of mathematics included the following: choosing specific topics to address with his classes (e.g., area, volume, surface area, perimeter), using mathematics-specific vocabulary in lecture and discussion, emphasizing in lecture conceptual ideas (e.g., formulae for rectangular prism volumes are area of the base of the object multiplied by height, there is a connection between the measurements of area and volume and the labels on units such as $\mathrm{cm}^{2}$ or $\mathrm{cm}^{3}$ ), providing a reference sheet of formulae and encouraging students to use it as a tool, encouraging students to examine their own work when students ask for help finding mistakes, and providing example problems completed in different ways. When reasoning about goals for students' learning of mathematics, Simon used language that focused on student actions, past experiences, and behaviors. He reflected that some instructional practices tied to goals for learning of mathematics aligned with his V4MI and some did not.

During his initial interview, Simon discussed his decisions to address perimeter, area, surface area, and volume with his eleventh-grade students: "According to Common Core 
Standards, it is mastered in the $7^{\text {th }}$ or $8^{\text {th }}$ grade - perimeter, area, surface area, volume. And I am finding to my students, largely those words are all the same. They don't have a clear understanding of the difference. So ... I can't send them away from here without that basic knowledge." Simon's goal for students was to have a clear understanding of these forms of measurement, and thus he chose this content to teach to his students. I took this portion of our interview to mean that students' prior knowledge and understanding of the content did not align with what he hoped students could know and do in his classroom. In all of Simon's interviews, he discussed his goal of remediating content that students had not mastered in previous grades and related this goal to his choices for content and lessons.

Simon also voiced his goals for learning of mathematics when discussing his planned lesson during the pre-lesson interview. In the following excerpt from that interview, Simon described the lesson as a presentation and individualized practice.

Simon: We will be following up on area, volume, etcetera with finding the arc lengths and area of a sector in circles.

Interviewer: What do you hope students will be able to do as the result of the lesson?

Simon: To see that arc length is nothing more than a fractional part of the circumference and that area sector is a fractional part of the total area.

Interviewer: Do you have any idea of the activities that you'll do during that lesson?

Simon: PowerPoint presentation and individualized practice.

I took this excerpt to mean that Simon felt his plans for the lesson should result in a conceptual understanding of arc length and sector area, as Simon voiced that he hoped students would understand the relationship between the fractional parts of a circle and the measures of arc length and circle sector area. 
Simon's goals for learning of mathematics also served as reasons for enacted instructional practices that he reflected on in his post-lesson interview. As an example of this, Simon paused the video of his lesson when a student referred to a formula sheet during the lesson's opening activity. In this activity, students had to find the volume of a cylinder. Simon stated, "And see, with that, that's the same thing I tried to do with looking at the reference [sheet]. It's all about that base. Because every one of your formulas for volume, I emphasize it's about that base. And then many of them saw that they're really not a bunch of different formulas. It's one formula." I took this to mean that Simon has emphasized to students the similarities in the formulas he provided on the formula sheet because he hopes students can gain a deeper understanding of the general formula for volume of a prism or cylinder.

Assessment. Assessment served as reasoning for instructional practices three times in Simon's initial interview and two times in his post-lesson interview. Simon reasoned that he hoped to teach students to decode the wording of standardized assessment questions and hoped to improve test scores in his classes. Instructional practices that he tied to this reasoning included asking students to use mathematics vocabulary in classroom discussion and working with students one-on-one to verbally assess them on make-up tests. He also voiced that students' poor skill execution on prior classroom exams served as a reason for doing such things as asking students to manipulate their own calculators instead of watching Simon and rereading exam directions. When reasoning about assessment, Simon used language that focused on student actions, past experiences, and behaviors. He reflected that instructional practices he tied to assessment aligned with his V4MI.

As an example, Simon stated that in an ideal classroom, the teacher would make correct and frequent use of mathematics vocabulary. To support the need for this instructional practice, 
he said, "Anytime you read a question, whether it be SAT or whatever, you're going to say, 'I don't know how to do that.' And yes, you do, but it may be worded differently. So, you've got to use the vocabulary." Simon also referred to assessment as reasoning for making sure students physically go through the motions of calculating solutions on their own calculator as opposed to only listening to Simon's calculator instructions or watching Simon press the buttons. He referred to students' inability to perform calculations on tests: "That's one of the things I noticed as I started going through their tests. I would go through the problems with them, but they were not manipulating on the calculator. And when it came time for the test, they were like, 'How do I put this into the calculator?' The same way we have done it all along." I took Simon's statement to mean that his instructional practice of encouraging students to use the calculators themselves was because he had noticed their inability to do so on tests.

\section{Explicit Mention of V4MI and CCSSM}

In order to further explore the contexts of each of Simon's categories of reasoning, I looked for explicit mention of vision and standards. This information helped me to understand Simon's categories of reasoning within the context of Cobb and Jackson's (2011) model for specifying instructional practices aimed at achieving learning goals. As a reminder, Cobb and Jackson (2011) asserted that organizations can be successful at implementing mathematics reform if they make explicit a detailed vision of high-quality mathematics instruction that specifies concrete instructional practices that have the potential to lead to the attainment of learning goals. This model can be seen in Figure 5. 


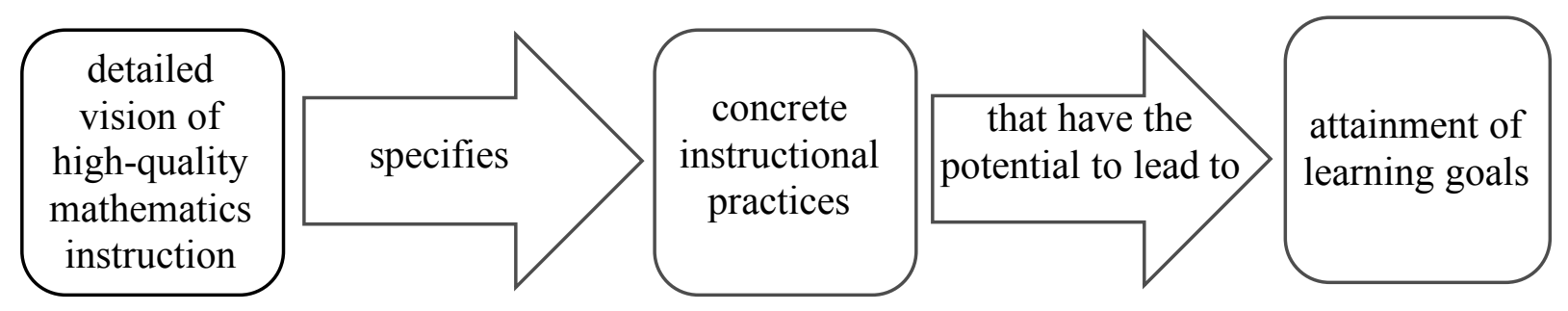

Figure 5. Cobb and Jackson's (2011) vision component of the Theory of Action.

When planning and executing his chosen lesson, Simon did not reason explicitly about his V4MI, meaning he did not make explicit that he chose or carried out instructional practices because they were "part of his vision" or "ideal." Simon reasoned about learning standards once during his initial interview in saying the following:

Right now, I'm working with kids, and according to the Common Core Standards, it is mastered in the $7^{\text {th }}$ and $8^{\text {th }}$ grade perimeter, area, surface area, volume. And I am finding to my students, largely those words are all the same. They don't have a clear understanding of the difference between. And it's because it went to quick, and they weren't really ready at that point. So, I've, in math investigations and geometry both, even though they're not supposed to be part of the curriculum, I can't send them away from here without that basic knowledge.

Outside of this statement, Simon did not reason about specifying instructional practices by discussing the CCSSM. As I discussed in the description of Simon's chosen lesson, in order to report the CCSSM that Simon intended to target with his lesson, I followed up with Simon after the post-lesson interview via email. 


\section{Paul}

During his initial interview, Paul indicated that he had been teaching for 3 years; 2 years of Paul's teaching had occurred at the study site, and 1-year prior had occurred at a middle school. Similar to Simon's sentiments, Paul expressed satisfaction in his current teaching position. Paul described a culture supported by the school's principal that allowed him to have authority in his classroom to take risks and try new instructional practices. The following excerpt from his initial interview reflects Paul's feelings:

[The principal] is great, you know, is awesome. As long as you're doing what you're supposed to be, you can kind of have control over it. . . Try new things. Failure is a good thing as long as you keep trying to make it better.

At the time of this study, Paul was teaching Algebra and Trigonometry classes. When asked to choose a lesson for me to observe and for the purpose of pre-lesson and post-lesson interviews, Paul chose an Algebra lesson that was a review of solving quadratic equations by graphing a quadratic equation in order to locate the roots, factoring to solve, making use of the quadratic formula, and isolating the unknown quantity to solve by finding the square root of both sides of the equation. This lesson was meant to serve as a review for the students' Algebra end-ofsemester final exam.

\section{Synopsis of Paul's Lesson}

Paul's began his lesson with a whole-group review of three methods students may use to solve a quadratic equation. First, he displayed the equation $y=x^{2}-10 x+21$ and asked students to work independently to factor the polynomial quantity and solve for $x$ in each of the two factors. Paul asked a student to come to the board and write her solution for viewing by the class. Following this, Paul reiterated the steps that the student had taken to achieve her solution. 
Then, Paul demonstrated in writing and verbally how to solve the same equation next by using the quadratic formula and finally by graphing the parabola represented by the equation in order to identify roots. Periodically during this review, Paul would pause and ask the class for input about next steps or intermediate findings (e.g., Where would I locate $a, b$, and $c$ ? How do I find the vertex?). Paul would pause for responses from students before moving on in his explanation of solving the quadratic equation.

Following the whole-class review, students worked in groups of four or five to collaborate in order to find the possible values of the unknown quantity in each of nine quadratic equations. Directions on the collaborative task instructed students to "Use each method at least twice." Paul stated that it was important each student "know each method." Though Paul did not discuss the need for students to determine a best or most-appropriate method for solving each quadratic equation, equations listed on the collaborative task could not be easily solved using all methods; therefore, the task required students to choose a method that might be best or mostappropriate. For example, $2 x^{2}+12=62$ provides opportunities to solve in a variety of ways (e.g., isolating the variable and taking the square root, manipulating to be a difference of two squares). Paul did not discuss isolating the unknown value on one side of the equal sign and taking the square root of both sides to solve during the whole class review. He indicated that he hoped for students to take pause and consider this alternative method. He stated in his postlesson interview that he hoped "one person from each group [would] take charge and take control of that one and figuring that out. Then hopefully tomorrow, they'll help everybody out."

During Paul's chosen lesson, he paused at two points to take a "brain break." During these times, students played a game of knockout using paper balls and the trash can and also reviewed end-of-semester academic goals that they had set for themselves in a prior class period. 
When discussing ideal instruction and when discussion planning and executing his chosen lesson, Paul did not explicitly mention learning standards or the CCSSM. In order to report the CCSSM that Paul intended to target with his lesson, I followed up with Paul after the post-lesson interview via email. Following are content standards and SMP identified by Paul as being addressed in whole or in part by his chosen lesson.

- CCSS.MATH.CONTENT.HSA.APR.B.3. "Identify zeros of polynomials when suitable factorizations are available, and use the zeros to construct a rough graph of the function defined by the polynomial" (NGA \& CCSSO, 2010d).

- CCSS.MATH.CONTENT.HSA.REI.B.4. "Solve quadratic equations in one variable" (NGA \& CCSSO, 2010d).

- CCSS.MATH.PRACTICE.MP5. "Use appropriate tools strategically" (NGA \& CCSSO, 2010f). In identifying this SMP, Paul wrote the following: "Students were taught multiple ways to solve quadratics. Some methods are much easier than others given a certain type of quadratic. Students 'hopefully' used the best/most efficient method of solving given their quadratic."

\section{Categories of Paul's Reasoning About Instructional Practices and Contexts Surrounding}

\section{Those Categories}

As evidenced in Paul's strand of interviews, he reasoned about ideal, planned, and enacted instructional practices in ways that I was able to conceptualize in three categories. In order to be included in Paul's conceptual framework for how he specified instructional practices, the concept appeared within more than one of Paul's interviews, and he connected the concept to specifying instructional practices more than once within each of those interviews. Table 8 provides each concept's name and a description of reasoning that fell under that concept 
category. Following Tables 8 and 9, I will go into more detail concerning the ways that Paul reasoned about instructional practices and associated these practices with his V4MI. I will provide examples of each category of reasoning as evidenced by interview transcript. These examples were chosen as straightforward presentations of the connection between instructional practice and reasoning. Specifically, Paul's description of his reasoning for a certain instructional practice in these examples was explicit without straying to another topic before returning to draw a connection between reasoning and practice.

Table 8

Paul's Reasoning for Specifying Instructional Practices

\begin{tabular}{|c|c|}
\hline Concept Name & Examples of Reasoning \\
\hline Cultivating Learner Qualities & $\begin{array}{l}\text { - } \quad \text { wanted to foster confidence } \\
\text { - } \quad \text { wanted to promote independence from teacher } \\
\text { - wanted students to grow as learners and members } \\
\text { of society in non-mathematical contexts }\end{array}$ \\
\hline External Sources of Influence & $\begin{array}{l}\text { - } \text { recognized time constraints of class period } \\
\text { - } \text { noted district grading policy } \\
\text { - highlighted principal's push to try new things and } \\
\text { allow teacher agency }\end{array}$ \\
\hline Establishing Classroom Culture & $\begin{array}{l}\text { - hoped to create a culture of respect } \\
\text { - wanted students to collaborate } \\
\text { - stressed the importance of building a classroom } \\
\text { community with more in common than just } \\
\text { mathematics }\end{array}$ \\
\hline
\end{tabular}

To address the first research question, I will provide a description of the categories of Paul's reasoning about specifying instructional practices. To address the second research question - understanding different forms of reasoning within the context of a theory of action, a V4MI, and the CCSSM-I will explore when, how, and with what consequences each category emerged. Results reflect the interviews in which the category emerged, the consistencies in the 
language used by the teacher when discussing the category, and the teacher's account of that category leading to instructional practices that aligned or did not align with ideal instructional practices described in the teacher's V4MI. Table 9 below delineates answers to the questions chosen to place meaning on the categories conceptualized using CCA.

Table 9

Understanding Paul's Categories of Reasoning about Instructional Practices

\begin{tabular}{|c|c|c|c|c|c|}
\hline \multirow[t]{2}{*}{$\begin{array}{l}\text { Category of } \\
\text { Reasoning }\end{array}$} & \multicolumn{3}{|c|}{$\begin{array}{l}\text { When Category } \\
\text { Occurred (Type of } \\
\text { Interview) }\end{array}$} & \multirow[t]{2}{*}{$\begin{array}{l}\text { How Category } \\
\text { Occurred (Focus of } \\
\text { Language Used) }\end{array}$} & \multirow{2}{*}{$\begin{array}{l}\text { Consequences of } \\
\text { Category Occurring } \\
\text { (Did Resulting } \\
\text { Instructional } \\
\text { Practices Align with } \\
\text { V4MI?) }\end{array}$} \\
\hline & initial & $\begin{array}{l}\text { pre- } \\
\text { lesson }\end{array}$ & $\begin{array}{l}\text { post- } \\
\text { lesson }\end{array}$ & & \\
\hline $\begin{array}{l}\text { Cultivating Learner } \\
\text { Qualities }\end{array}$ & 2 & 2 & 5 & $\begin{array}{l}\text { student actions and } \\
\text { student's past } \\
\text { experiences or } \\
\text { behaviors }\end{array}$ & aligned with V4MI \\
\hline $\begin{array}{l}\text { External Sources of } \\
\text { Influence }\end{array}$ & 2 & & 3 & $\begin{array}{l}\text { teacher actions and } \\
\text { teacher's past } \\
\text { behaviors and } \\
\text { experiences }\end{array}$ & $\begin{array}{l}\text { sometimes aligned } \\
\text { with and sometimes } \\
\text { did not align with } \\
\text { V4MI }\end{array}$ \\
\hline $\begin{array}{l}\text { Establishing } \\
\text { Classroom Culture }\end{array}$ & 3 & & 4 & $\begin{array}{l}\text { both student and } \\
\text { teacher actions and } \\
\text { students' and } \\
\text { teachers' past } \\
\text { behaviors and } \\
\text { experiences }\end{array}$ & aligned with V4MI \\
\hline
\end{tabular}

Cultivating Learner Qualities. Paul discussed his hopes for cultivating learner qualities as reasoning for instructional practices twice in his initial interview, twice in his pre-lesson interview, and five times in his post-lesson interview. He talked about moving students toward independence from relying on the teacher and fostering confidence. He connected this reasoning to the following instructional practices: eliciting student help to "teach" the class by providing 
guidance to Paul, including problems in the activity that did not follow the procedures Paul reviewed in class, including student-led, discovery-based lessons about once per week, and engaging students in group work to review topics for which they might lack confidence. He also reasoned that he wanted students to grow as learners and members of society in nonmathematical contexts. Instructional practices that Paul tied to this reasoning included helping students to set goals for their learning and success in and out of school and using student interest in non-mathematics classes as a tool to motivate students. When discussing cultivating learner qualities, Paul's language focused on his student actions, past behaviors, and experiences. $\mathrm{He}$ reflected that some practices tied to cultivating learner qualities aligned with his V4MI.

During Paul's initial interview, he described an instructional practice he would choose to help students rely less on the teacher and build their confidence. Paul stated:

I think that right now students are used to having the teacher tell them everything, but a lot of the times what we're missing is the student ... and they don't have enough selfconfidence that they can do something on their own. They don't need [emphasis added] the teacher's help, so I think that having regular student-led inquiry topics, you know, discovery on a regular basis would help them build their confidence and say, "Okay, this looks difficult, but I'm going to give it a try and look for a pattern. And I can become, you know, and independent learner instead of relying on the teacher all of the time." When Paul again described his desire to build student independence and confidence through student-led inquiry topics, I asked Paul what he meant by "regular student-led inquiry topics." He described a specific lesson model that he tried to incorporate about one time per week. He said: 
I would give them a small worksheet at the beginning of the hour where it gave them step-by-step. Not like listed out, but like "Here's what you want to do. Do the work. Here's questions. Can you see a pattern? Can you notice anything repetitive?’ And they would work through that together in their groups for about ten or so minutes, and then we would talk about it.

During his post-lesson interview, Paul also reasoned about the instructional practice of including two problems on the group activity that did not lend themselves to being solved easily by factoring. He hoped that students would isolate $x$ and solve for the variable by taking the square root of the quantities on either side of the equal sign. During the chosen lesson, Paul did not assist students with these problems. When reasoning about including these problems, he discussed a hope that students would step up to help each other. Paul said:

So, I didn't talk about [numbers] four and eight. Those were questions where they would solve using square roots. So, I was hoping that, and I was depending on one person from each group to kind of take charge and take control of that one and figuring that out. And then, hopefully, tomorrow, they'll help out everybody.

Paul also hoped to cultivate a learner quality described as helping students to grow as learners and members of society in non-mathematical contexts. When discussing ideal practice in his initial interview, he stated, "In my perfect classroom, making goals would be like a regular bi-weekly thing, or maybe monthly thing where the students set goals, we monitor them, and see if they achieve them. They graph what they did well, what they should improve on for their next goal." As an example of this, Paul reasoned in his post-lesson interview about his instructional practice of reflecting on goals that he helped students set. Paul said, "I gave back their goal sheets. So, in my perfect classroom, it's not solely academic. Like, students will grow, whether 
it's like their personal life, their work habits, their responsibility just in any other area. So, we wrote goals." Paul spent time passing these goals back during the chosen lesson and asking students to review and reflect on their goals.

External Sources of Influence. Paul reasoned that he was motivated by an external source of influence when envisioning or enacting some instructional practices. Paul cited external sources of influence twice in his initial interview and three times in his post-interview. External sources of influence that Paul used as reasoning included the allotted time in the scheduled class period, the district grading policy, and the principal of the school. When discussing external sources of influence, Paul discussed the instructional practices of breaking instructional time into manageable pieces, taking breaks in class to engage students in "brain breaks," omitting portions of the planned lesson, adhering to the grading policy, and trying new things in his classroom. When reasoning about external sources of influence, Paul used language that focused on teacher actions, past experiences, and behaviors. He reflected that some instructional practices tied to external sources of influence aligned with his V4MI and some did not.

In recognizing the limits of a 50-minutes class period, Paul reflected that he felt this was too long for students to remain on-task continually with mathematics content; he also lamented that he was unable to accomplish all that he set out to do within one class period. As an example of reasoning about the 50-minute time period, Paul commented on his choice to take a break while viewing the video of his lesson. "So, then this next five minutes or so, just take a brain break. It's unrealistic to have a full 50 minutes - brain 100\% engaged. We try different little things like knockout. We do trivia. We play silent ball. We play heads-tails game." I took this to mean that Paul thought 50 minutes was too long for students to remain engaged in mathematical 
tasks. To cope with this, Paul inserted a brain break. He portrayed a brain break as an instructional tool that allowed him to maximize the amount of time during the 50 -minute class period that he could engage students in mathematics. Paul spoke about brain breaks as a positive addition to his classroom practices and made no indication that this practice did not align with his V4MI. Paul spoke of brain breaks as a positive addition to his classroom. He made no mention of wishing that class periods were shorter so that students could remain engaged in mathematics tasks 100 percent of the class period. I therefore believe that Paul viewed brain breaks as part of ideal instruction.

Paul also discussed his wishes to employ the instructional practice of increasing the value of homework and classwork as a component of students' overall grades. However, he reasoned that he must maintain that $15 \%$ of students' total grades come from homework and classwork because this is a district-wide policy. The following exchange between me and Paul during his initial interview demonstrated this reasoning about his grading instructional practice that does not align with his V4MI:

Interviewer: Is there anything else you want to tell me about your vision?

Paul: That's about it. Well, I would change the grading. Like, they would still get grades, but maybe I would change the weight on the homework and classwork. Rather than just $15 \%$, I would want more. But-

Interviewer: Is the percentage departmental?

Paul: No, it's district wide. I think they changed it two years ago. Sixty-five percent summative, $10 \%$ quarter final, and then just $15 \%$.

As was the case with Simon, Paul felt that his grading practices were not ideal. Again, this practice was a direct result of a policy that Paul felt was out of his control. Though Paul felt 
that his principal was very supportive of Paul taking control in his own classroom, trying new things, and making instructional decisions, Paul's made no indication that he felt the same amount of support from district-level administration. Thus, I believe Paul did not feel empowered enough to question the district grading policy.

Though the district-wide grading policy was an external source of influence that led Paul to grade in a way that did not align with his V4MI, Paul cited the principal as a source of influence that has led him to take the liberty of trying new things. Paul stated that he was comfortable taking risks with things like "brain breaks" in his classroom. The following excerpt from Paul's initial interview reflects his reasoning about the support he feels from the principal:

[The principal] is great, you know, is awesome. As long as you're doing what you're supposed to be, you can kind of have control over it. . . Try new things. Failure is a good thing as long as you keep trying to make it better.

As sourced from my field notes, the principal described to me in conversation that Paul was an "innovative" teacher who was not afraid to take new approaches and receive constructive feedback.

Establishing Classroom Culture. Paul expressed the desire to establish a specific classroom culture and used this as reasoning for several instructional practices. Paul reasoned about establishing classroom culture three times during his initial interview and four times in his post-lesson interview. Specifically, Paul discussed a culture such that there was a feeling of respect between teacher and students, students collaborated about mathematics, and the classroom community had more in common than just mathematics. Instructional practices that Paul tied to this line of reasoning included opening a two-way line of communication between teacher and students, redirecting students in a positive way, arranging desks in groups for 
collaboration, and discussing life outside of the mathematics classroom. When reasoning about establishing classroom culture, Paul used language that I could not determine as heavily studentor teacher-focused. Instead, he discussed both student and teacher actions, past experiences, and behaviors. He reflected that instructional practices he tied to establishing classroom culture aligned with his V4MI.

Paul reasoned that in his class he wanted to build respect between teacher and student. In his initial interview, he described what he would look for in an ideal classroom by saying, "So, the first thing I would look at is how the students and teachers interact with each other. I would look for a two-way line of communication." I followed-up on this to gain more insight into his reasoning. The following is my exchange with Paul surrounding the instructional practice of twoway communication:

Interviewer: So, why do you think it's important to have two-way communication in the classroom?

Paul: So that, to me, is based on respect. I think if you can have open communication with someone, there's a foundation of respect between that teacher and student. If a student feels they can't ask a teacher a question, well then, they're never going to reach their full potential. Because they can ask another student but sometimes you need the teacher's answer to your question. And I don't think any student should feel afraid or nervous or scared to ask a question or to challenge a teacher on something they're saying, because, you know, we make mistakes, too.

I believe that this excerpt more-clearly explains the two-way communication that Paul envisioned and sheds light on his reasoning of respect between teacher and student. 
As another example of an instructional practice aimed at achieving a culture of respect, Paul described an ideal practice of calling everyone by their first names. When I asked Paul in his initial interview what he would look for in a classroom of ideal mathematics instruction, he said, "I just think respect. If I'm not looking at math instruction, I would look at the whole classroom culture. See the students respect each other. I would look to see if they're calling each other by their first name." He went on to describe a specific strategy for achieving the first-name basis in an ideal classroom:

In college, I took this literature class. And he said before you speak for the first two weeks, you have to say their name before any sentence. Start with their name and end with their name. I thought that was pretty stupid, but nobody knew each other. But by the end of the two weeks everybody knew each other's names and you could ask anybody questions. So, I thought that was cool. So, that's what I would want them to do.

Paul also reasoned about his instructional practice of seating students in groups in order to promote collaboration and teamwork. In his initial interview, he described his vision for seating if he were to observe ideal mathematics instruction:

Paul: I would also want to see their seating arrangements and how the desks are organized. I know some teachers in our department have columns and rows and others have groups. Whether that's groups of four or side-by-side a group of two.

Interviewer: So, what would your vision be for that?

Paul: I would have mine in groups. I wouldn't have them isolated. During his post-lesson interview Paul pointed out this vision playing out while watching the video of his lesson, and he commented on the success of grouping students in building a culture that he envisioned. He stated the following: 
So how I grouped this front group here. I like them a lot because they work really hard. . . This kid is a French-speaking student. Um, [another student] speaks Arabic. Her first language is Spanish. So, it's very diverse. But they all get along very well. And that's the type of culture that I'm trying to build. Where it doesn't matter who you are, what your name is, where you're from. We can all work together. Help each other out and achieve a common goal.

In order to establish classroom culture, Paul also reasoned about connecting with students in non-academic ways. During his post-lesson interview, he paused the video after commenting to the class that a student had practiced the day prior for the game of knockout. He made the following comment about the interaction with the class:

My ideal, my perfect classroom, I think a teacher and students connect on different levels than, you know, just education. And at the beginning, I was talking about [student name]. He was a basketball player. Yesterday, he had a game where he shot. So, just little comments throughout the lesson, I think, helps create the perfect culture. The perfect environment.

Paul's supported his instructional practice of joking with the student about his readiness to play knockout by citing the desire to create a culture where the teacher and students connect about activities outside of mathematics.

\section{Explicit Mention of V4MI and CCSSM}

When planning his lesson, Paul did not reason about any instructional practice choices by stating that it was part of his vision or because it was ideal. However, when reflecting on his lesson in the post-lesson interview, Paul reasoned about instructional practices by explicitly referring to his vision or his ideal classroom in seven separate instances. For example, Paul 
reflected that his choice for the length of direct instruction was a choice made to fit his ideal classroom. He stated:

In my ideal classroom—let's go back real quick. Students' attention spans have gotten, seems [emphasis added] like they have gotten shorter. I try to maximize my time I have with them by keeping my message under 13 minutes. So, it looks like, this is at, so 14 . And then with just the instruction, would've been about 12. In my eyes that's the somewhat ideal time. Because you don't want to be, in my opinion, talking too long with them. Because then you lose a lot of students and then your time becomes less valuable. As another example, Paul reasoned about Establishing Classroom Culture in a way that directly referred to his ideal classroom:

So, at the beginning, my ideal, a perfect classroom, I think a teacher and students connect on different levels than just education. And at the beginning, I was talking about [student name omitted]. He was a basketball player. Yesterday he had a game where he shot. So, just like little comments throughout the lesson, I think, helps create the perfect culture, the perfect environment.

In all of the seven instances that Paul reasoned about instructional practices by referring to his V4MI, he referred to instructional practices that involved his sense of agency, meaning he discussed the things that he chose to do instead of discussing things that students were doing.

As previously mentioned in the description of Paul's lesson, he did not explicitly discuss the CCSSM until prompted via email to identify learning standards he intended to address in his chosen lesson. 


\section{Marta}

At the time of this study, Marta had been teaching for 8 years. Marta's teaching assignment was unique from the other three case study teachers in that she worked with students who were hearing impaired or deaf. Because of this role, Marta's class sizes were smaller than the other three teachers. In describing her V4MI, Marta highlighted some of the constraints on her teaching that have resulted from her teaching assignment. In her initial interview, the following exchange between myself and Marta highlighted the differences in her teaching situation and that of her mathematics-teaching peers:

Interviewer: You've already mentioned the constraint of smaller class sizes. Are there other constraints that you could think of that might change what your vision might look like for a math class?

Marta: It depends on their hearing loss and their language mode. You have some students who are oral only and some students who are sign only and some students who do both. And that's a restraint that is sometimes difficult with that whole exploration piece and student-led group work - that they have such different modes of communication. Then, communicating with each other can sometimes be hard, too.

At the time of this study, Marta was teaching Bridges to Algebra (i.e., a mathematics course that provided students with prerequisite skills needed to be successful in Algebra) and Functional Mathematics (i.e., a mathematics course that ensures students achieve a basic understanding of mathematics skills needed in everyday life such as measurement, problem solving, and number sense). When asked to choose a lesson for me to observe for the purpose of pre-lesson and post- 
lesson interviews, Marta chose a Bridges to Algebra lesson. The lesson focused on finding the perimeter of rectangles. This lesson was meant to introduce students to the concept of perimeter.

\section{Synopsis of Marta's Lesson}

Marta's lesson guided students through the process of formalizing their understanding of rectangle perimeter into a workable formula that could be used to find perimeter of any rectangle. She began the lesson by presenting students with the task of fencing in a rectangular yard - projected as a measured and labeled figure on the board - in order to contain a puppy. Subsequent tasks and figures were either unaccompanied by written directions or directed students to "Find the perimeter of the figure." Rectangle side lengths on the projected presentation and student handouts were labeled with whole number measurements in metric and standard American units. Several times, Marta stressed the importance of students being able to tell her "that perimeter is like the distance around a shape" or "that to find perimeter, you add up all of the sides." She guided students to connect adding the four side lengths of a rectangle to the process of adding the product of one side length and 2 to the product of the adjacent side length and 2 (i.e., $2 \mathrm{l}+2 \mathrm{w})$.

Activities allowed students to demonstrate their abilities to explain their process for calculating perimeter and respond with feedback to peer's process explanations. Marta said a goal of the lesson was that students could "do a problem and have to talk with their peers about how they solved it and why they did the steps they did." Marta did not reason about specifying instructional practices by discussing the CCSSM or discuss learning standards in any of her interviews. In order to report the CCSSM that Marta intended to target with her lesson, I followed up with her after the post-lesson interview via email. Following are content standards and SMP identified by Marta as being addressed in whole or in part by her chosen lesson. 
- CCSS.MATH.CONTENT.3.G.A.1. "Understand that shapes in different categories (e.g., rhombuses, rectangles, and others) may share attributes (e.g., having four sides), and that the shared attributes can define a larger category (e.g., quadrilaterals). Recognize rhombuses, rectangles, and squares as examples of quadrilaterals, and draw examples of quadrilaterals that do not belong to any of these subcategories" (NGA \& CCSSO, 2010a).

- CCSS.MATH.CONTENT.4.OA.A.3. "Solve multistep word problems posed with whole numbers and having whole-number answers using the four operations, including problems in which remainders must be interpreted. Represent these problems using equations with a letter standing for the unknown quantity. Assess the reasonableness of answers using mental computation and estimation strategies including rounding" (NGA \& CCSSO, 2010c).

- CCSS.MATH.CONTENT.4.MD.A.3. "Apply the area and perimeter formulas for rectangles in real world and mathematical problems" (NGA \& CCSSO, 2010b).

- CCSS.MATH.PRACTICE.MP1. "Make sense of problems and persevere in solving them" (NGA \& CCSSO, 2010f).

- CCSS.MATH.PRACTICE.MP4. "Model with mathematics" (NGA \& CCSSO, 2010f). Marta's chosen lesson took place in a functional mathematics class for students spanning grades 9 through 12 who are deaf or hard of hearing. In her own words, "these students are working at grade levels varying from second through fourth grade ... so their experiences in the classroom are also at varying levels." For this reason, Marta was targeting content standards below the secondary level. However, she stated that, "for lesson planning, we are required to use grade-level standards that shows the grade-level content that we are working towards. They [the 
standards] may not be the exact task, but what we are building towards." Marta identified the following grade-level standards for this purpose:

- CCSS.MATH.CONTENT.HSA.CED.A.1. "Create equations and inequalities in one variable and use them to solve problems" (NGA \& CCSSO, 2010d).

- CCSS.MATH.CONTENT.HSA.REI.A.1. "Explain each step in solving a simple equation as following from the equality of numbers asserted at the previous step, starting from the assumption that the original equation has a solution. Construct a viable argument to justify a solution method" (NGA \& CCSSO, 2010d).

- CCSS.MATH.CONTENT.HSG.CO.A.1. "Know precise definitions of angle, circle, perpendicular line, parallel line, and line segment, based on the undefined notions of point, line, distance along a line, and distance around a circular arc" (NGA \& CCSSO, 2010e).

- CCSS.MATH.CONTENT.HSG.MG.A.1. "Using geometric shapes, their measures, and their properties to describe objects (e.g., modeling a tree trunk or a human torso as a cylinder)" (NGA \& CCSSO, 2010e).

- CCSS.MATH.PRACTICE.MP1. "Make sense of problems and persevere in solving them" (NGA \& CCSSO, 2010f).

- CCSS.MATH.PRACTICE.MP4. "Model with mathematics" (NGA \& CCSSO, 2010f).

Categories of Marta's Reasoning About Instructional Practices and Contexts Surrounding Those Categories

As evidenced by Marta's strand of interviews, she reasoned about ideal, planned, and enacted instructional practices in ways that I was able to conceptualize in four categories. In order to be included in Marta's conceptual framework for how she specified instructional 
practices, the concept appeared within more than one of Marta's interviews, and she connected the concept to specifying instructional practices more than once within each of those interviews. Table 10 provides each concept's name and a description of reasoning that fell under that concept category. Following Tables 10 and 11, I will go into more detail concerning the ways that Marta reasoned about instructional practices and associated these practices with her V4MI. I will provide examples of each category of reasoning as evidenced by interview transcript. These examples were chosen as straightforward presentations of the connection between instructional practice and reasoning. Specifically, Marta's description of her reasoning for a certain instructional practice in these examples was explicit without straying to another topic before returning to draw a connection between reasoning and practice.

Table 10

Marta's Reasoning for Specifying Instructional Practices

\begin{tabular}{|c|c|}
\hline Concept Name & Examples of Reasoning \\
\hline Prior Knowledge (PK) & $\begin{array}{l}\text { - wanted to create opportunities for students to } \\
\text { demonstrate PK } \\
\text { - hoped students would build on each other's PK } \\
\text { - felt students were limited by lack of PK }\end{array}$ \\
\hline Building Conceptual Knowledge & $\begin{array}{l}\text { - hoped students would learn not just how they came } \\
\text { to a solution but also why that was the process }\end{array}$ \\
\hline Mathematics Vocabulary & $\begin{array}{l}\text { - wanted students to use vocabulary in conversation } \\
\text { - pointed to the necessity of understanding } \\
\text { vocabulary to do well on standardized assessments } \\
\text { vanted increased exposure for students to use } \\
\text { vocabulary in light of language delays and differing } \\
\text { modes of communication }\end{array}$ \\
\hline $\begin{array}{l}\text { Other Mathematics Teachers' } \\
\text { Classes }\end{array}$ & $\begin{array}{l}\text { - wanted to model instruction after other } \\
\text { mathematics teachers that she felt were engaging } \\
\text { students in collaborative and exploratory tasks }\end{array}$ \\
\hline
\end{tabular}


To address the second research question — understanding different forms of reasoning within the context of a theory of action, a V4MI, and the CCSSM-I will explore when, how, and with what consequences each category emerged. Results reflect the interviews in which the category emerged, the consistencies in the language used by Marta when discussing the category, and Marta's account of that category leading to instructional practices that aligned or did not align with ideal instructional practices described in her V4MI. Table 11 below delineates answers to the questions chosen to place meaning on the categories conceptualized using CCA.

Table 11

Understanding Marta's Categories of Reasoning about Instructional Practices

\begin{tabular}{|c|c|c|c|c|c|}
\hline \multirow[t]{2}{*}{ Category } & \multicolumn{3}{|c|}{$\begin{array}{l}\text { When Category } \\
\text { Occurred (Type of } \\
\text { Interview) }\end{array}$} & \multirow[t]{2}{*}{$\begin{array}{l}\text { How Category } \\
\text { Occurred (Focus of } \\
\text { Language Used) }\end{array}$} & \multirow{2}{*}{$\begin{array}{l}\text { Consequences of } \\
\text { Category Occurring } \\
\text { (Did Resulting } \\
\text { Instructional } \\
\text { Practices Align with } \\
\text { V4MI?) }\end{array}$} \\
\hline & initial & $\begin{array}{l}\text { pre- } \\
\text { lesson }\end{array}$ & $\begin{array}{l}\text { post- } \\
\text { lesson }\end{array}$ & & \\
\hline Prior Knowledge & 2 & 3 & 3 & $\begin{array}{l}\text { focused on student } \\
\text { actions and student's } \\
\text { past experiences or } \\
\text { behaviors }\end{array}$ & $\begin{array}{l}\text { sometimes aligned } \\
\text { with and sometimes } \\
\text { did not align with } \\
\text { V4MI }\end{array}$ \\
\hline $\begin{array}{l}\text { Building Conceptual } \\
\text { Knowledge }\end{array}$ & & 2 & 2 & $\begin{array}{l}\text { focused on both } \\
\text { student and teacher } \\
\text { actions and students' } \\
\text { and teachers'past } \\
\text { behaviors and } \\
\text { experiences }\end{array}$ & aligned with V4MI \\
\hline $\begin{array}{l}\text { Mathematics } \\
\text { Vocabulary }\end{array}$ & 2 & 2 & 5 & $\begin{array}{l}\text { focused on student } \\
\text { actions and students' } \\
\text { past behaviors and } \\
\text { experiences }\end{array}$ & $\begin{array}{l}\text { sometimes aligned } \\
\text { with and sometimes } \\
\text { did not align with } \\
\text { V4MI }\end{array}$ \\
\hline $\begin{array}{l}\text { Other Mathematics } \\
\text { Teachers' Classes }\end{array}$ & 2 & & 2 & $\begin{array}{l}\text { focused on teacher } \\
\text { actions and teacher's } \\
\text { past behaviors and } \\
\text { experiences }\end{array}$ & aligned with V4MI \\
\hline
\end{tabular}


Prior Knowledge. Marta reasoned about prior knowledge (PK) when discussing instructional practices twice in her initial interview, twice in her pre-lesson interview, and three times in her post-lesson interview. Specifically, Marta wanted to create opportunities for students to demonstrate PK, hoped students would build on each other's PK in conversation, and felt students were sometimes limited during mathematics instruction by their lack of PK. She tied reasoning about PK to the instructional practices of asking students what they already know about real-life situations she presented, repeating student statements and probing their thinking with follow-up questions, encouraging students to take turns sharing what they know even when they were unsure if their understanding was correct, and teaching some concepts in a straightforward and procedural way. When discussing PK, Marta's language focused on student actions, past behaviors, and experiences. She reflected that some instructional practices tied to PK aligned with her V4MI and some did not.

When reflecting on her lesson in the post-lesson interview, Marta stopped the video when she was asking a student to describe what he thought was going on in a real-world scenario that she had presented to the class. In the scenario, a girl was trying to figure out the length of fence that she would need to enclose her yard in order for her puppy to have space to roam. Marta reflected about her effort to encourage the student to access his PK:

So, he couldn't think of an answer for what he thought perimeter was. And even though he never really got to the complete answer, just the fact that he was trying to make a connection and using words that he thought related to perimeter, that's part of my vision. That you want him to be making connections with what he already knows and using his prior knowledge and trying. 
In this excerpt, Marta reflects that the student's attempt to connect the presented scenario to perimeter was part of her V4MI.

In another example of Marta reasoning about PK, she reflected on the success of being able to support students in building on each other's PK to come to a conclusion:

So, here is where I was trying to get them to tell me that they know about the two sides are congruent or equal because it is a rectangle. And so, it took a while of me kind of pulling it out of them, but they eventually got there to where they were able to tell me it's a rectangle. After they said 'triangle' and every other shape under the sun. But eventually they reached the conclusion together. Which is what I like. They were taking pieces of what he said and what she said and concluding together to come to the concept that the rectangle has two, that these two sides are congruent, and these two sides are congruent. I don't think they ever came out and said that independently, but they reached that together.

In conjunction with this statement, Marta was asking students to listen to what each other was saying and encouraging them to question each other for information at the time that she paused the lesson video.

In contrast to the prior two examples of Marta's instructional practices aligning with her V4MI, Marta lamented in her initial interview that she is not always able to teach in ways that align with her V4MI due to students' lack of prior knowledge. She stated:

Because I want them to actually know the whys and the hows behind it all and not just, this is the formula that you need to do for this problem. And because of their language delays, so often because of their hearing loss, they miss a lot of those things. So, I think I have to teach them very straightforward, so then, it kind of takes away from that. So, how 
can I still fill in all of those gaps that they need, things that they've missed but still let them explore and think about it themselves and why that is the case.

I take this statement to mean that Marta's practice of often teaching "straightforward" corresponds with the practice of explaining for students the formula or procedures for completing a mathematics problem. Though this is not what Marta deemed ideal, she felt it was necessary because students have "gaps" and are missing PK due to language delays and hearing loss.

Building Conceptual Knowledge. Another category of Marta's reasoning about instructional practices was building conceptual knowledge. Marta supported instructional practices by describing her desire to build students' conceptual knowledge twice in her prelesson interview and twice in her post-lesson interview. Specifically, Marta hoped that her students could learn not just how they came to a solution but also why that was the process for reaching the solution. She tied this reasoning to the instructional practices of using real-life scenarios (e.g., a girl deciding the length of fence she must purchase to fence in her yard for a puppy), including activities in which students talk with peers about how and why they performed steps in a problem to reach a solution, and encouraging students to have conversations about what they are doing while they work on mathematics problems. When discussing building conceptual knowledge, Marta's language focused on both student and teacher actions, past behaviors, and experiences. Therefore, I was not able to determine a majority of student-centered or teacher-centered language. She reflected that instructional practices tied to building conceptual knowledge aligned with her V4MI.

During Marta's pre-lesson interview, she discussed the lesson she had planned for the following day. As a note, she planned to teach students about both perimeter and area but later 
decided that her lesson would only address perimeter. When discussing the introduction to the lesson, she reasoned that the real-life scenario she would be using should encourage students to reach a conceptual understanding of perimeter. That is, students would not just perform the calculation for perimeter but would instead understand what perimeter means. Marta stated:

I'm introducing perimeter and area of just basic shapes like squares and rectangles. And I I'm going to be using real-life scenarios such as putting up a fence or filling in a garden to figure out what that actually means. What is the perimeter? What is area, and what does it mean? And how do we solve to find it?

In addition to the instructional practice of including a real-life scenario, Marta focused on instructional practices aimed at increasing classroom conversation that could build conceptual knowledge. In her pre-lesson interview, Marta described her plan for an activity that pushed students to talk with each other about their steps for solving a perimeter problem. She said, "I am doing a piece of it where they do a problem, and they have to talk with their peers about how they solved it and why they did the steps that they did, to get that deeper understanding." During her post-lesson interview, Marta further described how her questioning and students' conversation led to a deeper conceptual understanding of perimeter. In the following excerpt, Marta described a point in the lesson when a student was providing only numerical answers without placing meaning on them:

Marta: Anytime I'd ask him, “What are you finding?” he'd say the answer. He didn't say, “The perimeter of the shape." And that's where I am wanting to go. That's the main thing. .. So, it's just be having more practice.

Interviewer: More practice with what?

Marta: More practice with having to use conversation about what they're doing in math. 
Not just doing the procedures. Talking about what they're doing. Why they're doing it, and what it means.

Though the student's expression of his understanding of perimeter did not match Marta's V4MI, she suggested that having students practice talking about what they are doing could improve their ability to voice why they are performing procedures and the meaning of their solutions. I took this to mean that her practice of asking the student to explain his process aligned with her V4MI and she hoped that students' ability to successfully provide such explanations would improve if she included this practice in her lessons more often.

Mathematics Vocabulary. Marta expressed her desire for students to use mathematics vocabulary during every interview and tied several instructional practices to this goal. She reasoned about mathematics vocabulary twice in her initial interview, twice in her pre-lesson interview, and five times in her post-lesson interview. Specifically, Marta said that she wanted students to use mathematics vocabulary in conversation with her and peers, she pointed to the necessity of understanding vocabulary to do well on standardized assessments, and she wanted to increase exposure for students to mathematics vocabulary in light of their language delays and differing modes of communication. Instructional practices that she tied to this line of reasoning included probing students when they didn't use mathematics vocabulary, pushing students to replace general phrases with mathematics terms they would see on assessments, and modeling the use of vocabulary in sentences and asking students to practice saying the modeled sentences. When discussing mathematics vocabulary, Marta's language focused on student actions, past behaviors, and experiences. She reflected that some instructional practices tied to mathematics vocabulary aligned with her V4MI and some did not. 
During her initial interview, Marta described her process for probing students' thinking and encouraging them to use specific mathematics terms instead of general descriptions. Marta said the following:

I guess the ultimate goal would be for the students to use the words. You know, instead of just saying, "Well, you put those two together." So, I ask, "Okay, but what is that? What is the word that describes that action?" And that's what I have a lot of times. I have one student, in particular, who can be like, "Well, this." He can point to stuff and be like, "this and this." Okay, but I ask, "What is that?" Okay they're parallel. I want him to be able to use those words when he's describing what he's doing.

In addition to encouraging students one-on-one to use more specific mathematics vocabulary, Marta also talked about modeling use of vocabulary and asking students to repeat the phrases she modeled. In her post-lesson interview, Marta paused the video when she was asking the whole class to repeat after her. At this point in the interview, she said the following: That's where we were talking about the two sides. It took them a little while to feel more comfortable about repeating the same phrases over and over. Like, for example, they were looking at me like I was nuts. But they started to see what my expectations were really quickly. And so, it was a really language-rich lesson because they knew that those were my expectations. Which is my vision, is that I want them to know that in math we still have to say complete phrases and use the right words and label things the way they need to be labelled. You can't just say, "we add it." or "We add that." I want them to be using more specific language all the time.

Marta seemed pleased with the result of this instructional practice. She described the subsequent portion of the lesson as language-rich and stated that was part of her V4MI. 
As another example of Marta reasoning about mathematics vocabulary, she described how she wanted to push students to use the word "congruent" as opposed to "equal" or "the same." She reasoned that "congruent" was the word students would see on assessments in the following excerpt from her post-lesson interview:

I feel like I could have done more with them having to explain with opposites maybe. They could have explained that I know these two go together because they're opposite of each other and gone more into depth with that language piece instead of just saying, "Those two sides are the same." I could've gone into more and even enriched the language more. I wanted to and I didn't with the word congruent. I let them just say “equal," but I really think they need to know what the word congruent means. Because that's the word they're going to be seeing on different assessments.

I took this statement to signify that Marta had not pushed students to use the mathematics vocabulary in the way that she believed would have benefitted them on future assessments; thus, this instance of reasoning was tied to an instructional practice that did not align with Marta's V4MI. It might be possible to relate this misalignment of V4MI and practice to Marta's other misalignment of V4MI and practice that involved student prior knowledge and a fear they are lacking skills or vocabulary. It is possible that Marta was accommodating students by allowing them to use a word that was familiar (i.e., equal) instead of pushing them to use the word congruent.

Other Mathematics Teachers' Classes. Twice in her initial interview and twice in her postlesson interview, Marta explained that she chose certain instructional practices because she looked to what other mathematics teachers' classes were doing that she wanted to model. She described a process of observing student-led and exploration activities in other mathematics 
classes and modifying those practices to work well with her smaller class sizes. When discussing other teacher's mathematics classes, Marta's language focused on her actions as well as the actions of other teachers, past behaviors, and experiences. She reflected that instructional practices adapted from other mathematics teachers' classes aligned with her V4MI.

In the following excerpt from Marta's initial interview, she described how she looks to other teachers' mathematics classes for guidance on instructional practices:

Well, since I teach really small groups, I think about how, what can I take of [other teachers'] lessons that I could make more simple or into a smaller group? Because I want to do more of those student-led and the exploration-type activities, but because I have such small groups sometimes that's difficult for me. So, I try to, that's my long-term goal, is to get them to do those types of things. So, how can I take what's already being done and modify it?

Following is a specific example of an activity that Marta had first seen in another mathematics classroom and then modified for her chosen lesson:

So, I'm going to the do-and-share part because this is the other part of my vision. The main part of them having to do more cooperative learning activities, which is where I struggle with the type of things that they're doing in the mainstream classroom with bigger groups. But I want to carry that into here so that it's not just me standing up in front of the room all the time, which is the majority of what this lesson was. So, I want to do more of that. So, this is doing that on a smaller scale.

The portion of the videoed lesson that Marta was referring to, the do-and-share activity, allowed students to complete a problem in which they found the perimeter of a rectangle. They then split 
into partner pairs and took turns explaining each step of their calculation, why they performed each step, and what the solution meant in the context of the rectangle.

\section{Explicit Mention of V4MI and CCSSM}

When reasoning about instructional practices by discussing Building Conceptual Knowledge and Other Teachers' Mathematics Classes, Marta explicitly described or reflected on instructional practices that aligned with her V4MI. Reasoning about Prior Knowledge and Mathematics Vocabulary resulted in instructional practices sometimes aligned and sometimes not aligned with Marta’s V4MI.

When reflecting on her lesson in the post-lesson interview, Marta reasoned about instructional practices by explicitly referring to her vision in six separate instances. For example, Marta reasoned about Other Teachers' Mathematics Classes and her choice to do a cooperative learning activity that aligned with her vision:

So, I'm going to the do-and-share part because this is the other part of my vision- the main part of them having to do more cooperative learning activities, which is where I struggle with the type of things that they're doing in the mainstream classroom with bigger groups.

As noted in her lesson description, Marta did not make explicit mention of the CCSSM until prompted via email to identify learning standards she intended to address in her chosen lesson. 


\section{Gwen}

Gwen was a 12-year teacher who had worked at multiple schools within the same district - including the school site for this study. At the time of this study, Gwen was teaching Algebra II, Transitions to College Math, and Geometry. When asked to choose a lesson for me to observe for the purpose of pre-lesson and post-lesson interviews, she chose an Algebra 2 lesson focused on solving radical equations such as $2 \sqrt[3]{13 x-5}=10$ for unknown values.

\section{Synopsis of Gwen's Lesson}

Gwen began her lesson by writing the equation $\mathrm{x}+1=\sqrt{7 x+15}$ on the front board.

She guided students through solving for the unknown value in this equation through questioning, explaining, and modeling a solution on the board. Students were then given about 10 minutes to work independently to solve radical equations that Gwen had passed out in the form of a worksheet. Following the independent work, students left class for lunch. Upon arriving back to the classroom from lunch, the students rearranged the desks so that they were seated in pairs facing each other. The pairs of desks were then arranged into two rows that ran the length of the classroom. For the remainder of class, Gwen engaged the students in a "speed-dating" activity. Students sat in pairs and explained to each other a problem they had been assigned to as an “expert." Every couple of minutes, Gwen would instruct one person from each pair to get up, the standing partners would shift along the row of paired desks to meet a new partner, and they would begin the process of explaining again.

Gwen identified the content standard during her pre-lesson interview and identified the standards for mathematical practice after I asked her to confirm via email the CCSSM that her lesson addressed upon the conclusion of the pre-lesson and post-lesson interviews. Following are 
content standards and SMP identified by Marta as being addressed in whole or in part by her chosen lesson.

- CCSS.MATH.CONTENT.HSA.REI.A.1. "Explain each step in solving a simple equation as following from the equality of numbers asserted at the previous step, starting from the assumption that the original equation has a solution. Construct a viable argument to justify a solution method" (NGA \& CCSSO, 2010d).

- Gwen stated that the lesson as it was presented addressed all of the " 8 standards by default of implementation." Below is a bulleted list of the eight standards for mathematical practice.

- Make sense of problems and persevere in solving them.

- Reason abstractly and quantitatively.

- Construct viable arguments and critique the reasoning of others.

- Model with mathematics.

- Use appropriate tools strategically.

- Attend to precision.

- Look for and make use of structure.

○ Look for and express regularity in repeated reasoning. (NGA \& CCSSO, 2010f)

\section{Categories of Gwen's Reasoning About Instructional Practices and Contexts Surrounding}

\section{Those Categories}

As evidenced in Gwen's strand of interviews, she reasoned about ideal, planned, and enacted instructional practices in ways that I was able to conceptualize in two categories. In order to be included in Gwen's conceptual framework for how she specified instructional practices, the concept had to have appeared within more than one of Gwen's interviews, and she connected the concept to specifying instructional practices more than once within each of those 
interviews. Table 12 provides each concept's name and a description of reasoning that fell under that concept category. Following Tables 12 and 13, I will go into more detail concerning the ways that Gwen reasoned about instructional practices and associated these practices with her V4MI. I will provide examples of each category of reasoning as evidenced by interview transcript. These examples were chosen as straightforward presentations of the connection between instructional practice and reasoning. Specifically, Gwen's description of her reasoning for a certain instructional practice in these examples was explicit without straying to another topic before returning to draw a connection between reasoning and practice.

Table 12

Gwen's Reasoning for Specifying Instructional Practices Concept Name Examples of Reasoning

Cultivating Learner Qualities

Goals for Learning of Mathematics
- wanted to build students' confidence

- aimed to engage students

- hoped to build student independence from teacher

- hoped to build connections between content

- wanted to foster higher-level content understanding

To address the first and second research questions, I will provide a description of the categories of Gwen's reasoning about specifying instructional practices and explore when, how, and with what consequences each category emerged. Results reflect the interviews in which the category emerged, the consistencies in the language used by Gwen when discussing the category, and Gwen's account of that category leading to instructional practices that aligned or did not align with ideal instructional practices described in her V4MI. Table 13 below delineates answers to the questions chosen to place meaning on the categories conceptualized using CCA. 
Table 13

Understanding Gwen's Categories of Reasoning about Instructional Practices

\begin{tabular}{|c|c|c|c|c|c|}
\hline \multirow[t]{2}{*}{ Category } & \multicolumn{3}{|c|}{$\begin{array}{l}\text { When Category Occurred } \\
\text { (Type of Interview) }\end{array}$} & \multirow{2}{*}{$\begin{array}{l}\text { How Category } \\
\text { Occurred (Focus of } \\
\text { Language Used) }\end{array}$} & \multirow{2}{*}{$\begin{array}{l}\text { Consequences of } \\
\text { Category Occurring } \\
\text { (Did Resulting } \\
\text { Instructional Practice } \\
\text { Align with V4MI?) }\end{array}$} \\
\hline & initial & $\begin{array}{l}\text { pre- } \\
\text { lesson }\end{array}$ & $\begin{array}{l}\text { post- } \\
\text { lesson }\end{array}$ & & \\
\hline $\begin{array}{l}\text { Cultivating } \\
\text { Learner } \\
\text { Qualities }\end{array}$ & 4 & 2 & 5 & $\begin{array}{l}\text { student actions and } \\
\text { student's past } \\
\text { experiences or } \\
\text { behaviors }\end{array}$ & $\begin{array}{l}\text { sometimes aligned } \\
\text { with and sometimes } \\
\text { did not align with } \\
\text { V4MI }\end{array}$ \\
\hline $\begin{array}{l}\text { Goals for } \\
\text { Learning of } \\
\text { Mathematics }\end{array}$ & & 2 & 4 & $\begin{array}{l}\text { student actions and } \\
\text { students' past } \\
\text { behaviors and } \\
\text { experiences }\end{array}$ & $\begin{array}{l}\text { sometimes aligned } \\
\text { with and sometimes } \\
\text { did not align with } \\
\text { V4MI }\end{array}$ \\
\hline
\end{tabular}

Cultivating Learner Qualities. Gwen discussed her hopes for cultivating learner qualities as reasoning for instructional practices four times in her initial interview, two times in her pre-lesson interview, and five times in her post-lesson interview. She expressed that she wanted to build students' confidence, aimed to increase students' engagement in learning activities, and hoped to move students toward independence from relying on the teacher. Gwen connected this reasoning to the following instructional practices: incorporating a variety of cooperative learning strategies that she had learned from Kagan- and AVID-based trainings (e.g., the speed math dating activity that Gwen chose for the lesson she described in her pre-lesson and post-lesson interviews), fostering an environment in which students formulate questions that allow them to compare and contrast topics and actively seek understanding, and using a pointbased grading system to evaluate student participation in class activities.

As a note, Kagan and AVID are organizations that provide professional development in order to guide teachers in using specific instructional strategies. Kagan-centered tasks in 
mathematics often begin with exploratory exercises that allow students to use inductive reasoning to discover new mathematical concepts and vocabulary followed with "cooperative learning activities designed for students to process" (Bride, 2007, p. v) material. AVID (2019) stated that their professional development helps teachers "design learning opportunities that challenge students to think critically, ask questions, and collaborate to create solutions" (para. 4). When discussing cultivating learner qualities, Gwen's language focused on student actions, past behaviors, and experiences. She reflected that some instructional practices tied to cultivating learner qualities aligned with her V4MI and some did not.

When I asked Gwen what she would look for in a classroom to know if the mathematics instruction aligned with her V4MI, she said:

I would look for the cooperative learning strategies. So, are they using Kagan? Are they using AVID? Are they using higher-level thinking? How are they engaging them? I would be looking for that. I would be looking for the level of engagement of the students. Like how much they actually want or desire to learn what they're doing, or are they just doing it because they're told to?

This statement highlighted Gwen's connection of activities that incorporated strategies, such as Kagan and AVID strategies, to the level of student engagement. I wanted to know more about what Gwen meant when she said, "engagement of the students." The following exchange further details the actions that Gwen would hope to see students taking at her envisioned level of engagement:

Interviewer: And when you say levels of engagement for the students, how would you see that? What would you see that would tell you that they are doing your ideal level of engagement? 
Gwen: How on task they are. What kinds of questions are they asking? If they're taking it to the next level by comparing and contrasting to something else. Making their own questions, like practice questions. Like, "Okay, if I did it like this, would this happen again?" or "How could I apply it to something else?” I would be looking for those kinds of questions. Or even for them just actively seeking understanding. To say, "How did you get this? Like, I got to this point, how did you get it here? Or where do I go from here?"

In addition to engagement, Gwen discussed her desire to foster confidence in students as they do mathematics. In her pre-lesson interview, she described to me the speed math dating game that would comprise the second half of her lesson:

Gwen: What they'll be doing is the speed math dating game, where one will be facing another one. And then, one side of their table will be explaining their problem while the other one is listening and writing their problem down. Then I will ring, um, I don't have a gong like they would normally do. But for speed math dating, I use my wind chimes. So, when they ring, they know for the other side of the room to get up and move and switch chairs. And then we will repeat. They keep doing this until we are about halfway through. Then we'll flip it where the other side of the table has now become the student, so the other side of the table gets practice as well.

Interviewer: What do you hope students will be able to do as a result?

Gwen: I hope that they will be able to not only basically attempt the problem but to actually have more confidence in solving and to be able to get to a higher level of understanding of why they're doing what they're doing. 
In this exchange, Gwen described the speed dating math as an activity that she hoped would foster confidence in students as they gained practice explaining one problem several times to several peers.

There was a single instance when Gwen reflected that an instructional practice that she utilized in her chosen lesson to increase engagement did not align with her V4MI. She paused the lesson video to view a portion of the lesson when she stopped to mark down a point value on a clipboard and look at a student. At this point in the interview, we had the following exchange:

Gwen: So, as I said, the one student that was completely checked out. I see him, when he came back, he was really into it. He definitely did a lot better talking in groups, and realizing it was for credit as I came through and marking it down, actually started asking really good questions and explaining things. Especially when he knew he was being watched.

Interviewer: Is that part of your vision that you can use grading to-like you talked about how he knew if you did it, there were points involved - is it part of your vision that grading can be used for engagement?

Gwen: It is not part of my vision. I want students to do it because they desire to learn. However, realistically, some students' mindsets are, "If it's not for points, I'm not doing it."

I took this exchange to signify that Gwen reasoned about grading participation by stating that the practice increased student engagement; however, she recognized that this practice was not aligned with her V4MI. Throughout her interviews, Gwen reflected that she hoped students would be engaged in mathematical discussions as a result of grouping and activity styles. In the case of Gwen's reflection about grading for engagement, she did not discuss any alternative 
methods for increasing student engagement. It is possible that Gwen had not gained through colleague collaboration or professional development a repertoire of specific instructional practices meant to support student engagement. Conversely, Gwen may have had ideas alternative to grading but may have felt that constraints such as lesson topics or breadth of content limited her ability to explore different options for increasing student engagement.

Goals for Learning of Mathematics. In discussing her planned and executed lesson, Gwen reasoned about some instructional practices by citing her goals for students' learning of mathematics. She reasoned about goals for learning of mathematics two times in her pre-lesson interview and four times in her post-lesson interview. Specifically, Gwen focused on students' abilities to make connections between the chosen lesson and prior lessons and to pursue a higherlevel of understanding of the content. Instructional practices that Gwen tied to such reasoning included the following: voicing connections during the whole class mini lesson between order of operations and solving an equation that contains a radical symbol, discussing with students common misconceptions that occur when students do not follow order of operations rules, asking students to analyze and justify their steps for solving their equations during the speed math dating activity, and modeling for students the types of higher-level thinking questions she wanted them to ask each other during the speed math dating activity. When discussing goals for learning of mathematics, Gwen's language focused on student actions, past behaviors, and experiences. She reflected that some instructional practices tied to goals for learning of mathematics aligned with her V4MI and some did not.

During the pre-lesson interview, Gwen explained how she planned to begin her chosen lesson. She stated the following: 
So, I'll do a mini lesson with them real quick, just to really emphasize or re-emphasize PEMDAS and to point out that under the radical is actually parentheses, so to leave it alone. And they'll be connecting it to what they were doing on the quiz ... which is to solve the square root. So, what they're going to be doing then, after I do a couple model problems and discuss misconceptions just about why students try to do things under the radical and discuss with them as a whole group why that's wrong, they'll each have a problem to do.

In this statement, she revealed that she would be drawing connections between the process of solving an equation that contains a radical and the rules for order of operations. She voiced that she would highlight with students the importance of considering the value under the radical symbol as a single quantity. Gwen hoped that students would connect the chosen lesson to a prior lesson in which they had simplified square root values such as $\sqrt{4+4}$ (as evidenced by my field notes). The connections that Gwen hoped students would make due to the instructional practices that she planned were goals for the students' learning of mathematics.

During the post-lesson interview, Gwen chose to pause the lesson video during the speed dating activity to comment on several students' actions. As part of the activity, students had to explain their problems to each other. One example of Gwen's comments on this portion of the video evidenced her satisfaction that the listening student was seeking understanding his partner's problem. Gwen stated, “That's really cool. They didn't even know you were videotaping them. She's explaining and he's seeking understanding." When commenting on another student pair's interaction, Gwen noticed that the speaking student was understanding his own work through explaining it to his partner. Gwen stated, "Yeah, look at that. Isn't it awesome? Not only is he actually explaining it because I am making him. But he is actually 
smiling and getting it and enjoying it." I took these comments to mean that Gwen was pleased with students' learning of the mathematics content, and this learning resulted from the speed dating math game and students' practices of explaining their process for solving radical equations.

Also, during Gwen's post-lesson interview, she commented on the questions that she was asking students in order to get them to a higher level of thinking about the mathematics:

Gwen: I do want them to start using the words of, "First, I ... Then, I did this because" or "I did this in this problem." Then the student should ideally be asking, "Well, why didn't you do it here?" I went around and asked those things, but I didn't hear them saying, "Well, why is it different in this problem?" I did in my sixth hour, but I wasn't hearing it in fifth hour. So, I would like to get them to that higher level. So that part of my vision, I guess I should add, was not met as much as I want.

Interviewer: So, let me make sure I am understanding what you said. You kind of wish that the questions you were asking to push students to think higher-level, they were asking each other instead?

Gwen: Yes.

Though Gwen was asking the students questions about their work, she had hoped that the students would take over for her and ask the same questions to each other. Thus, this instance demonstrated an instructional practice tied to goals for learning of mathematics that did not align with Gwen's V4MI. As with Gwen's only other instance of misalignment between V4MI and practice, she seemed to lament that students had not reached the level of engagement that she deemed ideal. Both of these misalignments indicated that Gwen strived for a level of student- 
centered instruction that had not yet been attained. So, although she may have perceived her instructional practices as not aligned with her V4MI in this instance, it may also be the case that her practice of modeling what she wanted to see was aligned with her V4MI; however, students might have not yet demonstrated the collaboration skills Gwen desired to see in response.

\section{Explicit Mention of V4MI and CCSSM}

When reflecting on her lesson in the post-lesson interview, Gwen reasoned about instructional practices by explicitly referring to her vision in one instance.

Part of my vision is for them to take ownership... They really took initiative and started explaining things in detail of how they were doing it and why they were doing it and helping other students. And I like that they were continuing to go onto other problems instead of just staying on their own problem. When I first heard of this activity, I think that was the focus. Become confident in one problem and then explain it and practice your vocabulary. And now mastery, the higher-level thinking, that justification of your problems. But they were actually able to get the confidence and then take it to the next level which I think is very much part of my vision.

In reference to the CCSSM, Gwen was the only teacher to explicitly mention standards in her initial interview and her pre-lesson interview. She stated that part of her V4MI was that the "standards are actually matching with your teaching." She did not go into further detail in reference to that statement. During her pre-lesson interview, she began her description of the lesson by referring to the Common Core content standard that she planned to address. Following is the first few lines of Gwen's pre-lesson interview. I refer to myself as the Interviewer. 
Interviewer: Can you tell me about your lesson?

Gwen: So, the students will be learning for their solving standard, AREI.A.1, how to solve a radical equation.

After the completion of all three interviews, I emailed all four teachers and asked them to reply with any Common Core content standards or SMPs that they had intended to target with their chosen lesson. Gwen replied to confirm AREI.A.1 was the content standard targeted by her lesson. Additionally, at the time of the email, she replied that her chosen lesson targeted all eight SMPs.

\section{Themes in Teachers' Reasoning About Instructional Practices and Contexts Surrounding Those Categories}

After summarizing each case study teacher's reasoning about ideal, planned, and enacted instructional practices, I considered categories of reasoning that emerged as thematic among the case study teachers as a collective group. In doing so, I hoped to gain an understanding of categories of reasoning that more than one teacher drew on when discussing instructional practices. Here, I will present six conceptual categories of reasoning that appeared thematic in more than one teacher's strand of interviews. Some concept names have been modified from the concept names previously used to encompasses elements of individual teachers' reasoning that fell into similar categories among the four teachers. For this reason, along with concept names and definitions, Table 14 incorporates columns describing specific descriptions of the forms of reasoning that were included and excluded from the categories. 
Table 14

Themes in Teachers' Reasoning About Specifying Instructional Practices

\begin{tabular}{|c|c|c|c|}
\hline $\begin{array}{l}\text { Concept } \\
\text { Name }\end{array}$ & Concept Definition & Concept Includes & $\begin{array}{l}\text { Concept } \\
\text { Excludes }\end{array}$ \\
\hline $\begin{array}{l}\text { Use of Prior } \\
\text { Knowledge }\end{array}$ & $\begin{array}{l}\text { decision was made with } \\
\text { respect to students' prior } \\
\text { knowledge }(\mathrm{PK})\end{array}$ & $\begin{array}{l}\text { building missing PK; } \\
\text { creating opportunities for } \\
\text { students to share PK; } \\
\text { encouraging students to } \\
\text { build on others' PK; } \\
\text { acknowledging limitations } \\
\text { due to PK }\end{array}$ & $\begin{array}{l}\text { teachers' } \\
\text { choices due to } \\
\text { their own PK } \\
\text { or lack of PK }\end{array}$ \\
\hline $\begin{array}{l}\text { Building } \\
\text { Conceptual } \\
\text { Knowledge }\end{array}$ & $\begin{array}{l}\text { decision was made with the } \\
\text { general reasoning of "building } \\
\text { a deeper understanding" or } \\
\text { with the goal of connecting a } \\
\text { specific instance to a broader } \\
\text { concept }\end{array}$ & $\begin{array}{l}\text { teachers stating that they } \\
\text { want to build a deeper } \\
\text { understanding; specific } \\
\text { examples of conceptual } \\
\text { understanding such as } \\
\text { connecting } 2(1+.15)^{3} \text { to } \\
\text { the concept of exponential } \\
\text { growth. }\end{array}$ & \\
\hline $\begin{array}{l}\text { External } \\
\text { Sources of } \\
\text { Influence }\end{array}$ & $\begin{array}{l}\text { decision was made based on } \\
\text { constraints or guidance } \\
\text { perceived from an external } \\
\text { source of influence }\end{array}$ & $\begin{array}{l}\text { building administration } \\
\text { goals; parental feedback; } \\
\text { other teachers' guidance; } \\
\text { policies or actions mandated } \\
\text { by district or state }\end{array}$ & $\begin{array}{l}\text { personal } \\
\text { beliefs, } \\
\text { personal } \\
\text { knowledge }\end{array}$ \\
\hline $\begin{array}{l}\text { Establishing } \\
\text { Classroom } \\
\text { Culture }\end{array}$ & $\begin{array}{l}\text { decision was made to foster } \\
\text { certain qualities within the } \\
\text { community of the classroom }\end{array}$ & $\begin{array}{l}\text { fostering characteristics in } \\
\text { the classroom group as a } \\
\text { whole (e.g., collaboration, } \\
\text { respect); making a behavior } \\
\text { a well-known classroom } \\
\text { expectation; framing } \\
\text { students' perceptions of } \\
\text { teacher/student and } \\
\text { student/student relationships }\end{array}$ & $\begin{array}{l}\text { goals meant } \\
\text { for a select few } \\
\text { students (e.g., } \\
\text { enacting a } \\
\text { practice in } \\
\text { order to } \\
\text { engage off- } \\
\text { task students) }\end{array}$ \\
\hline
\end{tabular}

(Table Continues) 
Table 14 cont'd.

\begin{tabular}{|c|c|c|c|}
\hline $\begin{array}{l}\text { Concept } \\
\text { Name }\end{array}$ & Concept Definition & Concept Includes & $\begin{array}{l}\text { Concept } \\
\text { Excludes }\end{array}$ \\
\hline $\begin{array}{l}\text { Cultivating } \\
\text { Learner } \\
\text { Qualities }\end{array}$ & $\begin{array}{l}\text { decision was made to } \\
\text { encourage a quality that will } \\
\text { help students be more } \\
\text { effective learners in any } \\
\text { content area, students will vary } \\
\text { in their current display of these } \\
\text { qualities }\end{array}$ & $\begin{array}{l}\text { qualities of confidence, } \\
\text { engagement, perseverance, } \\
\text { and independence from the } \\
\text { teacher }\end{array}$ & $\begin{array}{l}\text { practices that } \\
\text { are } \\
\text { mathematics- } \\
\text { specific }\end{array}$ \\
\hline $\begin{array}{l}\text { Cultivating } \\
\text { Mathematics } \\
\text { Learner } \\
\text { Practices }\end{array}$ & $\begin{array}{l}\text { decision was made to improve } \\
\text { a practice that will help } \\
\text { students be more effective } \\
\text { mathematicians }\end{array}$ & $\begin{array}{l}\text { examples of such practices } \\
\text { include interpreting others' } \\
\text { written mathematics work, } \\
\text { finding errors in one's own } \\
\text { mathematics, making } \\
\text { explicit connections } \\
\text { between the mathematics } \\
\text { content of various lesson, } \\
\text { using mathematics } \\
\text { vocabulary, engaging in } \\
\text { mathematics dialogue }\end{array}$ & $\begin{array}{l}\text { learner } \\
\text { qualities or } \\
\text { skills void of } \\
\text { mathematics- } \\
\text { specific } \\
\text { description }\end{array}$ \\
\hline
\end{tabular}

Results in Table 15 reflect the interviews in which the category emerged, the consistencies in the language used by the teachers when discussing the category, and teachers' accounts of that category leading to instructional practices that aligned or did not align with ideal instructional practices described in their V4MIs. Table 15 below delineates answers to the questions chosen to place meaning on the categories conceptualized using CCA. In order to be included in Table 15, the results were consistent among all teachers that utilized that category of reasoning. For example, the category of Prior Knowledge encompasses reasoning that both Simon and Marta voiced in all three of their interviews. Further, both Simon and Marta used language focused on student actions, past experiences, and behaviors when reasoning about PK. If the contexts in which a category emerged were not consistent among all teachers that reasoned 
in that way, that portion of the table is left blank. For example, in the category of Prior

Knowledge, Simon and Marta did not both reflect the same alignment of resulting instructional practices with their V4MIs; therefore, the column dedicated to the consequences of the category occurring is left blank.

Table 15

Understanding Themes in Teachers' Reasoning About Instructional Practices

\begin{tabular}{|c|c|c|c|c|}
\hline Category & Teachers & $\begin{array}{l}\text { When Category } \\
\text { Occurred (Type of } \\
\text { Interview) }\end{array}$ & $\begin{array}{l}\text { How Category } \\
\text { Occurred (Focus } \\
\text { of Language } \\
\text { Used) }\end{array}$ & $\begin{array}{l}\text { Consequences of } \\
\text { Category Occurring } \\
\text { (Did Resulting } \\
\text { Instructional } \\
\text { Practice Align with } \\
\text { V4MI?) }\end{array}$ \\
\hline $\begin{array}{l}\text { Prior } \\
\text { Knowledge }\end{array}$ & $\begin{array}{l}\text { Simon } \\
\text { Marta }\end{array}$ & $\begin{array}{l}\text { initial } \\
\text { pre-lesson } \\
\text { post-lesson }\end{array}$ & $\begin{array}{l}\text { student actions } \\
\text { and student's past } \\
\text { experiences or } \\
\text { behaviors }\end{array}$ & $\begin{array}{l}\text { sometimes aligned } \\
\text { and sometimes did } \\
\text { not align with } \\
\text { V4MI }\end{array}$ \\
\hline $\begin{array}{l}\text { Building } \\
\text { Conceptual } \\
\text { Knowledge }\end{array}$ & $\begin{array}{l}\text { Simon } \\
\text { Marta } \\
\text { Gwen }\end{array}$ & $\begin{array}{l}\text { initial } \\
\text { pre-lesson } \\
\text { post-lesson }\end{array}$ & & \\
\hline $\begin{array}{l}\text { External } \\
\text { Sources of } \\
\text { Influence }\end{array}$ & $\begin{array}{l}\text { Simon } \\
\text { Paul } \\
\text { Marta }\end{array}$ & $\begin{array}{l}\text { initial } \\
\text { post-lesson }\end{array}$ & $\begin{array}{l}\text { teacher actions } \\
\text { and teachers' past } \\
\text { behaviors and } \\
\text { experiences }\end{array}$ & \\
\hline $\begin{array}{l}\text { Establishing } \\
\text { Classroom } \\
\text { Culture }\end{array}$ & $\begin{array}{l}\text { Simon } \\
\text { Paul }\end{array}$ & $\begin{array}{l}\text { initial } \\
\text { post-lesson }\end{array}$ & & aligned with V4MI \\
\hline $\begin{array}{l}\text { Cultivating } \\
\text { General } \\
\text { Learner } \\
\text { Qualities }\end{array}$ & $\begin{array}{l}\text { Simon } \\
\text { Paul } \\
\text { Gwen }\end{array}$ & $\begin{array}{l}\text { initial } \\
\text { pre-lesson } \\
\text { post-lesson }\end{array}$ & $\begin{array}{l}\text { student actions } \\
\text { and students' past } \\
\text { behaviors and } \\
\text { experiences }\end{array}$ & $\begin{array}{l}\text { sometimes aligned } \\
\text { and sometimes did } \\
\text { not align with } \\
\text { V4MI }\end{array}$ \\
\hline $\begin{array}{l}\text { Cultivating } \\
\text { Mathematics } \\
\text { Learner } \\
\text { Practices }\end{array}$ & $\begin{array}{l}\text { Simon } \\
\text { Marta } \\
\text { Gwen }\end{array}$ & $\begin{array}{l}\text { initial } \\
\text { pre-lesson } \\
\text { post-lesson }\end{array}$ & $\begin{array}{l}\text { student actions } \\
\text { and students' past } \\
\text { behaviors and } \\
\text { experiences }\end{array}$ & \\
\hline
\end{tabular}




\section{Prior Knowledge}

Both Simon and Marta used reasoning about prior knowledge to support their choices in instructional practices. Both teachers made mention of prior knowledge as a factor in their instructional decisions during the initial, pre-lesson, and post-lesson interviews. Altogether, Simon and Marta used prior knowledge as reasoning for instructional practices 10 times.

In Simon's results, I included reasoning about prior knowledge under the conceptual category of Goals for Learning of Mathematics. However, his specific mention of prior knowledge reflected goals similar to Marta's individual conceptual category of Prior Knowledge. Both Simon's and Marta's language reflected that they felt students were limited by their prior knowledge. For example, in Simon's pre-lesson interview, he stated:

According to the Common Core standards, it is mastered in the seventh and eighth grade perimeter, area, surface area, and volume. And I am finding to my students, largely those words are all the same. They don't have a clear understanding of the difference between.

This statement, along with others made by Simon, evidenced that Simon reasoned about the instructional practice of choosing remedial topics for lessons because of lacking prior knowledge. Similar to this lamentation, Marta stated that "because of their language delays, so often because of their hearing loss, they miss a lot of [understanding beyond just formulas]." She discussed her choice to teach in a straightforward manner and stated that she asks herself, "So, how can I still fill in all of the gaps that they need, things that they've missed but still let them explore and think about it themselves and why that is the case?" This misalignment of V4MI and practice seemed to parallel that of Simon's misalignment in the category of Goals for Learning of Mathematics. Interestingly, both Simon and Marta compromised their ideal vision for instruction to allow for and address student deficits that might be either real or perceived. 
In contrast to the instances when Simon and Marta reasoned about students' lack of prior knowledge, Marta also reasoned about wanting to create opportunities for students to demonstrate PK and hoping that students would build on each other's PK during class discussions. In these instances, unlike Simon, Marta connected reasoning about PK to instructional practices that aligned with her V4MI.

\section{Building Conceptual Knowledge}

Simon, Marta, and Gwen reasoned about instructional practices by discussing their hopes to build students' conceptual knowledge. Included in this category of reasoning were both mentions of the general goal of building a deeper understanding of mathematics material and teachers' specific examples of deeper conceptual understandings they targeted in their chosen lessons. Reasoning about building conceptual knowledge occurred 12 times when considering all three teachers' reasoning collectively. These teachers were similar in their use of this line of reasoning in that it occurred in all three stages of interviewing (i.e., initial, pre-lesson, and postlesson interviews). However, the teachers' ideas about what constituted a deeper conceptual understanding and the instructional strategies they tied to this reasoning varied based on the teacher and their lesson description.

Both Simon and Marta provided specific examples of mathematics content when describing a deeper conceptual understanding that they hoped their students might achieve. For example, Simon hoped that his students would make connections among volume formulas for various types of prisms: "And see, with that, that's the same thing I tried to do with looking at the reference [sheet]. It's all about that base. Because every one of your formulas for volume, I emphasize it's about that base. And then many of them saw that they're really not a bunch of different formulas. It's one formula.” Marta also related reasoning about a deeper conceptual 
understanding to a specific topic (i.e., perimeter). In her pre-lesson interview, Marta reasoned about developing a deeper conceptual understanding for the process of finding perimeter: "I am doing a piece of it where they do a problem, and they have to talk with their peers about how they solved it and why they did the steps that they did, to get that deeper understanding."

Though Gwen also reasoned about her students developing a deeper conceptual understanding of the material, her reasoning in this category was not specific to any mathematics content. Unlike Simon and Marta, Gwen spoke about gaining a deeper conceptual understanding of mathematics in general and broad terms. As an example, she suggested that cooperative learning strategies and opportunities for students to interact with their notes were important to get students to a "deeper level of understanding."

Though Simon, Marta, and Gwen reasoned about building a deeper conceptual understanding, they did not align in their use of strictly teacher-based or student-based language. They also did not align with regards to their reflection about instructional practices related to building conceptual understanding as being in support of or at odds with their V4MIs.

\section{External Sources of Influence}

Simon, Paul, and Marta identified external sources of influence as a reason for carrying out some instructional practices. Collectively, they used this reasoning 18 times throughout their interviews. All three teachers cited this form of reasoning in their initial and post-lesson interviews, meaning they did not reason about external sources of influence when discussing their planned lesson in the pre-lesson interview. Additionally, all three teachers utilized language that focused on teacher actions, past behaviors, and past experiences when reasoning about external sources of influence. In their individual results, Simon and Paul's reasoning of this type was categorized as External Sources of Influence. However, Marta's reasoning about external 
sources of influence was categorized individually as Other Mathematics Teachers' Classes in her individual results, as Marta only reasoned about her attention to what other mathematics teachers were doing in their classrooms as an external source of influence.

Both Simon and Paul discussed the district grading policy as being a reason for their grading practices. They seemed to disfavor the policy but felt compelled to follow the guidelines set forth by the district. Simon evidenced disfavor of the grading policy when stating, "Is it the standard of excellence when we were giving them $40 \%$ for nothing and $50 \%$ for a name? ... It's the district level." Similarly, Paul reflected in his initial interview that the current district grading policy did not align with his V4MI. He even expressed a desire to change the current policy during his initial interview: "Well, I would change the grading. Like, they would still get grades, but maybe I would change the weight on the homework and classwork. Rather than just 15\%, I would want more." I interpreted Simon's and Paul's statements to mean that they did not agree with the district grading policy; however, they chose to follow the grading guidelines set forth by the district.

Counter to the misalignment of the district grading policy with Simon's and Paul's V4Mis, Simon, Paul, and Marta reasoned about other education professionals as being positive external source of influence. Simon discussed the principal as a reason that he tries his best each day and worked for years to teach at his current school. In his initial interview, Simon said, "We got a principal that supports us, that respects us. And I think you have to have that or you're not going to walk into that classroom everyday doing your best, but it's expected." Similar to these positive comments, Paul reasoned about his efforts to try new things in the classroom and constantly improve upon his instruction by citing the principal as an external source of influence. In his initial interview, Paul stated, "[The principal] is great, you know, is awesome. As long as 
you're doing what you're supposed to be, you can kind of have control over it. . Try new things. Failure is a good thing as long as you keep trying to make it better." Marta also reasoned about colleagues that were a positive influence on her classroom instruction, but instead of the building principal, Marta discussed other mathematics teachers. She explained that she tried to incorporate the types of activities that other mathematics teachers were doing in the following excerpt from her initial interview: "I think about how, what can I take of [other teachers'] lessons that I could make more simple or into a smaller group? Because I want to do more of those student-led and the exploration-type activities. .." When looking to colleagues for support and ideas, all three teachers evidenced that practices connected to this line of reasoning were aligned with their V4Mis.

\section{Establishing Classroom Culture}

Simon and Paul reasoned about instructional practices by discussing their hopes to establish classroom culture. They discussed fostering characteristics such as collaboration and respect within the community of their classroom. Establishing classroom culture was a category of reasoning that Simon and Paul collectively cited 12 times throughout their interviews. Both Simon and Paul mentioned establishing classroom culture during their initial and post-lesson interviews but not during their pre-lesson interviews. Additionally, the instructional practices that Simon and Paul tied to establishing classroom culture were aligned with their V4MIs.

Both Simon and Paul hoped to achieve a classroom environment that allowed for discussion and collaboration among teacher and students. They also discussed respect and teamwork as important to their classroom culture. As evidence of the classroom culture that Simon hoped to establish, he said the following in his initial interview: "I always tell the kids, 'I'm here to work with you. I'm not the opposing team here.' I think that's one of the biggest 
things that makes me successful." Paul voiced similar sentiments when discussing the need for two-way communication in his classroom. When I asked Paul in his initial interview why twoway communication was important to mathematics instruction, he said, "So that, to me, is based on respect. I think if you can have open communication with someone, there's a foundation of respect between that teacher and student."

Paul differed from Simon in his description of the classroom culture he hoped to approach by stating that some instructional practices were aimed at fostering a classroom community with more in common than just mathematics. He emphasized discussing students' lives outside of the mathematics classroom as a way for students and teacher to build relationships that promoted a positive classroom culture.

\section{Cultivating General Learner Qualities}

Simon, Paul, Gwen reasoned about specifying instructional practices by discussing their hopes to cultivate learner qualities. Reasoning of this type indicated that instructional practices were aimed at encouraging student qualities that would make them more effective learners in any content area. Such qualities included confidence, engagement, perseverance, and independence from the teacher. In all, Simon, Paul, and Gwen presented reasoning that was categorized as cultivating general learner qualities 26 times throughout their initial, pre-lesson, and post-lesson interviews. All three teachers used language in this category of reasoning that reflected their attention to student actions, past behaviors, and past experiences.

When reasoning about cultivating learner qualities, Simon, Paul, and Marta seemed to focus on real or perceived student deficits. For example, in his post lesson interview, Simon stated that he has noticed many students are unable to identify where they went wrong when completing a mathematics problem. To address this, Simon discussed instructional practices such 
as whole-class discussions of the meaning of perseverance and encouraging students to reexamine their work in order to locate an error. Paul also discussed a struggle common among his students during his initial interview, "I think that right now students are used to having the teacher tell them everything, but a lot of the times what we're missing is the student ... and they don't have enough self-confidence that they can do something on their own." In order to increase students' independence and confidence, Paul suggested the instructional practice of student-led inquiry or discovery topics.

Like Simon and Paul, Gwen identified a struggle that she has regularly observed in her classes. She reflected in her post-lesson interview that she noticed a need to increase student engagement and participation during her chosen lesson. Unlike Simon and Paul, Gwen reflected that the instructional practice she chose was not ideal and therefore did not align with her V4MI. When Gwen was reflecting about the practice of circulating the room to assign points for participation, I asked her if that practice was part of her vision. She responded, "It is not part of my vision. I want students to do it because they desire to learn. However, realistically, some students' mindsets are, 'If it's not for points, I'm not doing it.." Though all three teachers reasoned about instructional practices meant to address real or perceived student deficits, Gwen stood out in that she did not find a way to reconcile her goals for cultivating engagement and participation with her V4MI.

\section{Cultivating Mathematics Learner Practices}

Simon, Marta, and Gwen discussed cultivating mathematics learner practices when reasoning about instructional practices. This category of reasoning differs from cultivating general learner qualities in that this type of reasoning reflected a hope of engaging students in practices that would benefit them specifically in mathematics. Such practices include interpreting 
written mathematics work, finding errors in their own student work, making explicit connections between the mathematics content of various lessons, using mathematics vocabulary, and engaging in mathematics dialogue. All three teachers reasoned about cultivating mathematics learner practices in all three stages of their interview strands (i.e., initial interview, pre-lesson interview, and post lesson interview). In sum, their reasoning fell into this category 15 times. Simon, Marta, and Gwen used language that centered around student actions, past behaviors, and past experiences when reasoning about cultivating mathematics learner practices.

Much of the reasoning of in this category occurred when the teachers were explaining their choices of instructional practices that required students to interact or speak with each other. For example, Simon hoped that students could use mathematics-specific vocabulary in context. During his post-lesson interview, he reflected about a time when he asked the students to respond to a question about finding arc length and sector area. He stated, "I was looking at: Could they put into words how to find arc length and how to find area of a sector using proper vocabulary of mathematics." Simon's focus in this instance was on students' responses to the teacher in a whole-group setting. This differed from Gwen and Marta in that their goals for cultivating mathematics learner practices relied heavily on the practice of student-to-student collaboration and discussion.

By implementing the math speed dating game, Gwen hoped that students could practice "explaining their problem while the other one is listening and writing their problem down." She voiced during her post-lesson interview that she hoped students would ask each other how to finish a problem if they got stuck and practice justifying the steps they took to reach their solutions. Marta reflected Gwen's sentiments when justifying the do-and-share portion of her lesson. She stated that "it also tied the whole language piece of them having to explain their 
process and use those words to each other instead of just to me." Both Gwen and Marta reasoned about practices that fostered discussion among students in order to cultivate mathematics learner practices. It is interesting to note that both Gwen and Marta reflected that the math speed dating game and do-and-share activity respectively were instructional practices that aligned with their V4MIs. Alternatively, Simon reflected that the student response after he posed a question did not align with his V4MI.

\section{Explicit Mention of V4MI and CCSSM Considered for the Collective Group of Case Study}

\section{Teachers}

Three of four teachers reasoned about instructional practices by explicitly stating that it was part of their vision or ideal classroom practice. Throughout his interviews, Simon did not state that he favored an instructional practice or chose an instructional practice because it was part of his vision or because he thought it was ideal classroom practice.

By comparison, in his post-lesson interview, Paul referred to his V4MI when discussing instructional practices more times than any of the three other case study teachers. When considering Paul's reference to his V4MI, it is interesting to note that he only once reflected a misalignment of practice and V4MI (i.e., enacting the district grading policy). Paul's heightened awareness — by comparison — of what he considers ideal mathematics instruction coincided with a heightened level of practice aligned with V4MI — again, by comparison to the other case study teachers. It is interesting to note that Marta discussed during her post-lesson interview that vision was informed her practice only one fewer time than Paul. However, Marta's misalignments of V4MI and practice related to student understandings and actions, whereas Paul's misalignment of V4MI and practice related to an administrative policy. In both instances, Marta and Paul made 
reference to constraints they were adjusting to that were put in place by someone other than themselves (i.e., students and administration).

Paul and Marta exceeded the other case study teachers in their reflection on V4MI aligning with practice by explicitly discussing their enaction of practice as a result of what they deemed ideal seven and six times respectively in their post-lesson interviews. In contrast, Gwen only mentioned her vision as part of choosing practice one time in her post-lesson interview, and Simon did not make such a mention at all. When considering themes in the four teachers' categories for reasoning, I noted that most misalignments of V4MI and practice occurred in instances when teachers reflected on constraints that they viewed as out of their control. Specifically, Simon and Paul noted a misalignment between their ideal practice and the district grading policy. Simon and Marta reasoned about students' lack of mathematical knowledge or vocabulary as altering their ideal instruction.

Of the four case study teachers, only two explicitly mentioned instructional standards. Even so, mention of standards was marginal and lacked detail. As a reminder, Simon attended to the fact that students had not achieved Common Core Standards that were targeted in lower grades. In her initial interview, Gwen briefly mentioned that standards should match teaching, but she did not go further to describe what she meant by that statement or to what standards she was referring. Gwen was the only teacher to explicitly name a Common Core content standard as part of her lesson planning during her pre-lesson interview. Thus, mathematics learning standards were only named three times within 12 interviews that were explicitly targeting teachers' descriptions of V4MIs and instructional practices within the context of Common Core. It should again be noted that during these interviews, I prompted teachers by explaining that I was interested in their visions for mathematics instruction that targeted the CCSSM. 


\section{Summary of Findings}

In the previous findings related to the four case study teachers individually and collectively, I organized information by category of reasoning. Within each category of reasoning, I described the type of reasoning that teachers evidenced that fell within the category and provided examples from interview transcripts. Within each category of reasoning, I described when, how, and with what consequences the category emerged. In the following summary of findings, I will provide an overview of each case study teachers' categories of reasoning with special attention to drawing out commonalities in the stages of interviews (i.e., initial, pre-lesson, and post-lesson) in which the categories emerged, the focus of the teachers' language (i.e., teacher-centered or student-centered) when discussing each category of reasoning, and teachers' reflection about the category of reasoning aligning, sometimes aligning, or not aligning with their V4MIs.

\section{Case Study Teachers' Reasoning Considered Collectively}

Collectively, teachers whose reasoning could be categorized as Building Conceptual Knowledge, Cultivating General Learner Qualities, or Cultivating Mathematics Learner Practices consistently presented these categories of reasoning in initial, pre-lesson, and post-lesson interviews. Teachers whose reasoning could be categorized collectively as External Sources of Influence or Establishing Classroom Culture only presented those categories of reasoning in initial and post-lesson interviews. Teachers consistently used student-centered language when reasoning was categorized as Use of Prior Knowledge, Cultivating General Learner Qualities, and Cultivating Mathematics Learner Practices. Teacher-centered language was consistent within the category of External Sources of Influence. Reasoning within the category of Cultivating General Learner Qualities was consistently tied to instructional practices that both aligned and 
did not align with V4MIs, and Establishing Classroom Culture was the only category of reasoning that was consistently used in conjunction with instructional practices named as aligning with V4MIs.

Three of the four teachers reasoned by stating an instructional practice was ideal, planned, or enacted because it was explicitly part of their vision or ideal classroom. It should be noted that all four teachers discussed practices aligning or misaligning with their V4MI after being prompted by me, the interviewer; however, the three teachers reasoning about a practice being part of their vision specifically noted that a practice was ideal, planned or enacted "because it was part of their vision." Two of the four teachers mentioned mathematics learning standards at any stage of interviewing. Only one teacher, Gwen, specifically identified a Common Core content standard during her pre-lesson interview. None of the teachers identified SMPs that they intended to or did target during their chosen lessons.

\section{Chapter IV Summary}

For this chapter, I presented a description of Simon, Paul, Marta, and Gwen as it related to their reasoning about specifying ideal, planned, and enacted instructional practices. I placed this reasoning into context of the interviews and V4MIs by describing when, how, and with what consequences the categories of reasoning occurred. Specifically, I detailed in what interviews the concepts emerged, whether the teachers' language was student-centered or teacher-centered, and if the related instructional practices aligned, sometimes aligned, or did not align with the teachers' V4MIs. I also described the teachers' specific mention of their V4MIs and the CCSSM in order to illuminate the connections between the teachers' reasoning, V4MIs, and the CCSSM. I also described concepts that emerged as thematic among case study teachers as they reasoned about specifying instructional practices. I provided context for these conceptual categories by 
reflecting on commonalities about when, how, and with what consequences the concepts emerged. In the final chapter, I will present a summary of the study, a discussion of the findings, limitations of the study, implications for teaching, and recommendations for future research. 


\section{CHAPTER V: CONCLUSIONS}

My experiences as a pre-service and in-service teacher during the initial adoption and first decade of the CCSSM has led me to ask how teachers might choose to address the standards after verbalizing and considering their personal visions for mathematics instruction. CCSSM has laid a framework for the content knowledge and expertise that teachers should seek to develop in their students but has explicitly stated that "schools and teachers will decide how best to help students reach the standards" (CCSSI, 2019a, para. 1). Smaller-scale mathematics education reform efforts have employed institutional visions in order to specify instructional practices that have the potential to achieve learning goals (e.g., Cobb \& Jackson, 2011). Thus, in this study I sought to understand what teachers attend to when specifying instructional practices aimed at achieving the goals of the CCSSM. In order to understand the role that V4MIs play in the process, I asked teachers to describe their visions of ideal classroom instruction.

In the previous chapters, I have laid the groundwork for understanding V4MIs and other factors that play a role in teachers' choices for instructional practices. I have also described how four case study teachers reasoned about ideal, planned, and enacted instructional practices and summarized the concepts that each teacher thematically discussed in their reasoning. I placed each teacher's reasoning concepts within the context of when, how, and with what consequences each concept arose by specifically considering the following; during which interviews (i.e., initial, pre-lesson, or post-lesson) categories of reasoning emerged, the focus of teachers' language (i.e., student-centered or teacher-centered), and if teachers evidenced that categories of reasoning aligned, sometimes aligned, or did not align with their V4MIs. Finally, I considered the case study teachers collectively and discussed reasoning that appeared thematic among the group. Following, I will summarize and discuss the findings of this study. I will also discuss the 
benefits and shortfalls of the methodology and bring to light limitations of the study, implications for large-scale reform, recommendations for future research, and closing thoughts.

\section{Summary of Findings}

During initial interviews, 10 secondary mathematics teachers detailed their V4MIs. In describing their visions for ideal mathematics instruction, the teachers varied in their focus on the role of the teacher, classroom discourse, and mathematical tasks — components of Munter's (2014) rubrics for assessing visions of high-quality mathematics instruction. Teachers also varied in the range of their V4MI—an aspect of vision constellations defined by Hammerness (1999) as how closely teachers view themselves as embodying their vision. I selected four focus teachers as case studies to serve as representatives of differing V4MIs. The four case study teachers were instructed to select a lesson that they felt would be representative of their V4MI, and they participated in interviews and observations in order to elaborate upon their planning, enacting, and reflecting surrounding those lessons that targeted standards found in the CCSSM.

I considered reasoning that teachers provided as they talked about choices for ideal instructional practices during their initial interview and also as they discussed instructional practices that they planned and carried out in their chosen lessons during their pre-lesson and post-lesson interviews. I found that collectively, case study teachers reasoned about specifying instructional practices by considering prior knowledge, building conceptual knowledge, attending to external sources of influence, establishing classroom culture, cultivating learner qualities, and cultivating mathematics learner practices. Interestingly, the case study teachers did not always believe that the instructional practices they planned or enacted were aligned with their V4MI; however, they felt that such instructional practices were necessary due to factors that 
seemed out of their control. These factors included district policies, students' real or perceived deficits, and students' levels of engagement and autonomy. Three of the four teachers reasoned by stating an instructional practice was ideal, planned, or enacted because it was explicitly part of their vision or ideal classroom. Two of the four teachers did not mention mathematics learning standards at any stage of interviewing. Only one teacher, Gwen, specifically identified a Common Core content standard during her pre-lesson interview. None of the teachers identified SMPs that they intended to or did target during their chosen lessons.

\section{Discussion of Findings}

In order to discuss the findings of this study, I will begin by interpreting the results through the lens of my theoretical framework. I will also discuss the generalized nature of teachers' descriptions of their V4MIs and how the nature of their descriptions might relate to their use of V4MIs in specifying planned and enacted instructional practices. Finally, I will consider teachers reasoning—or lack thereof-about their V4MI and the CCSSM.

\section{Reasoning About Instructional Practices Within the Framework of Cobb and Jackson's (2011) Theory of Action}

Large-scale mathematics education reform efforts have often seen success with the adoption of theories of action that are tailored to the goals of the reform effort (e.g., Anderson et al., 2014; Cobb \& Jackson, 2011). As a framework for the current study, I considered the premise of Cobb and Jackson's (2011) theory of action that an institutional vision motivates instructional practices that, when enacted, provide students the opportunity to achieve the learning goals. I acknowledged CCSSI's (2019a) intentional omission of a vision on the same national scale as the CCSSM and examined how individual teachers were wrestling with their own visions and specifying instructional practices aimed at achieving the goals of the CCSSM. I 
found that teachers reasoned about their instructional practice choices by considering several factors that sometimes aligned and sometimes did not align with their V4MI. Consistent with the related literature, teachers considered such things as other people's support and opinions (Clarke, 1997; Hammerness, 1999; Little, 1996; NCTM, 2014), administrative policies (Hammerness, 2004; Little, 1996), and standardized assessment (Dunlap et al., 2015; NCTM, 2014). Instead of a large-scale vision that explicitly laid out a set of instructional practices, it seemed that teachers looked to several factors to determine which instructional practices they thought were best-suited to achieve the goals of the lesson. Figure 6 provides a linear conceptualization of how teachers might reason in order to specify instructional practices when left to act based on their own visions and other constraints and influencing factors in their teaching settings. Reasoning concepts such as the one portrayed as reasoning concept A in Figure 6 sometimes aligned and sometimes did not align with teachers' V4MIs. To illustrate this point, Marta and Simon reasoned about students' prior knowledge when specifying instructional practices. In some instances, students' limited prior knowledge led Marta and Simon to choose instructional practices misaligned with their V4MIs (e.g., direct instruction.) In other cases, these teachers reflected that students' prior knowledge allowed them to draw upon what students already knew and thus enact instructional practices aligned with their V4MIs (e.g., asking students to verbalize what they already knew). Additionally, some reasoning concepts were directly labelled by teachers as being part of their V4MI. This situation is denoted in Figure 6 as reasoning concept B. Such a case occurred when Paul reasoned about establishing classroom culture. Paul spent a great deal of time describing the classroom culture of mutual respect that he hoped to create; when anticipating and reflecting upon his lesson, he noted that practices such as expressing interest in students' lives outside the classroom and normalizing mathematical mistakes directly 
aligned with his V4MI. There are not reasoning concepts completely separate from the V4MI in Figure 6. This is because there were no reasoning concepts that specified instructional practices only misaligned with a teacher's V4MI.

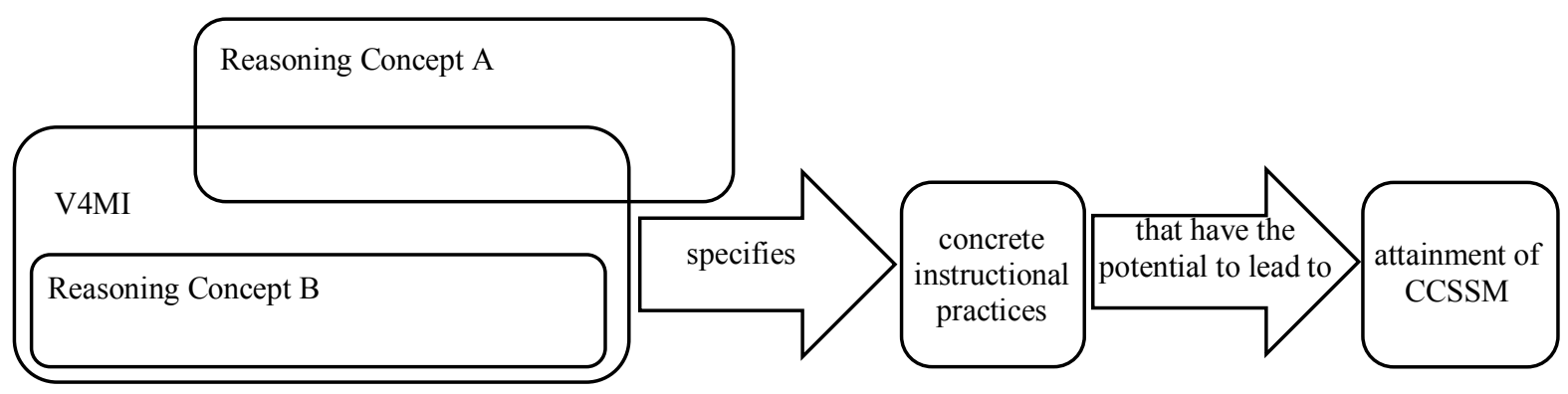

Figure 6. Individualized efforts in CCSSM reform: how teachers specified instructional practices.

Figure 7 illustrates how Simon reasoned about instructional practices when that reasoning was conceptualized using the structure from Figure 6. When Simon reasoned about personal experiences, external sources of influence, students' individualized needs, and goals for learning of mathematics, he reflected that reasoning and practice were sometimes aligned and sometimes not aligned with his V4MI. Reasoning about establishing classroom culture and assessment when specifying instructional practice was consistently aligned with Simon's V4MI.

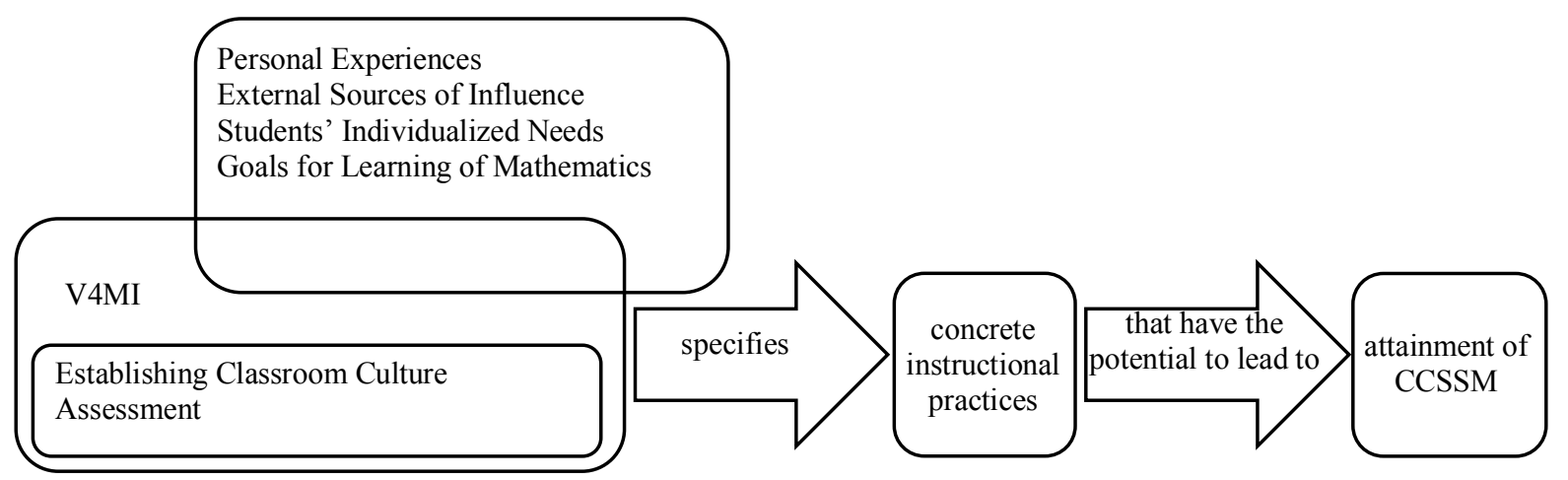

Figure 7. How Simon specified instructional practices. 
Figure 8 illustrates how Paul reasoned about instructional practices. When Paul reasoned about external sources of influence, he reflected that reasoning and practice were sometimes aligned and sometimes not aligned with his V4MI. Reasoning about cultivating learner qualities and establishing classroom culture when specifying instructional practice was consistently aligned with Paul's V4MI.

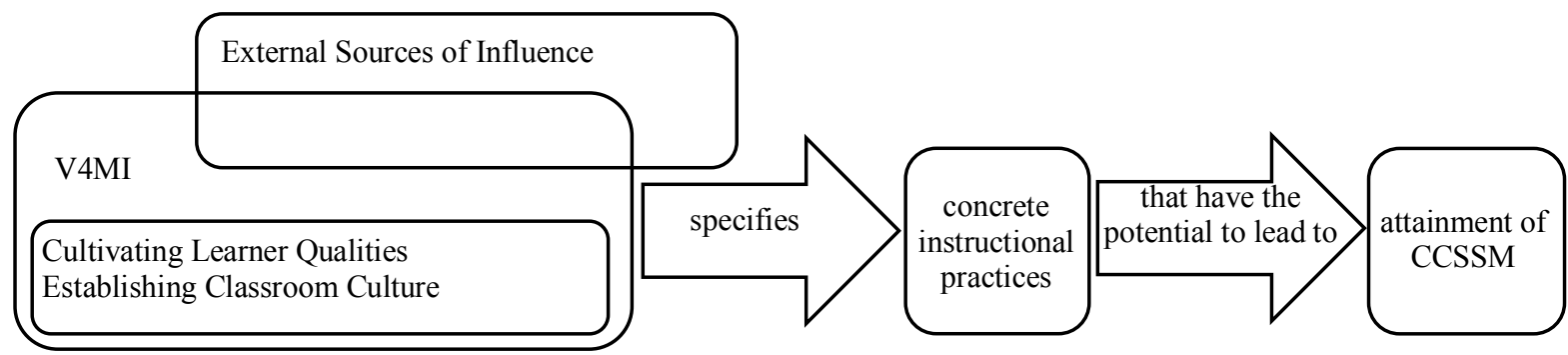

Figure 8. How Paul specified instructional practices.

Figure 9 illustrates how Marta reasoned about instructional practices. When Marta reasoned about prior knowledge and mathematics vocabulary, she reflected that reasoning and practice were sometimes aligned and sometimes not aligned with her V4MI. Reasoning about building conceptual knowledge and other mathematics teachers' classes when specifying instructional practice was consistently aligned with Marta’s V4MI.

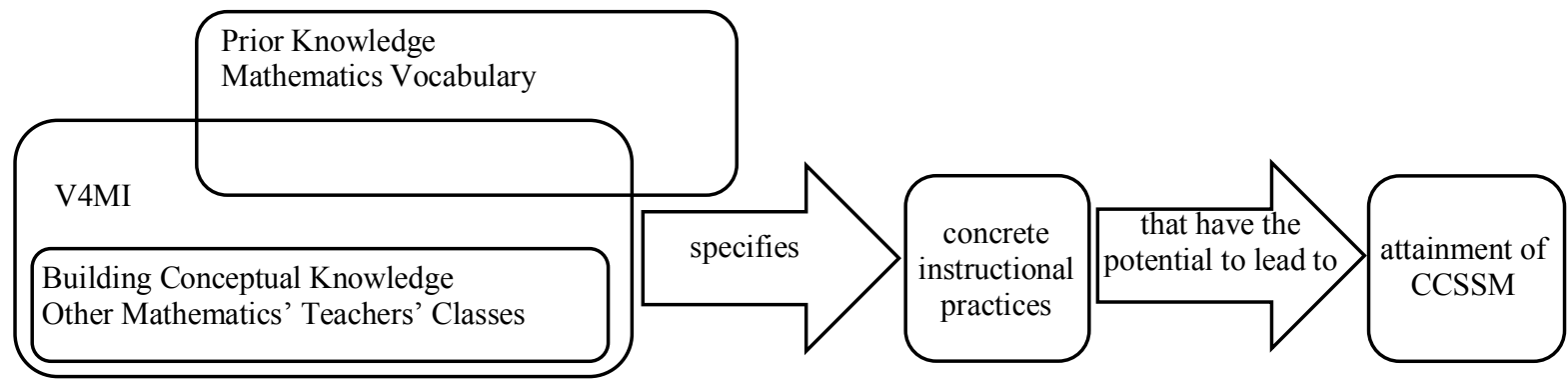

Figure 9. How Marta specified instructional practices. 
Figure 10 illustrates how Gwen reasoned about instructional practices. When Gwen reasoned about cultivating learner qualities and goals for learning of mathematics, she reflected that reasoning and practice were sometimes aligned and sometimes not aligned with her V4MI. Gwen did not reason in a way that was consistently aligned with her V4MI.

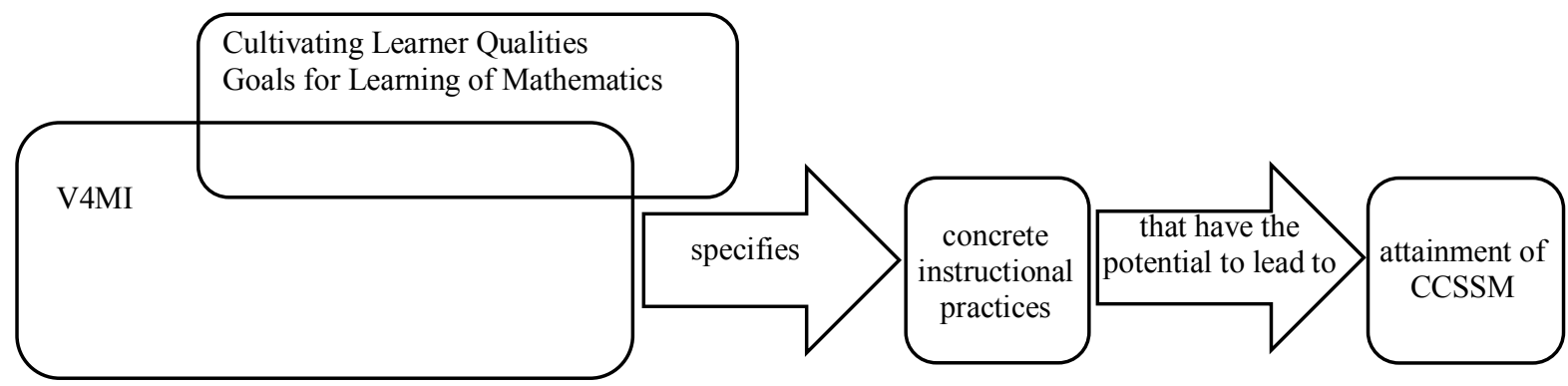

Figure 10. How Gwen specified instructional practices.

\section{Generalized Reasoning and Generalized V4MIs}

Inconsistent with Hammerness's (1999) findings that teachers' visions were detailed and specific, some concepts that shaped teachers' V4MIs and that were used as reasoning to specify instructional practices remained vague and brief. For example, on several occasions, Gwen, Marta, and Simon described their V4MI or reasoned about instructional practices by saying they wanted to build a "deeper understanding" of content. On several occasions, they did not relate their desire to help students develop deeper understanding to specific instructional practices or provide examples of what a deeper understanding might look like for students. Similarly, Marta spoke often about incorporating collaborative or exploration-type activities into her instruction, but she did not detail what such activities might look like. Though vague in some ways, the V4MIs that teachers described and the reasons they provided for instructional practices should not be discounted when considering how teachers operate individually within the context of CCSSM reform. Maxson \& Sindelar (1998) asserted that individual visions are credible 
representations of notions about how things should operate; therefore, it is possible that more could have been done to draw out these representations more precisely. Efforts to probe teachers' thinking about what they really mean by "deeper understanding" or "collaborative activity" might provide what Johnston (1992) described as an opportunity for valuable discussion about images of teaching translated into classroom reality. Perhaps by taking note of the findings by Maxson and Sindelar (1998) and Johnston (1992), administrators could encourage teachers to detail specific evidence of such pieces of their V4MI as what it means for students to gain a deeper understanding or engage in a collaborative activity. Such a professional development activity might provide teachers with a toolkit of specific practices that align with their V4MI.

\section{Teachers' Reasoning Explicitly about V4MIs and CCSSM}

Though efforts were made to direct teachers to attend to their V4MI and the CCSSM, it was surprising to find that one teacher did not reason at all about instructional practices by saying it was part of his V4MI and two teachers made no mention of considering or targeting goals of the CCSSM. During reflection on their chosen lessons, teachers were asked to point out instances in which instruction aligned or did not align with their V4MI. When they reasoned about these instances, specifically stating that something was done because it was part of their vision was rare. Instances when teachers reasoned about an instructional practice by stating that it was part of their vision often occurred when the teacher was discussing his or her own behavior. For example, Simon and Paul reflected on instructional practices meant to create a positive classroom culture in which the teacher is viewed as a teammate. Both teachers focused on their own language and interactions with students. Conversely, misalignment between instructional practice and V4MI often occurred when the teacher was reasoning about a real or

perceived student deficit or another factor out of the teacher's control. As an example of real or 
perceived student deficit, Simon and Marta lamented a lack of students' prior knowledge and thus reflected that the practices of remedial and direct instruction did not align with their V4MIs. To illustrate reasoning about a factor out of the teacher's control, Simon and Paul both disagreed with the district grading policy. Though it did not align with their V4MIs, both teachers maintained the practice of using the grading policy.

Hammerness (1999) stated the importance of using vision as a guidepost during reflection on practice and cited increased motivation and learning and a greater sense of agency as teachers worked toward their personal pictures of ideal classroom practice. A greater sense of agency could lead teachers to view real or perceived student deficits as something that is in the realm of the teacher's control. Intentional repetitiveness of the pre-lesson and post-lesson interview cycle with explicit direction to consider V4MIs might allow teachers to develop a greater sense of agency in specifying instructional practices when there is a real or perceived student deficiency or factors not under the teachers' control.

As for the very limited discussion of the CCSSM, Coburn (2003) warned that the CCSSM must be thoughtfully considered when developing instructional practices in support of the standards. It is possible that the case study teachers were considering CCSSM as a code name for generalized mathematics reform efforts and were therefore not naming the CCSSM specifically. If so, the teachers might have been relying on their understanding of content and practices of past reform efforts (Little, 1993). This could prove a danger to CCSSM implementation with fidelity, as the CCSSM has signaled a drastic departure from instructional practices that most teachers would consider typical in the past (Jackson, Gibbons, and Sharpe, 2017). As Coburn (2003) warned, simply adopting a reform effort does not equate to 
implementation or implementation with fidelity. Thus, the results of this study indicate a need for teachers to reason about the CCSSM specifically when considering instructional practices.

\section{Discussion of Methodology}

Because the chosen methodology was constructed to meet a goal that had not yet been specifically pursued in the related research, I reflected on the collection of methods I had employed for their usefulness and consistency in providing answers to the research questions. I considered each tool that allowed me to maintain an etic perspective (i.e., a theory of action, a framework for instructional practices, a framework for visions, and a framework for instructional goals) for both its benefits and shortcomings in allowing me to fully detail and analyze the reasoning for specifying instructional practices aimed at the goals of CCSSM while considering personal V4MIs. I attended to memos written during data analysis for clues to frustrations, difficulties, fruitful moments, and redirections of effort. I also considered the robustness of my answers to the research questions as clues to the usefulness of the employed methodology.

I designed the methodology in this study to elicit the data needed to understand how teachers, after making explicit their V4MI, reason about their choices for instructional practices in pursuit of the CCSSM. I was able to conceptualize teachers' V4MIs and instructional practices in a detailed and consistent manner because of attending to the conceptual frameworks presented by Dancy and Henderson (2007), Hammerness (2001), and Munter (2014). These frameworks also allowed me to maintain an etic perspective when moving to the CCA stage of data analysis.

By modeling CCA based on Boije's (2002) suggested iterations, I ensured consistency in analysis of interviews and moved from the scope of a single interview to themes emerging overall. I made choices about how to identify units of analysis and had to interpret statements 
about reasoning for instructional practice choices. As there was not a specific protocol for identifying reasoning, subjective choices had the potential to affect validity and consistency.

After creating conceptual categories for each teacher's sets of reasoning that appeared thematic, I chose to utilize questions suggested by Scott (2004) in order to make sense of the conceptual categories within the context of the study. Using the questions of when, how, and with what consequences the categories occurred, I found success placing a non-evaluative tone on the results that allowed me to understand the findings within the framework of concepts that guided choices of instructional practices aimed at achieving the goals of the CCSSM (i.e., the framework chosen adapted from the work of Cobb and Jackson [2011]).

I could have more consistently defined units of analysis throughout CCA if I had altered the interview questions used throughout data collection. After allowing for an open interview style at each stage, clarifying questions could have been beneficial. For example, in the initial interview participants described their V4MI. It would have been helpful to follow up with "You said your vision is that students would . Describe an instructional choice you would make to elicit that behavior in students. What is your reason for choosing that instructional practice?" In the planning and reflection interviews, I could have modeled follow-up questions that would allow me to explicitly confirm instructional practices, reasoning for the instructional practice, and an understanding of whether or not the practice aligns with a teacher's V4MI. Specifically, I could ask teachers the following: (1) What would/will/did you do? (2) Why did you do [specific instructional practice]? (3) Does [specific instructional practice] align with your V4MI? (4) Why or why not?

The methodology did not allow me to fully explore the implications for teachers' reasonings about specifying instructional practices. That is to say, I was only able to understand 
teachers' reasoning within the context of planning and enacting one lesson. It is possible that by following teachers through the process of planning and enacting more lessons, I would be able to observe a wider variety of reasoning related to different instructional practices or perhaps deepen my understanding of the already-established categories of reasoning as they relate to certain types of instructional practices. Further exploring and detailing the categories of reasoning that came to fruition in this study would move the current research past the already realized goal of establishing categories of reasoning that could be used in related research.

\section{Limitations of the Study}

In the current study, I set out to understand the nuances of teachers' reasoning about instructional practices aimed at achieving the goals of the CCSSM. Though case studies and the use of CCA allowed for an in-depth consideration of a phenomenon not specifically investigated in the past, I recognize that such a study has limitations.

First, only 10 teachers were considered as a sample for choosing representative case study teachers. Thus, a larger sample might have revealed groupings of V4MIs that were not represented by the four chosen teachers. Also, in regard to the participants, all teachers were selected from the same mathematics department. Though this accomplished the goal of understanding the variety in reasoning within a single environment, it has limited the understanding of the results. Results of the study might not be applicable to teachers at different levels (e.g., primary grade teachers, middle school teachers), locations (e.g., rural, suburban), or difference settings (e.g., with regard to school culture, with regard to student demographics).

Second, I was limited in my understanding of teachers' responses to interview questions. After analyzing transcripts, I realized that the questions I posted in interviews could have been more direct in targeting teachers' reasoning about instructional practices. If I had directly asked 
teachers why they specified a practice and if that practice aligned with their V4MI, it is possible that my interpretation of their reasoning into conceptual categories might have led to different results. Additionally, the results might be viewed in a different light if I had investigated the professional development opportunities teachers have had with regards to Common Core or visions. I might have had a more in-depth understanding of teachers' reasoning if I had asked them about the content and experiences of relevant professional development.

Lastly, I recognize that I was only able to paint a picture of teachers' reasoning about instructional practices in the context of one lesson chosen to exemplify their V4MI. If I had followed teachers through the process of planning, enacting, and reflecting on several lessons, teachers might have reasoned about instructional practices in ways that were not captured in this study. Even if data from multiple lessons did not reveal new ways of reasoning, additional data may have solidified or condensed the conceptual categories I developed to represent teachers' reasoning.

\section{Opportunities to Connect V4MI, Instructional Practices, and the CCSSM}

In the current study, teachers considered their V4MIs and were asked to discuss ideal mathematics instruction and their own mathematics instruction aimed at achieving the goals of the CCSSM. As teachers explored their V4MIs in the contexts of instruction and in instruction, they scarcely made specific mention of their vision or of Common Core. There was not enough data to consider the benefit of making specific mention of the target CCSSM, as only two teachers mentioned Common Core. Further, only Gwen cited a specific content standard when planning her instruction. However, it was clear that teachers reasoning about instructional practices did include pieces of their V4MI. I suggest that teachers in states using CCSSM consider the possibility of strengthening the connections between their V4MIs, instructional 
practices, and the CCSSM. Cobb and Jackson (2011) asserted that successful large-scale mathematics reform efforts begin with a vision that specifies practices aimed at achieving the learning goals. This study has shown that there are relationships between the first two components of Cobb and Jackson's (2011) assertion (i.e., vision and practice). By planning and reflecting in a way that allows teachers to specifically connect their V4MI and the CCSSM to instructional practices, teachers might reveal connections between their personal goals for ideal mathematics instruction and the goals of the CCSSM, thus supporting their own individuality within the large-scale reform efforts of Common Core.

Because individual teachers have been charged with deciding how best to implement the CCSSM through instructional practices (CCSSI, 2019a), it is imperative to understand how teachers are making these decisions. Interestingly, the case study teachers participating in this study rarely specifically attended to their V4MI or the CCSSM in order to reason about instructional practices. Loeb et al. (2008) pointed to teachers' views about what constitutes highquality mathematics instruction as the medium between what is intended by the CCSSM and what instructional practices are decided upon by teachers. Thus, consistent with suggestions by Hammerness (1999), I believe teachers should experience opportunities to make explicit and articulate their personal visions in arenas such as professional development workshops.

Because the CCSSM does not specify a vision for ideal instructional practice, perhaps teachers should be encouraged to look at particular instructional practices specified by NCTM (2014) as being research-based and opportunistic for students to attain the goals of the CCSSM. By looking to NCTM's (2014) suggestions, teachers might be able to avoid what Coburn (2003) warned to be a limited understanding of what it means for the reform effort to be successful due to tacit implications for practice. By comparing their V4MIs to suggested instructional 
practices — such as those provided by NCTM (2014) — teachers would be taking an important step in moving toward high-quality mathematics instruction aligned with the goals of CCSSM. Consistent with the literature, professional development that equips teachers with abilities to choose and enact such instructional practices is necessary for successful CCSSM reform (Clark, 1997; Little, 1993; NCTM, 2014). Even more promising, Fullan (1995) and Moffett (1997) found that when teachers use their visions as a tool for reflection on practice, they were more motivated to learn and enact new instructional practices- perhaps instructional practices morealigned with the goals of the CCSSM.

\section{Upper-level Support for Teachers}

The results of my study indicated that teachers encountered situations where they intentionally enacted instructional practices that were misaligned with their V4MI. I suggest that administration, policymakers, and others initiating and supporting standards-based reform efforts enact specific supports to aid teachers in dealing with factors that affect their instructional choices. By supporting teachers in coping with factors that might cause these alignments, teachers might be empowered to enact instructional practices aimed at achieving the goals of the CCSSM while remaining true to their V4MI.

Results of this study indicated that teachers reason about choosing and enacting instructional practices by considering factors such as External Sources of Influence and Attention to Assessment, and sometimes attention to these factors resulted in instructional practices not aligned with their V4MIs. Hammerness (2004) suggested that understanding the factors that support or obstruct progress towards teachers' visions might help teachers to navigate the disconnect between vision and practice. Thus, I suggest that those leading CCSSM reform 
efforts — such as administration, curriculum writers, and policymakers — provide teachers opportunities to explore these factors.

Prior research has asserted that the creators of the CCSSM assume teachers and education policymakers will translate the standards into best-aligned instructional practices (Board on Testing and Assessment, 2009; Loweb, Knapp, \& Elfers, 2008), and often, those in charge at the school, district, and state level do so by providing collective visions and specifying best practices (e.g., Cobb \& Jackson, 2011; Spillane, 2000). However, externally-sourced, general ideals imposed upon teachers can lead to disconnected reform efforts (Fullan, 1992; Goodwin, 1994), negative emotional experiences for teachers, and even careers cut short in teaching (Little, 1996).

By providing support for individual teachers in understanding the factors that they must encounter and reason about in guiding instructional practices and by helping teachers reconcile with these factors, those leading CCSSM reform might be able to achieve a balance in individuality and institution (Fullan, 1992; Hammerness, 1999). When those in positions of authority have recognized the personal visions of teachers and the factors influencing teachers reasoning about instruction, teachers have felt a sense of agency in and personal agreement with the ways they teach (Gitlin \& Margonis, 1995). Thus, opportunities for reform stakeholders to understand and address factors that teachers view as important to instructional decisions could lead to fruitful professional development experiences in which teachers and those in positions of authority over teachers are able to collaborate and plan for improved instruction aimed at achieving the CCSSM.

\section{Suggestions for Future Research}

This study has aimed to address the call by NCTM (2014) to provide a better understanding of the progress that has been made, the challenges that remain, and the actions 
needed in order to ensure that we as a collective mathematics education community reach the potential set forth by the adoption of the CCSSM. Though this work has signaled a beginning to investigating how individual teachers reason about specifying instructional practices aimed at achieving the goals of the learning standards, much more could be done to deepen the understanding of this study's results as well as to extend the understanding of this study.

\section{Research Targeted at Deepening the Understanding of This Study}

In order to deepen the understanding of the results presented in this dissertation, I suggest that a study of similar methodology be carried out with an extended pool of teachers. Case studies have served to understand teachers' reasoning in depth, but a larger sample of case studies could reveal similarities and differences in teachers' reasoning that were not made apparent in the data of four teachers. Additionally, extending the data pool to include several lessons chosen by teachers - as opposed to just one lesson per teacher-could reveal an understanding of teachers' reasoning as it relates to different content and different learning goals. Finally, a similar study that allows teachers to describe their V4MI in an initial interview as well as a final interview might reveal more about how a teachers' V4MIs are affected by the opportunities to make V4MIs explicit and utilize V4MIs as tools for reflecting on practice.

\section{Research Targeted at Extending the Understanding of This Study}

During this study, teachers utilized language that centered on students' behaviors and experiences or teachers' behaviors and experiences, and the practice of defining conceptual categories for reasoning revealed that language differed in being student-centered or teachercentered depending on the reasoning category. Additionally, different categories of reasoning resulted in differing alignment of practices and V4MIs. Thus, I am left to wonder if the language used to reason about instructional practices has an impact on teachers' perceived alignment with 
their V4MIs. Jackson et al. (2017) found that student difficulties perceived as outside of a teacher's locus of control, led teachers to alter or compensate by altering instructional practices. My findings support those of Jackson et al. (2017) in that Simon and Marta cited deficits in students' prior knowledge and understandings as a reason for choosing instructional practices misaligned with their V4MI. Therefore, research should be conducted to understand studentcentered language versus teacher-centered language as it relates to teachers' choices for instructional practices and perceived alignment of those practices with individual visions.

Additionally, results from this study have led me to suggest specific professional development opportunities for teachers to make explicit their V4MIs and explore connections between their V4MIs and instructional practices best suited to the CCSSM. Additional research is needed to understand if such professional development opportunities would prove beneficial to teachers as they work to implement the CCSSM.

Finally, there is potential to connect the work explored in this study with that of Munter (2009; 2014) and Munter and Correnti (2017). Though this previous research investigated individuals' visions and their alignment with a collective vision for high-quality mathematics instruction, further understanding is needed to understand V4MIs' alignment with instructional practices aimed at the CCSSM in contexts where an institutional vision is not present.

\section{Closing Thoughts}

As we move into the second decade of Common Core mathematics education reform, I believe we must reflect on our development as a nation toward implementation of the CCSSM. Through this research, I hoped to shed light on the attention to individuality in teaching that is inherent in the writing of the standards. I observed four very different individuals who were teaching differing content and reasoning about their instruction in varied ways. I hope that by 
asking teachers to describe and consider their V4MIs while reasoning about their instruction, I have provided an avenue for research in the future that might lead to tangible teacher professional development and improved implementation of Common Core. Whether we move forward as a nation to implement the CCSSM with fidelity or we exchange this large-scale reform effort for another in the future, I believe that attention to V4MIs and consideration of teachers' concepts of reasoning about practice can guide us down a fruitful path toward successful large-scale mathematics education reform. 


\section{REFERENCES}

Anderson, J. (2019). In search of reflection-in-action: An explanatory study of the interactive reflection of four experienced teachers. Teaching and Teacher Education, 86(1), 1-17. doi:10.1016/j.tate.2019.102879

Anderson, A. Steffen, B., Wiese, C., \& King, M. B. (2014). From theory to action: Learning shifts into high gear with structured supports. The Learning Professional, 35(5), 58-62.

AVID. (2019). Teacher effectiveness / professional development for educators. Retrieved from https://www.avid.org/teacher-effectiveness

Bloomberg, L. D., \& Volpe, M. (2019). Completing your qualitative dissertation: A road map from beginning to end (4th ed.). Thousand Oaks, CA: Sage.

Board on Testing and Assessment. (2009). Letter report to the U.S. Department of Educational on the Race to the Top Fund. Retrieved from http://cft.org/images/k12/docs/letterreport.pdf

Boeije, H. (2002). A purposeful approach to the constant comparative method in the analysis of qualitative interviews. Quality \& Quantity, 36(4), 391-409.

Bride, B. (2007). Cooperative learning \& algebra 1: Secondary activities. San Clemente, CA: Kagan.

Brown, J. L., \& Moffett, C. A. (1999). The hero's journey: How educators can transform schools and improve learning. Alexandria, VA: Association for Supervision and Curriculum Development

Clarke, D. M. (1997). The changing role of the mathematics teacher. Journal for Research in Mathematics Education, 28(3), 278-308. doi:10.2307/749782 
Cobb, P., \& Jackson, K. (2011). Towards an empirically grounded theory of action for improving the quality of mathematics teaching at scale. Mathematics Teacher Education and Development, 13(1), 6-33.

Coburn, C. E. (2003). Rethinking scale: Moving beyond numbers to deep and lasting change. Educational Researcher, 32(6), 3-12. doi:10.3102/0013189X032006003

Common Core State Standards Initiative. (2018). Development Process. Retrieved from http://www.corestandards.org/about-the-standards/development-process/

Common Core State Standards Initiative. (2019a). Myths vs. facts. Retrieved from http://www.corestandards.org/about-the-standards/myths-vs-facts/

Dancy, M., \& Henderson, C. (2007). Framework for articulating instructional practices and conceptions. Physics Education Research, 3(1), 1-15. doi:10.1103/PhysRevSTPER.3.010103

Dunlap, C., Webster, M., Jackson, K., \& Cobb, P. (2015). Schooling leaders on the common core. Retrieved from http://www.kappancommoncore.org/schooling-leaders-on-the-commoncore/

Elmore, R. (2004). School reform from the inside out: Policy, practice, and performance. Cambridge, MA: Harvard Education.

Ferrucci, B. J. (1996). Institutionalizing mathematics education reform: Visions, leadership, and the standards. Journal for Research in Mathematics Education. Monograph, 8. The recognizing and recording reform in mathematics education project: Insights, issues, and implications. 35-47+129-133. doi:10.2307/749974 
Finn, C. E. (2002). Theories of action for effecting education reform. In Y. K. Kodrzycki (Ed.). Proceedings of 47th Economic Conference Education in the 21st Century: Meeting the Challenges of a Changing World (pp. 291-294). Boston, MA: Federal Reserve Bank of Boston.

Flyvbjerg, B. (2006). Five misunderstandings about case-study research. Qualitative Inquiry, 12(2), 219-245. doi.org/10.1177/1077800405284363

Fram, S. M. (2013). The constant comparative analysis method outside of grounded theory. The Qualitative Report, 18(Art. 1), 1-25. Retrieved from http://www.nova.edu.ssss.QR/QR18.gram1.pdf

Fullan, M. G. (1992). Visions that blind. Educational Leadership, 49(5), 19-20.

Fullan, M. (1993). Why teachers must become change agents. Educational Leadership, $50(6), 12-17$.

Garland, S. (2014). The man behind Common Core Math. Retrieved from https://www.npr.org/sections/ed/2014/12/29/371918272/the-man-behind-common-core-math

Germain-McCarthy, Y. (2014). Bringing the Common Core Math Standards to life: Exemplary practices from middle schools. New York, NY: Taylor \& Francis.

Gitlin, A., \& Margonis, F. (1995). The political aspect of reform: Teacher resistance as good sense. American Journal of Education, 103(4), 377-405. doi:10.1086/444108

Glaser, B. G. (1965). The constant comparative method of qualitative analysis. Social Problems, 12(4), 436-445. doi:10.2307/798843

Goals 2000-Educate America Act Title III Public Law 103-227, 302. Retrieved from http://www.ed.gov 
Goodwin, C. (1994). Professional vision. American Anthropologist, 96(3), 606-633. doi.org/10.1525/aa.1994.96.3.02a00100

Hammerness, K. (2001). Teachers' visions: The role of personal ideals in school reform. Journal of Educational Change, 2(2). 143-163.

Hammerness, K. (2004). Teaching with vision: How one teacher negotiates the tension between high ideals and standardized teaching. Teacher Education Quarterly, 31(4), 33-43.

Hammerness, K. M. (1999). Seeing through teachers' eyes: An exploration of the content, character and role of teachers' vision (Doctoral dissertation). Retrieved from ProQuest. (Accession No. 9943659)

Heyd-Metzuyanim, E., Munter, C., \& Greeno, J. (2018). Conflicting frames: A case of misalignment between professional development efforts and a teacher's practice in a high school mathematics classroom. Educational Studies in Mathematics, 97(1) 21-37. doi:10.1007/s10649-017-9777-0

Jackson, K., Gibbons, L., \& Sharpe, C. J. (2017). Teachers' views of students' mathematical capabilities: Challenges and possibilities for ambitious reform. Teachers College Record, $119(7), 1-43$.

Johnston, S. (1992). Images: A way of understanding the practical knowledge of student teachers. Teaching \& Teacher Education, 8(2), 123-136. doi:10.1016/0742-051X(92)90003$\mathrm{L}$

Jones, A. (2018). Transparency: Operating with a clear instructional vision to put policy into practice. Retrieved from https://www.competencyworks.org/insights-intoimplementation/transparency-operating-with-a-clear-instructional-vision-to-put-policy-intopractice/ 
Lee, J. (2010, January 19). Speeding up the race to the top [Web log post]. Retrieved from https://obamawhitehouse.archives.gov/blog/2010/01/19/speeding-race-top

Little, J. W. (1993). Teachers' professional development in a climate of educational reform [NCREST Reprint Series]. New York, NY: National Center for Restructuring Education, Schools, and Teaching. doi:10.2307/1164418

Little, J. W. (1996). The emotional contours and career trajectories of (disappointed) reform enthusiasts. Cambridge Journal of Education, 26(3), 345-359. doi: $10.1080 / 0305764960260304$

Loeb, H., Knapp, M., \& Elfers, A. M. (2008). Teachers' response to standards-based reform: Probing reform assumptions in Washington state. Education Policy Analysis Archives, 16(8), 1-29. doi.org/10.14507/epaa.v16n9.2008

Lombard, M., Snyder-Duch, J., \& Bracken, C. C. (2010). Practical resources for assessing and reporting intercoder reliability in content analysis research projects. Retrieved from http://matthewlombard.com/reliability/index_print.html

Maxson, M., \& Sindelar, R. (1998). Images revisited: Examining preservice teachers' ideas about teaching. Teacher Education Quarterly, 25(2), 5-26.

Merriam, S. B. (1998). Qualitative research and case study applications in education. San Francisco, CA: Jossey-Bass.

Merriam, S. B., \& Tisdell, E. J. (2016). Qualitative research: A guide to design and implementation (4th ed.). San Francisco, CA: Jossey-Bass.

Montgomery, K., Darling-Hammond, L., \& Campbell, C. (2011). Developing common instructional practice across a portfolio of schools: The evolution of school reform in Milwaukee. Stanford, CA: Stanford Center for Opportunity Policy in Education. 
Munter, C. (2009). Defining visions of high-quality mathematics instruction. In S. L. Swars, D. W. Stinson, \& S. Lemons-Smith (Eds.). Proceedings of the 31st Annual Meeting of the North American Chapter of the International Group for the Psychology of Mathematics Education (pp. 983-991). Atlanta GA: Georgia State University.

Munter, C. (2014). Developing visions of high-quality mathematics instruction. Journal for Research in Mathematics Education, 45(5), 584-635.

Munter, C., \& Correnti, R. (2017). Examining relations between mathematics teachers' instructional vision and knowledge and change in practice. American Journal of Education, 123(2), 171-202.

National Commission on Excellence in Education. (1983). A nation at risk: The imperative for educational reform: A report to the nation and the Secretary of Education, United States. Washington, DC: Author.

National Council of Teachers of Mathematics. (2013). Supporting the Common Core State Standards for Mathematics. Retrieved from https://www.nctm.org/uploadedFiles/Standards_and_Positions/Position_Statements/Common $\% 20$ Core $\% 20$ State $\% 20$ Standards.pdf

National Council of Teachers of Mathematics. (2014). Principles to actions: Ensuring mathematical success for all. Reston, VA: Author.

National Council of Teachers of Mathematics. (2018). Catalyzing change in high school mathematics. Reston, VA: Author.

National Education Association. (n.d.). NEA's involvement in the Common Core State Standards. Retrieved from http://www.nea.org/home/46665.htm 
National Governors Association Center for Best Practices, Council of Chief State School Officers. (2010a). Common Core State Standards (Grade 3 Geometry). Washington, DC: Author.

National Governors Association Center for Best Practices, Council of Chief State School Officers. (2010b). Common Core State Standards (Grade 4 Measurement \& Data). Washington, DC: Author.

National Governors Association Center for Best Practices, Council of Chief State School Officers. (2010c). Common Core State Standards (Grade 4 Operations \& Algebraic Thinking). Washington, DC: Author.

National Governors Association Center for Best Practices, Council of Chief State School Officers. (2010d). Common Core State Standards (High School Algebra). Washington, DC: Author.

National Governors Association Center for Best Practices, Council of Chief State School Officers. (2010e). Common Core State Standards (High School Geometry). Washington, DC: Author.

National Governors Association Center for Best Practices, Council of Chief State School Officers. (2010f). Common Core State Standards (Standards for Mathematical Practice). Washington, DC: Author.

No Child Left Behind Act of 2001 Pub. L. 107-110, 115 STAT. 1425 (2002).

Pense, S. L., Freeburg, B. W., \& Clemons, C. A. (2015). Implementation of Common Core State Standards: Voices, position, and frames. Career and Technical Education Research, 40(3), 157-173. doi:10.5328/cter/40.3.157 
Radišic, J., \& Baucal, A. (2016). Using video-stimulated recall to understand teachers' perceptions of teaching and learning in the classroom setting. Psihološka istraživanja, 29(2), 165-183.

Rorrer, A. K., Skrla, L., \& Scheurich, J. J. (2008). Districts as institutional actors in educational reform. Educational Administration Quarterly, 44(3), 307-358. doi:10.1177/0013161X08318962

Rosenholtz, S. J. (1985). Effective schools: Interpreting the evidence. American Journal of Education, 93(3), 352-388. doi.org/10.1086/443805

Schmidt, W. H., \& Houang, R. T. (2012). Curricular coherence and the Common Core State Standards for Mathematics. Educational Researcher, 41(8), 294-308. doi:10.3102/0013189X12464517

School Reform Initiative. (2016). Theory of action for the work of the school reform initiative. Retrieved from http://www.paulofreireschool.org/wp-content/uploads/2016/10/SRI-Theoryof-Action.pdf

Simon, M. A., \& Tzur, R. (1999). Explicating the teacher's perspective from the researchers' perspectives: Generating accounts of mathematics teachers' practice. Journal for Research in Mathematics Education, 30(3), 252-264.

Smith, M. S., \& O’Day, J. (1990). Systemic school reform. Journal of Education Policy, 5(5). 233-267. doi.org/10.1080/02680939008549074

Snyder, J. (1980). Picturing vision. Critical Inquiry, 6(3), 499-526. doi.org/10.1086/448062

Spillane, J. P. (2000). Cognition and policy implementation: District policymakers and the reform of mathematics education. Cognition and Instruction, 18(2), 141-179. doi.org/10.1207/S1532690XCI1802_01 
Strauss, A., \& Corbin, J., (1998). Basics of qualitative research: Techniques and procedures for developing grounded theory (2nd ed.). Newbury Park, CA: Sage.

Thomas, J. Y., \& Brady, K. P. (2005). The Elementary and Secondary Education Act at 40: Equity, accountability, and the evolving federal role in public education. Review of Research in Education, 29(1), 51-67. doi.org/10.3102/0091732X029001051

Wallender, J. (2014). The Common Core State Standards in American public education: Historical underpinnings and justifications. The Delta Kappa Gamma Bulletin, 80(4), 7-11.

Walther, J., Sochacka, N. W., \& Kellam, N. N. (2013). Quality in interpretive engineering education research: Reflections on an example study. Journal of Engineering Education, 102(4), 626-659. doi.org/10.1002/jee.20029

Yin, R. K. (2003). Case study research design and methods. Thousand Oaks, CA: Sage. 


\section{APPENDIX A: PARTICIPANT SELECTION CONSENT FORM}

Dear Teacher,

Thank you for considering participation in this research study. The main objective of this project is to capture and describe your vision for mathematics instruction and understand how it relates to your instructional practices aimed at achieving the Illinois Learning Standards, or Common Core State Standards for Mathematics.

As a participant in this study, you will discuss your vision for mathematics instruction during an initial interview with the researcher, who then might follow up with you and ask you to select a lesson to be videotaped. All interviews will be audio recorded. Your participation in this portion of the study will take no longer than 1 hour of time beyond your normal teaching responsibilities. If you are asked to select a lesson for videotaping, you will be provided with a second consent form specific to that portion of the study. During the study, you will be assigned a pseudonym that will be used to label all data artifacts, which will be kept under lock and key. Any data shared via reports or presentations will contain pseudonyms so that your identity will be protected. After your data has been deidentified, your data may be used in other research projects.

It is hoped that the experience of reflecting on, and making explicit, your vision for mathematics instruction will have a positive impact on your planning for instruction in the future. Continued use of this process of reflection could make you more aware of goals you have for your classroom and instruction. This study would lay the groundwork for investigating the relationship between teachers' visions and instructional practices on a larger scale, potentially providing information for improved teacher support in standards-based reform.

There are only minimal perceived physical, psychological, or social risks associated with participation in the research study. These minimal foreseeable risks include (a) loss of time, (b) risk of coercion, (c) loss of confidentiality, and (d) discomfort of being audio recorded. To minimize these risks, I want to remind you that (a) the amount of time required for participation in this portion of the study is no more than 1 hour; (b) the researcher is in no position of authority over you, and you can withdraw at any time without penalty or refuse to answer any question during the interview; and (c) all data shared via written reports or presentations will have identifiers removed. Interview responses will be kept confidential, and the focus of the interviews is not on evaluating the teacher's vision but on the relationship between visions and instructional practices. If, at any point during the interview, you grow frustrated, I will ask you if you are comfortable proceeding. In addition, you can stop the interview at any time.

Your participation in this research study is voluntary! If you choose to not participate in this study, there will be no negative consequences. In addition, you can withdraw from the study at any time; if you choose to withdraw from the study all analysis involving your data will stop and your data will be removed from the study. If you have any questions about your rights as a participant, or if you feel you have been placed at risk, contact the Illinois State University Research Ethics \& Compliance Office at (309) 438-5527 or IRB@ilstu.edu. You may also 
contact Kelsey Clarkson at kaclar2@ilstu.edu or Dr. Craig Cullen at cjculle@ilstu.edu with any concerns or questions.

Thank you for your time and consideration! Kelsey Clarkson, Illinois State University, Department of Mathematics

Statement of Consent for Initial Interviews: I have read the information contained in this letter and have received answers to any questions I had. I consent to take part in the study.

Signature:

Date:

You will be given a copy of this form to keep for your records. 


\section{APPENDIX B: CASE STUDY CONSENT FORM}

Dear Teacher,

Thank you for participating in the initial interview stage of this research project. You have been selected to follow up by choosing a lesson to be videotaped and reflected upon. The objective of this exercise is to explore your vision for mathematics instruction in the context of your teaching. Prior to the designated lesson, you would meet one-on-one with the researcher to expand on your vision and review your lesson plan. Lessons will be videotaped by the researcher using a camera placed at the back of the classroom to minimize the capture of students' faces. If any student is inadvertently captured on film, the researcher will not identify any of the student's features or information. The video will only be used to prompt reflection and comments on the lesson in a follow-up interview. The video will never be used for analysis or dissemination and will be destroyed after interviews are completed. Your participation in this portion of the study will take no longer than 2 hours of time beyond your normal teaching responsibilities.

As a reminder, you will be assigned a pseudonym that will be used to label all data artifacts, which will be kept under lock and key. Any data shared via reports or presentations will contain pseudonyms so that your identity will be protected. After your data has been deidentified, your data may be used in other research projects.

This study would lay the groundwork for investigating the relationship between teachers' visions and instructional practices on a larger scale, potentially providing information for improved teacher support in standards-based reform.

There are only minimal perceived physical, psychological, or social risks associated with participation in the research study. These minimal foreseeable risks include (a) loss of time, (b) risk of coercion, (c) loss of confidentiality, and (d) discomfort of being audio or video recorded. To minimize these risks, I want to remind you that (a) the amount of time required for participation in the study is no more than 3 hours; (b) the researcher is in no position of authority over you, and you can withdraw at any time without penalty or refuse to answer any question during interviews; and (c) all data shared via written reports or presentations will have identifiers removed. At no time will the videotaped lessons be used in data analysis or in presentations. In addition, interview responses will be kept confidential and the focus of the interviews is not on evaluating the teacher's vision or lesson but on the relationship between visions and instructional practices. If, at any point during the interview, you grow frustrated, I will ask you if you are comfortable proceeding. In addition, you can stop the interview or video at any time.

Your participation in this research study is voluntary! If you choose to not participate in this study, there will be no negative consequences. In addition, you can withdraw from the study at any time; if you choose to withdraw from the study all analysis involving your data will stop and your data will be removed from the study. If you have any questions about your rights as a participant, or if you feel you have been placed at risk, contact the Illinois State University Research Ethics \& Compliance Office at (309) 438-5527 or IRB@ilstu.edu. You may also contact Kelsey Clarkson at kaclar2@ilstu.edu or Dr. Craig Cullen at cjculle@ilstu.edu with any concerns or questions. 
Thank you for your time and consideration!

Kelsey Clarkson, Illinois State University, Department of Mathematics

Statement of Consent for Lesson Videoing and Related Interviews: I have read the information contained in this letter and have received answers to any questions I had. I consent to take part in the study.

Signature:

Date:

You will be given a copy of this form to keep for your records. 


\section{APPENDIX C: INITIAL INTERVIEW QUESTIONS}

Opening statement made to participant: I would like to talk to you about your vision for math instruction that has the potential to reach the standards, the Illinois Standards, which are the Common Core Standards for Mathematics. Your vision represents your personal images of ideal classroom practice.

Primary interview question: If you were asked to observe another teacher's math classroom, what would you look for to decide whether the mathematics instruction aligns with your vision?

Follow-up for each piece of vision voiced by participant: Why do you think it is important to see in a math class?

Prompt if participant ceases to volunteer more information: What else would you look for?

Question asked after vision has been fully described: Are there any constraints that you can think of that might limit or change your vision? By this I mean is there anything you think might make you say, "Well, if the class was this way, then my vision would be different."

Follow-up for each constraint voiced by participant: How would your vision of ideal classroom practice look different in light of ?

If the participant provides minimal description of their V4MI, the below questions can be used to provide a richer description of their V4MI. The topics of the below questions were taken from Munter's (2009) categories for teachers' statements in regards to vision. If a question is not understood, the researcher should work with the participant to clarify the meaning.

What do you see the role of the teacher being in your vision of ideal practice?

What are the characteristics of classroom discourse in your vision?

What would be the organization and purpose of classroom activities in your vision?

What would be the social and cultural norms of the classroom in your vision?

What would be the nature of the tasks used in your vision?

What role would student thinking play in the lesson?

What would be the structure of the lesson in your vision?

What measures would be taken for equity and accessibility of learning in your vision? 


\section{APPENDIX D: PRE-LESSON INTERVIEW QUESTIONS}

Opening statement made to participant: I'd like to get an idea of the lesson we will be reflecting on later. Tell me about your lesson.

\section{Follow up questions:}

What activities are included in the lesson?

What do you hope students will be able to do as a result of this lesson?

Is there anything else you would like to tell me about the lesson? 


\section{APPENDIX E: POST-LESSON INTERVIEW QUESTIONS}

Opening statement made to participant: As we watch the video, I would like you to stop the video when there are instances that you feel demonstrate your vision for mathematics instruction. These instances can be statements, actions, or anything else. I would also like you to stop the video when there are instances you would do something differently next time to better align the lesson with your vision. Go ahead and watch the video at your pace.

Prompt to be used when a teacher stops the video: Go ahead and describe to me what you saw happening in the video that made you pause.

After teacher describes the events on which they paused the video: Does what happened align with your vision, or are you thinking of how you would want to change what happened to align with your vision?

Follow-up question if instance aligns with teacher's vision: Tell me how this instance fit into your vision of what should ideally happen during mathematics instruction.

Follow-up question if instance does not align with teacher's vision: Tell me how things could have gone differently to better-align with your vision.

Question to reflect on lesson as a whole: Thinking about the lesson as a whole, is there anything that you would like to reflect on that we haven't already discussed?

Question to reflect on the intersection of vision of and vision in instruction: Are there any aspects of your vision that were not in this lesson, anything that is part of your ideal mathematics instruction that did not come out in this lesson that you want to talk about now? If so, how would you typically include that aspect in a lesson?

Final question: Is there anything else that you would like to say about this lesson or your vision for math instruction or anything else? 